Universidade de Brasília

Faculdade de Ciências da Saúde

Departamento de Enfermagem

Programa de Pós Graduação em Enfermagem

SIMONE PRADO DE LIMA DE MIRANDA

DIAGNÓSTICOS DE ENFERMAGEM EM CLIENTES ONCOLÓGICOS CRÍTICOS EM CUIDADOS PALIATIVOS FUNDAMENTADOS NA TEORIA DO ALCANCE DE METAS DE KING

BRASÍLIA 
UNIVERSIDADE DE BRASÍLIA

FACULDADE DE CIENCIAS DA SAÚDE

DEPARTAMENTO DE ENFERMAGEM

PROGRAMA DE PÓS-GRADUAÇÃO EM ENFERMAGEM

SIMONE PRADO DE LIMA DE MIRANDA

DIAGNÓSTICOS DE ENFERMAGEM EM CLIENTES ONCOLÓGICOS CRÍTICOS EM CUIDADOS PALIATIVOS FUNDAMENTADOS NA TEORIA DO ALCANCE DE METAS DE KING

Dissertação apresentada como requisito parcial para a obtenção do Título de Mestre em Enfermagem pelo Programa de Pós-Graduação em Enfermagem da Universidade de Brasília.

Área de concentração: Políticas Práticas e Cuidado em Saúde e Enfermagem.

Linha de pesquisa: Processo de Cuidar em Saúde e Enfermagem.

Orientador: Prof. Dra Cristine Alves Costa de Jesus

\section{BRASÍLIA}


Prado de Lima de Miranda, simone

Diagnósticos de Entermagem em clientes oncologicos criticos en cuidadoa paliativos fundamentados na teoria do alcance de metas de King / simone prado de Lima de Miranda; orientador Cristine Alves Costa de Jesus. -- Brasfilia, 2015.

$152 \mathrm{p}$.

Dissertação (Mestrado - Mestrado em Enfermagem) -. Universidade de Branfila, 2015.

1. Diagnostico de enfermagen. 2. Enfermagem oncologica, 3. Cuidados Paliativos. 4, Cuidados criticos. 5. Modelon de enfermagem. I, Alves Costa de Jesus, Criatine, orient. II. Título. 
SIMONE PRADO DE LIMA DE MIRANDA

\title{
DIAGNÓSTICOS DE ENFERMAGEM EM CLIENTES ONCOLÓGICOS CRÍTICOS EM CUIDADOS PALIATIVOS FUNDAMENTADOS NA TEORIA DO ALCANCE DE METAS DE KING
}

Aprovado em 16 de Dezembro de 2015

\author{
BANCA EXAMINADORA
}

Professora Doutora Cristine Alves de Jesus - Presidente da Banca

Departamento de Enfermagem - Faculdade de Ciências da Saúde - Universidade de Brasília

Professor Doutor Rinaldo de Souza Neves - Membro Efetivo, externo ao Programa

Escola Superior de Ciências da Saúde da Fundação de Ensino e Pesquisa em Ciências da Saúde

Professora Doutora Christiane Inocêncio Vasques - Membro efetivo

Departamento de Enfermagem - Faculdade de Ciências da Saúde - Universidade de Brasília

Professora Doutora Moema da Silva Borges - Membro Suplente

Departamento de Enfermagem - Faculdade de Ciências da Saúde - Universidade de Brasília 
Ao meu esposo, André de Miranda, por seu amor, apoio e sustentação em todos os momentos da nossa vida, me fazendo acreditar na certeza da vitória ao final da caminhada, mesmo quando os obstáculos pareciam intransponíveis...

A minha amada mãe, que sempre ter acreditado em mim como pessoa e profissional, vibrando com cada conquista e me ajudando a percorrer os caminhos necessários para o alcance dos objetivos...

As minhas filhas por me proporcionarem os momentos de maior felicidade desta vida e por me apresentarem a face do mais profundo e verdadeiro amor... 


\section{AGRADECIMENTOS}

À Deus por me amparar nos momentos difíceis, me dar força para superar as dificuldades, por me mostrar o caminho nas horas incertas e me suprir em todas as minhas necessidades.

À minha orientadora, Dra. Cristine Alves Costa de Jesus, fonte singular de inspiração ao longo de todo o processo de formação, por acreditar em mim, me mostrar o caminho da ciência, e em especial pela paciência em compreender meus tempos e limites.

À minha família, amor singular, pelo carinho, paciência e incentivo. Vocês sempre serão a razão de tudo. Vocês motivam fazem de mim o desejo de ser a cada dia um ser humano melhor. Vocês me fizeram e fazem conhecer a melhor parte da existência humana.

Às minhas grandes amigas Marianne Soares, Tatiane Lemos, Thassia Soares e Lorenna Simões pela sua ajuda nos momentos mais críticos e nas mudanças de rumo ao longo da caminhada, por acreditarem no futuro deste projeto, contribuírem para o meu crescimento profissional e por serem também um exemplo a ser seguido, cada uma à sua maneira. A participação de vocês foi fundamental para a realização deste trabalho.

Aos meus diretores Dr. Frederico Costa, Dr. Renato Cury e Fernando Lopes por serem muito além de chefes. Vocês foram e são profundos conhecedores, cada um em sua área de atuação, extremamente humanos e queridos. Força nos momentos de fraqueza, equilíbrio na hora da tempestade. Vocês acreditaram em mim como profissional e ser humano e me ensinaram grande parte de todas as habilidades na área de gestão em saúde que fazem parte de mim hoje. Vocês sempre priorizaram o cuidado e me deram todas as ferramentas possíveis para conduzir o cuidado. 
"Houve um tempo em que nosso poder perante a Morte era muito pequeno. E, por isso, os homens $e$ as mulheres dedicavam-se a ouvir a sua voz $e$ podiam tornar-se sábios na arte de viver. Hoje, nosso poder aumentou, a Morte foi definida como inimiga a ser derrotada, fomos possuídos pela fantasia onipotente de nos livrarmos de seu toque. Com isso, nós nos tornamos surdos às lições que ela pode nos ensinar. $E$ nos encontramos diante do perigo de que, quanto mais poderosos formos perante ela (inutilmente, porque só podemos adiar...), mais tolos nos tornaremos na arte de viver."

(Rubem Alves) 
MIRANDA, S.P.L. Diagnósticos de Enfermagem em clientes oncológicos críticos em cuidados paliativos fundamentados na teoria do alcance de metas de King. 2015. P. Dissertação (Mestrado) Departamento de Enfermagem, Faculdade de Ciências da Saúde, Universidade de Brasília, Brasília, 2015.

\section{RESUMO}

Realizou-se o presente estudo, do tipo descritivo, com o objetivo de analisar a aplicação do Processo de Enfermagem, fundamentado no referencial teórico de Imogene King, em clientes oncológicos críticos hospitalizados inclusos em Protocolo de cuidados paliativos. O estudo objetivou ainda relacionar o perfil da amostra à abordagem sistêmica, identificar os diagnósticos de enfermagem mais frequentes utilizando a Taxonomia II de diagnósticos da NANDA-I e comparar os diagnósticos encontrados com o modelo de sistemas de King. Os dados foram coletados a partir da aplicação do Processo de Enfermagem e estruturados no modelo de Imogene King. A coleta foi realizada pela própria autora, em 34 clientes. Quanto ao perfil observou-se que a idade média da amostra foi de 74,4 anos, em relação ao estado civil $22(64,7 \%)$ dos clientes eram viúvos, $9(26,5 \%)$ eram casados e 3 $(8,8 \%)$ eram solteiros. Sobre a topografia da doença oncológica, as doenças pulmonares foram as mais frequentes $(17,6 \%)$, seguido de tumores de sistema nervoso central $(14,7 \%)$, próstata e mama com 11,8\% cada. Foram elaborados no estudo 718 diagnósticos para os 34 clientes. Analisando sob a perspectiva dos três sistemas mencionados por King observou-se que os diagnósticos encontrados contemplaram todos os sistemas propostos, e estão divididos de forma percentual em sistema pessoal, com $82,4 \%$ dos diagnósticos, sistema interpessoal com $13,7 \%$ e sistema social com 3,9\%. Na clientela estudada foram observados 51 diagnósticos de enfermagem distintos. Os diagnósticos de Déficit no autocuidado, Deglutição prejudicada, Mobilidade física prejudicada, Proteção ineficaz, Risco de aspiração e Risco de queda estiveram presentes em 34 clientes (100\%). O diagnóstico Risco de sangramento esteve presente em 33 clientes $(97,1 \%)$. Os diagnósticos de Eliminação urinária prejudicada, Risco de síndrome do desuso apresentarem-se em $32(94,1 \%)$ dos clientes avaliados no estudo. Comunicação verbal prejudicada e Risco de olho seco estiveram presentes em 31 clientes $(91,2 \%)$, Processos familiares disfuncionais e Dentição prejudicada em 30 (88,2\%), Pesar e Tristeza crônica estiveram presentes em 29 famílias (85,3\%), Incontinência intestinal em 27 clientes $(79,4 \%)$, Ventilação espontânea prejudicada/ Padrão respiratório ineficaz em 26 (76,5\%), a Dor aguda em 23 clientes $(67,6 \%)$, Risco de integridade da pele prejudicada esteve presente em 21 clientes $(61,8 \%)$ da amostra, Volume de líquidos excessivo esteve presente em 20 clientes $(58,8 \%)$. Os demais diagnósticos apresentaram frequência menor que 50\%. Acredita-se que, com os resultados obtidos neste estudo, os instrumentos utilizados servirão de apoio aos enfermeiros atuantes em Unidades oncológicas e Unidade de Terapia Intensiva no que se refere à aplicação do processo de enfermagem nos casos de clientes oncológicos em cuidados paliativos e às suas famílias.

Descritores: diagnóstico de enfermagem, enfermagem oncológica, cuidados paliativos, cuidados críticos, Modelos de enfermagem. 
MIRANDA, S.P.L. Nursing diagnoses in critical cancer patients in palliative care based on the theory of reach of King targets. P. 2015. Dissertation (Master) Department of Nursing, Faculty of Health Sciences, University of Brasília, Brasília, 2015.

\begin{abstract}
We conducted this study, descriptive, for the purpose of reviewing the implementation of Nursing Process, based on the theoretical framework of Imogene King, hospitalized in critical oncology client included in palliative care protocol. The study aimed to further relate the sample profile to the systemic approach, identifying the most frequent nursing diagnoses using the Taxonomy II diagnoses of NANDA-I and compare diagnoses found with the model of King systems. Data were collected from the application of the nursing process, structured on the model of Imogene King. Data collection was conducted by the author in 34 guests. The profile was observed that the average age of the sample was 74.4 years, compared to the marital status $22(64.7 \%)$ customers were widowed, $9(26.5 \%)$ were married and $3(8,8 \%)$ were single. On the topography of oncological diseases, lung diseases were the most common $(17.6 \%)$, followed by central nervous system tumors (14.7\%) and prostate and breast with $11.8 \%$ each. They were drafted in the study 718 diagnoses for 34 guests. Analyzing from the perspective of the three systems mentioned by King revealed that the diagnoses found beheld all the proposed systems, and are divided percentage shaped personal system with $82.4 \%$ of diagnoses, interpersonal system with $13.7 \%$ and social system to $3.9 \%$. In the studied clientele were observed 51 different nursing diagnoses. The Deficit in self-care diagnostics, impaired swallowing, impaired physical mobility, ineffective protection, Risk of aspiration and fall risk were present in 34 customers (100\%). Diagnosis bleeding risk was present in 33 customers $(97.1 \%)$. The impaired urinary elimination diagnosis, disuse syndrome risk was present in $32(94.1 \%)$ customers studied. Impaired verbal communication and dry eye risk customers were present in 31 (91.2\%), dysfunctional family processes and impaired dentition in $30(88.2 \%)$, chronic sadness and grief were present in 29 families (85.3\%), bowel incontinence in 27 customers (79.4\%), impaired spontaneous ventilation / Ineffective breathing pattern in $26(76.5 \%)$, acute pain in 23 customers $(67.6 \%)$, the Impaired skin integrity risk was customers present in $21(61.8 \%)$ of the sample, excess liquid was present at 20 volume customers $(58.8 \%)$. The other diagnoses had a lower frequency than $50 \%$. It is believed that, with the results obtained in this study, the instruments used will serve to support nurses working in oncology units and intensive care unit as regards the application of the nursing process in cases of cancer clients in palliative care and their families.
\end{abstract}

Descriptors: nursing diagnosis, oncology nursing, palliative care, critical care, nursing models 
MIRANDA, S.P.L. Diagnósticos de enfermería en clientes con cáncer de críticos en los cuidados paliativos basados en la teoría del alcance de los objetivos King. P. 2015. Tesis (Maestría) del Departamento de Enfermería de la Facultad de Ciencias de la Salud de la Universidad de Brasilia, Brasilia, 2015.

\section{RESUMEN}

Hemos llevado a cabo este estudio, descriptivo, con el propósito de examinar la aplicación del proceso de enfermería, basado en el marco teórico de Imogene King, hospitalizado en el cliente de la oncología crítico incluido en el protocolo de cuidados paliativos. El objetivo del estudio fue relacionar aún más el perfil de la muestra con el enfoque sistémico, la identificación de los diagnósticos de enfermería más frecuentes utilizando la taxonomía II diagnósticos de la NANDA-I y comparar los diagnósticos encontrados con el modelo de los sistemas de King. Los datos fueron obtenidos de la aplicación del proceso de enfermería, estructurado según el modelo de Imogene King. La recolección de datos se llevó a cabo por el autor en 34 huéspedes. El perfil se observó que la edad media de la muestra fue de 74,4 años, en comparación con el estado civil de $22(64,7 \%)$ clientes quedaron viudas, $9(26,5 \%)$ eran casados y $3(8,8 \%)$ eran solteros. En la topografía de las enfermedades oncológicas, enfermedades pulmonares fueron los más frecuentes $(17,6 \%)$, seguido de los tumores del sistema nervioso central $(14,7 \%)$ y de próstata y de mama con un $11,8 \%$ cada uno. Fueron redactadas en el estudio 718 diagnósticos para 34 huéspedes. Analizando desde la perspectiva de los tres sistemas mencionados por el rey reveló que los diagnósticos se han encontrado contempló todos los sistemas propuestos, y se dividen sistema personal en forma de porcentaje con $82,4 \%$ de los diagnósticos, el sistema interpersonal con $13,7 \%$ y el sistema social hasta el 3,9\%. En la clientela estudiadas se observaron 51 diagnósticos de enfermería diferentes. El Déficit en el diagnóstico de autocuidado, la deglución alterada, movilidad física alterada, la protección ineficaz, Riesgo de riesgo de aspiración y la caída estaban presentes en 34 clientes (100\%). Riesgo de hemorragia Diagnóstico estaba presente en 33 clientes $(97,1 \%)$. El diagnóstico eliminación urinaria deteriorado, el desuso de riesgo El síndrome estuvo presente en $32(94,1 \%)$ clientes estudiados. Comunicación verbal con deficiencias y riesgo del ojo seco clientes estaban presentes en $31(91,2 \%)$, los procesos disfuncionales de la familia y la dentición deteriorada en $30(88,2 \%)$, la tristeza crónica y el dolor estaban presentes en 29 familias $(85,3 \%)$, incontinencia intestinal en 27 clientes $(79,4 \%)$, la ventilación espontánea alteración / patrón de respiración ineficaz en 26 (76,5\%), dolor agudo en 23 clientes (67,6\%), el riesgo de integridad de la piel alterada era clientes presentes en $21(61,8 \%)$ de la muestra, el exceso de líquido estuvo presente en 20 clientes volumen (58,8\%). Los otros diagnósticos tenían una frecuencia inferior a 50\%. Se cree que, con los resultados obtenidos en este estudio, los instrumentos utilizados servirán para apoyar a las enfermeras que trabajan en unidades de oncología y unidad de cuidados intensivos en cuanto a la aplicación del proceso de enfermería en casos de clientes de cáncer en cuidados paliativos y su familias.

Descriptores: diagnóstico de enfermería, enfermería de oncología, cuidados paliativos, cuidados críticos, modelos de enfermeira. 


\section{LISTA DE FIGURAS}

Figura 1 - Evolução para a Teoria de Imogene King ........................................................ 36

Figura 2 - Diagrama do Modelo Conceitual de Imogene King, 1981 ...............................44

Figura 3 - Diagrama dos Sistemas Interatuantes de Imogene King 1981 ......................... 45

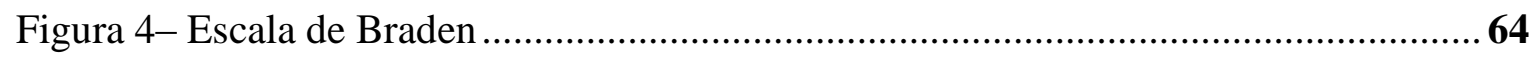

Figura 5 - Escala de Risco de quedas de Morse ............................................................65

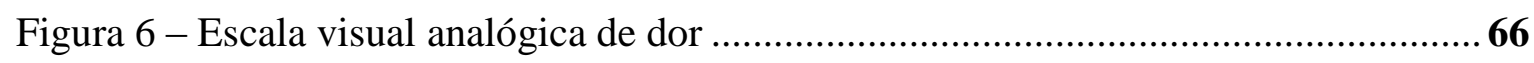

Figura 7 - Escala de dor Behavior Pain Scale ................................................................66

Figura 8 - Escala de Percepção de Estresse (PSS 14) ...................................................... 67

Figura 9 - Histograma de idade dos clientes oncológicos críticos em cuidados paliativos $(n=34)-$ Brasília, dezembro 2014 a julho 2015. ....................................................... 70

Figura 10 - Topografia da doença oncológica dos clientes oncológicos críticos em cuidados paliativos $(n=34)$ - Brasília, dezembro 2014 a julho 2015.

Figura 11 - Distribuição dos diagnósticos de enfermagem segundo os Sistemas Pessoal, Interpessoal e Social dos clientes oncológicos críticos em cuidados paliativos $(n=34)-$

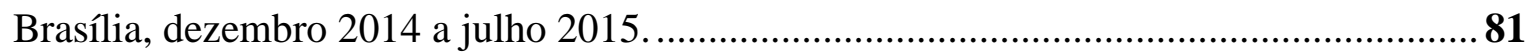




\section{LISTA DE TABELAS}

Tabela 1: Caracterização dos clientes oncológicos críticos em protocolo de cuidados paliativos quanto ao perfil socioeconômico-demográfico na amostra estudada $(n=34)-$ Brasília, dezembro 2014 a julho 2015 .

Tabela 2: Caracterização dos fatores condicionantes à internação hospitalar dos pacientes oncológicos críticos em protocolo de cuidados paliativos na amostra estudada $(n=34)-$ Brasília, dezembro 2014 a julho 2015.

Tabela 3: Caracterização de frequência sobre a existência de metástase nos clientes oncológicos críticos em protocolo de cuidados paliativos na amostra estudada $(n=34)-$ Brasília, dezembro 2014 a julho 2015.

Tabela 4: Tratamentos prévios aos quais foram submetidos os pacientes oncológicos críticos em protocolo de cuidados paliativos na amostra estudada $(n=34)$ - Brasília, dezembro 2014 a julho 2015.

Tabela 5: Escalas de avaliação aplicadas aos pacientes oncológicos críticos em protocolo de cuidados paliativos na amostra estudada $(n=34)$ - Brasília, dezembro 2014 a julho 2015.

Tabela 6: Diagnósticos de enfermagem reais mais frequentes nos pacientes oncológicos críticos em protocolo de cuidados paliativos na amostra estudada $(n=34)$ - Brasília, dezembro 2014 a julho 2015.

Tabela 7: Diagnósticos de enfermagem potenciais ou de risco mais frequentes nos pacientes oncológicos críticos em protocolo de cuidados paliativos na amostra estudada $(n=34)$ - Brasília, dezembro 2014 a julho 2015.

Tabela 8: Distribuição dos diagnósticos de enfermagem reais da NANDA-I, conforme os sistemas de King, na amostra estudada $(n=34)$ - Brasília, dezembro 2014 a julho 2015. 79

Tabela 9: Distribuição dos diagnósticos de enfermagem reais da NANDA-I, por domínio, na amostra estudada $(n=34)$ - Brasília, dezembro 2014 a julho 2015.

Tabela 10: Distribuição dos diagnósticos de enfermagem de risco da NANDA-I, por domínio, na amostra estudada $(n=34)$ - Brasília, dezembro 2014 a julho 2015.

Tabela 11: Distribuição das frequências das características definidoras para os diagnósticos de enfermagem com frequências iguais ou superiores a $50 \%$, segundo a NANDA-I - Brasília, dezembro 2014 a julho 2015. a

Tabela 12: Distribuição das frequências dos fatores relacionados e fatores de risco para os diagnósticos de enfermagem com frequências iguais ou superiores à $50 \%$, segundo a NANDA-I - Brasília, dezembro 2014 a julho 2015. 
Tabela 13: Distribuição das frequências dos fatores de risco para os diagnósticos de enfermagem com frequências iguais ou superiores à 50\%, segundo a NANDA-I - Brasília, dezembro 2014 a julho 2015. 


\section{LISTA DE QUADROS}

Quadro 1 - Sistema Pessoal de Imogene King: Conceitos, definições, características e implicações para a Enfermagem - Brasília, dezembro 2014 a julho 2015.

Quadro 2 - Sistema Interpessoal de Imogene King: Conceitos, definições, características e implicações para a Enfermagem - Brasília, dezembro 2014 a julho 2015.

Quadro 3 - Sistema Social de Imogene King: Conceitos, definições, características e implicações para a Enfermagem - Brasília, dezembro 2014 a julho 2015. 


\section{LISTA DE SIGLAS}

APACHE II- Acute Physiology and Chronic Health Evalution - versão 2

BPS- Behavioral Pain Scale

CAAE - Certificado de Apresentação para Apreciação Ética

CEP - Comitê de ética em pesquisa

CFM - Conselho Federal de Medicina

CID - Classificação internacional de doenças

CIPE - Classificação Internacional para a Prática da Enfermagem

DF - Distrito Federal

EVA - Escala visual analógica

FTP - Fora de possibilidade terapêutica

GONR - Registro de enfermagem orientado por metas

INCA - Instituto Nacional do Câncer

IOELC - International Observatory on End of Life Care

NANDA-I - North American Nursing Diagnosis Association - International

NIC - Nursing Interventions Classification

NIH -National Cancer Institute

NOC - Nursing Outcomes Classification

OMS - Organização Mundial da Saúde

ONA - Organização Nacional de Acreditação

pCO2 - Pressão de gás carbônico

PSS 14 - Escala de estresse percebido - Versão 14

TCLE - Termo de Consentimento Livre e Esclarecido

UTI - Unidade de Terapia Intensiva 


\section{SUMÁRIO}

1. INTRODUÇ̃̃O

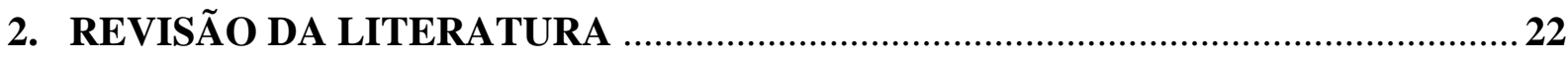

2.1 O CONTEXTO ATUAL DA DOENÇA ONCOLÓGICA …………………………...22

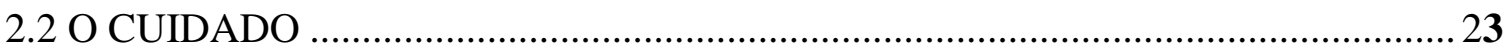

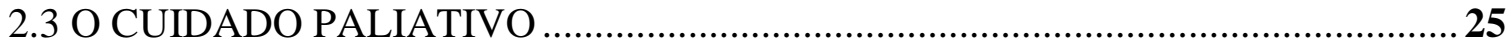

2.4 O PACIENTE ONCOLÓGICO CRÍTICO EM CUIDADOS PALIATIVOS ...............31

2.4.1 COMPLICAÇÕES MAIS COMUNS NO PACIENTE ONCOLÓGICO EM

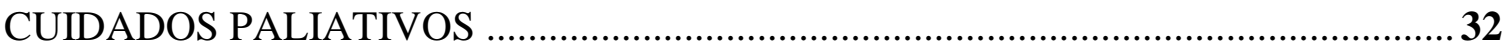

2.5 ESTRUTURAS CONCEITUAIS DA ENFERMAGEM …………………………......34

2.6 TEORIA DO ALCANCE DE METAS DE IMOGENE KING ......................................36

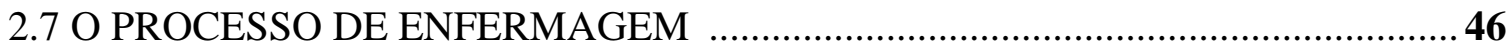

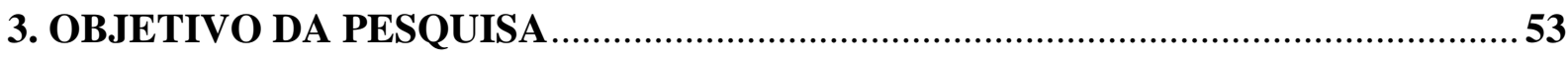

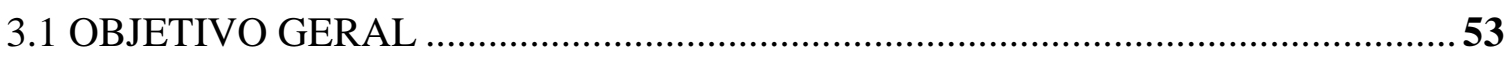

3.2 OBJETIVOS ESPECÍFICOS .........................................................................53

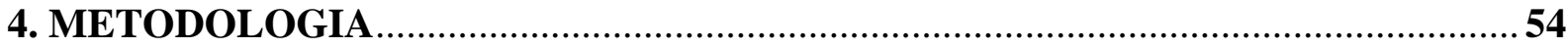

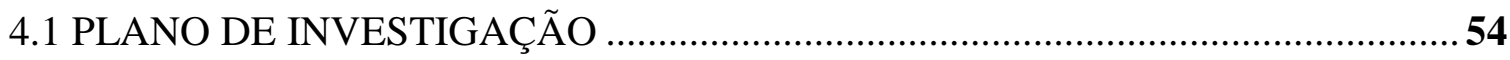

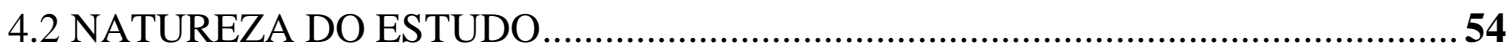

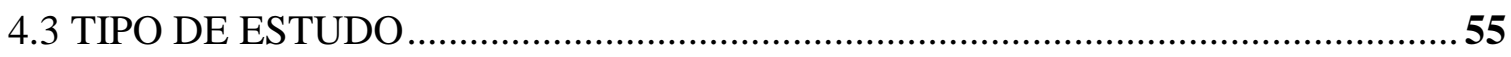

4.4 DEFINIÇÃO DO PROBLEMA DE PESQUISA ………………………..............55

4.5 DELIMITAÇÃO DO PROBLEMA DE PESQUISA …………………………......55

4.6 FORMULAÇÃO DO PROBLEMA DE PESQUISA ……………………………....56

4.7 FUNDAMENTAÇÃO TEÓRICA DA PESQUISA ……………………………….....56

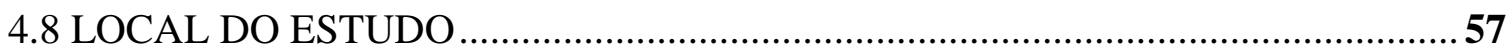

4.9 CARACTERIZAÇÃO DA AMOSTRA, CRITÉRIOS DE INCLUSÃO E

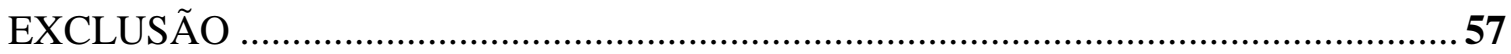

4.10 PROCEDIMENTO PARA COLETA DE DADOS ………………………………...59

4.11 INSTRUMENTO DE COLETA DE DADOS ..........................................................61

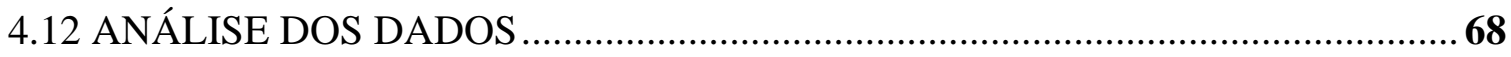

4.13 CONSIDERAÇÕES ÉTICAS E LEGAIS ..............................................................68

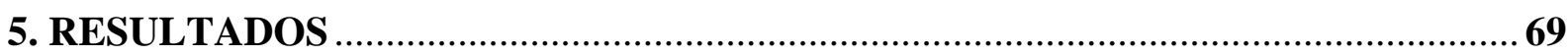


5.1 CARACTERIZAÇÃO DOS CLIENTES ONCOLÓGICOS CRÍTICOS EM CUIDADOS PALIATIVOS QUANTO AO PERFIL SOCIOECONÔMICODEMOGRÁFICO

5.2 CARACTERIZAÇÃO DOS FATORES CONDICIONANTES À INTERNAÇÃO HOSPITALAR DOS CLINTES ONCOLÓGICOS CRÍTICOS EM PROTOCOLO DE CUIDADOS PALIATIVOS

5.3 PERFIL DIAGNÓSTICO DOS CLIENTES ONCOLÓGICOS CRÍTICOS EM PROTOCOLO DE CUIDADOS PALIATIVOS .............................................................76

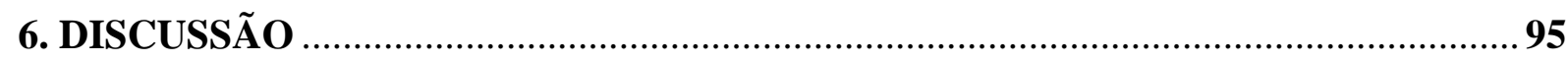

6.1 CARACTERIZAÇÃO DOS CLIENTES ONCOLÓGICOS CRÍTICOS EM CUIDADOS PALIATIVOS QUANTO AO PERFIL SOCIOECONÔMICODEMOGRÁFICO . .96

6.2 CARACTERIZAÇÃO DOS FATORES CONDICIONANTES À INTERNAÇÃO HOSPITALAR DOS CLINTES ONCOLÓGICOS CRÍTICOS EM PROTOCOLO DE CUIDADOS PALIATIVOS . .98

6.3 PERFIL DIAGNÓSTICO DOS CLINTES ONCOLÓGICOS CRÍTICOS EM PROTOCOLO DE CUIDADOS PALIATIVOS ………………………………......... 107

6.3.1 DÉFICIT NO AUTOCUIDADO …………………………………….......109

6.3.2 DEGLUTIÇÃO PREJUDICADA ……………………………………......110

6.3.3 MOBILIDADE FÍSICA PREJUDICADA...............................................111

6.3.4 PROTEÇÃO INEFICAZ ........................................................................112

6.3.5 ELIMINAÇÃO URINÁRIA PREJUDICADA............................................113

6.3.6 COMUNICAÇÃO VERBAL PREJUDICADA ……………………….....114

6.3.7 PROCESSOS FAMILIARES DISFUNCIONAIS ......................................115

6.3.8 DENTIÇÃO PREJUDICADA …………………………………….....116

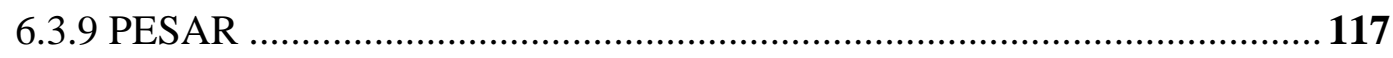

6.3.10 TRISTEZA CRÔNICA ………………………………………….........118

6.3.11 INCONTINÊNCIA INTESTINAL ......................................................119

6.3.12 VETILAÇÃO ESPONTÂNEA PREJUDICADA / PADRÃO RESPIRATÓRIO INEFICAZ .............................................................................. 120

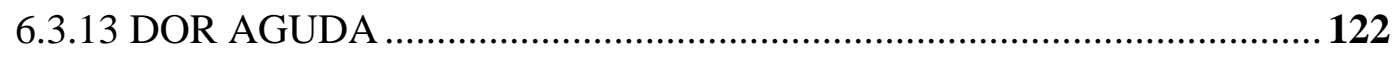

6.3.14 VOLUME DE LÍQUIDOS EXCESSIVO.................................................123

6.3.15 RISCO DE ASPIRAÇÃO ..................................................................124

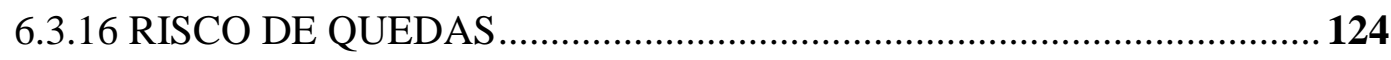

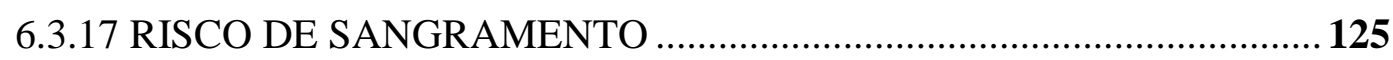

6.3.18 RISCO DE SÍNDROME DO DESUSO ................................................126 


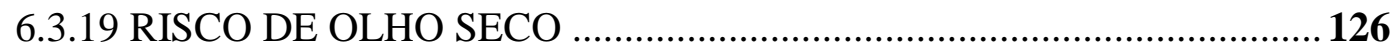

6.3.20 RISCO DE INTEGRIDADE DA PELE PREJUDICADA ......................127

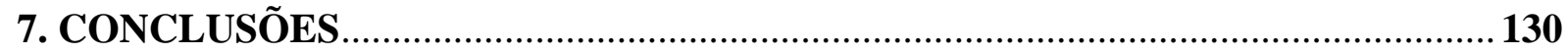

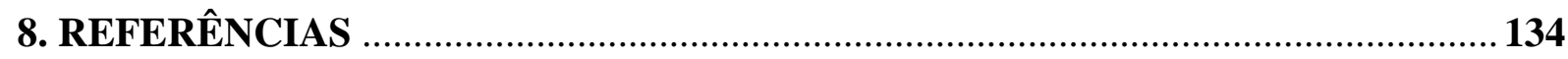

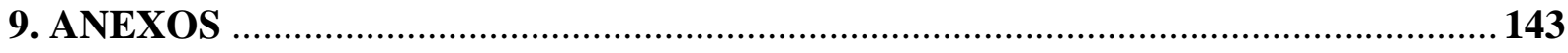

9.1 ANEXO A - PROTOCOLO DE SUBMISSÃO DE PESQUISA ............................ 143

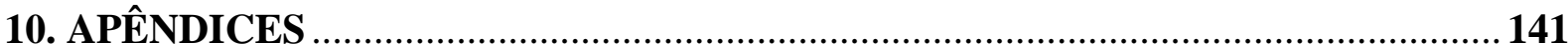

10.1 APÊNCICE A - TERMO DE CONSENTIMENTO LIVRE E ESCLARECIDO . 144

10.2 APÊNCICE B - INSTRUMENTO DE COLETA DE DADOS ..............................146 


\section{APRESENTAÇÃO}

Trabalhar com o Processo de Enfermagem constitui-se ainda hoje numa tarefa complexa e grande desafio, em especial quando a proposta é atuar com fundamentação em um referencial teórico de enfermagem. Os conteúdos e reflexões expostos buscam focar na sistematização da assistência de enfermagem a clientes oncológicos críticos inclusos em protocolo de cuidados paliativos a fim de oferecer contribuição às pesquisas nesta área com consequente possibilidade de melhoria na qualidade do cuidado prestado.

O segundo grande desafio é estudar a doença oncológica e o Paliativismo. As políticas já existem há algum tempo no Brasil e no mundo, mas a sua compreensão e execução na prática ainda permeiam inúmeras variáveis sociais, culturais e individuais. E diria ainda que $\mathrm{o}$ terceiro e maior desafio consiste no estudo do processo de morte e morrer, onde algumas pessoas ainda tem findada sua passagem por aqui sem sequer saber de sua condição de Paliativismo. O câncer, o paliativismo e a morte são ainda tabus e barreiras para muitos profissionais que compõe a equipe de saúde. Muitos que não compreendem sua existência e nem tampouco sua finitude, o que contribui de forma marcante para a falta de habilidades nos cuidados a essa clientela tão peculiar.

O estudo busca articular cliente, enfermeiro, organização social e processo de enfermagem em uma perspectiva sistêmica com a finalidade de formar uma filosofia que apoie a reflexão. Optou-se por utilizar o marco conceitual de Imogene King, uma vez que este contem ideais e pressupostos que vão ao encontro da abordagem sistêmica.

O estudo traz inicialmente uma reflexão sobre a doença oncológica, o cuidado de enfermagem e os princípios do cuidado paliativo. Após isto são expostos aspectos do cliente oncológico critico, suas internações nas unidades de terapia intensiva e suporte teórico com revisão da literatura acerca dos conceitos e princípios. A seguir, é apresentada a caracterização da amostra no diz respeito aos aspectos sócio demográficos e topografia da doença. Na última etapa são apresentados e analisados os problemas/diagnósticos de enfermagem de maior frequiência na amostra em questão.

$\mathrm{Na}$ finalização temos as considerações finais e apresentação das referencias bibliográficas. 


\section{INTRODUÇÃO}

São várias as teorias e referenciais que tem contribuído na assistência ou no processo de cuidar, dentre elas podemos destacar a teoria do Alcance de Metas de Imogene King. A partir do referencial teórico de Imogene King pode-se definir o processo de enfermagem como um processo de ação, reação e interação pelo qual o enfermeiro e cliente compartilham informações sobre suas percepções na situação de enfermagem. A luz desse referencial podese entender a saúde como um estado dinâmico no ciclo de vida de um ser humano o que implica em ajustamentos contínuos a estressores, no ambiente interno e externo, através do uso de recursos próprios para alcançar o máximo potencial para a vida diária (VIEIRA, 2003).

Dados do INCA retratam o câncer como um problema de saúde pública mundial tendo apresentado aumento de $20 \%$ em sua incidência na última década. No âmbito mundial esperase para 27 milhões de novos casos para 2030, sendo 80\% destes entre os países em desenvolvimento. Para o ano de 2016 espera-se para o Brasil 596 mil novos casos, sendo $51 \%$ (214.350) nos homens e 49\% (205.960) nas mulheres. O câncer é a segunda maior causa de morte no Brasil por doença, estando abaixo apenas das doenças cardiovasculares em termo de mortalidade (BRASIL, 2015).

Embora a cultura ocidental apresente inúmeras dificuldades acerca da finitude da vida, é inegável que a morte faz parte do ciclo dinâmico. E quando a morte se aproxima através de uma condição de prognóstico ruim, tanto os clientes como seus familiares, e até mesmo a equipe de saúde apresentam inúmeras dificuldades em encontrar recursos para a realização dos ajustamentos necessários ao alcance do máximo potencial para a vida (AYER, 2008).

Na condição de cuidados paliativos há muito a ser feito pelo cliente e por sua família e o desenvolvimento de visão sistêmica é uma forma de organizar e racionalizar um método para atingir um objetivo. A assistência de enfermagem uma vez norteada por fundamentos sistêmicos caminha em busca de maior organização e sistematização (AYER, 2008).

A aplicação do processo de enfermagem, metodologia de trabalho capaz de melhorar grandemente a qualidade da assistência de enfermagem prestada, deve ser o objetivo do enfermeiro, sendo vista como um instrumento metodológico que favorece o cuidado e documenta a prática profissional, sendo constituído por etapas inter-relacionadas, de acordo com a estrutura teórica utilizada (BARROS, 2009). 


\section{FUNDAMENTAÇÃO TEÓRICA DA PESQUISA}

\subsection{O CONTEXTO ATUAL DA DOENÇA ONCOLÓGICA}

A cada ano 20 milhões de pessoas no mundo são diagnosticadas com câncer. No Brasil $60 \%$ dos diagnósticos acontecem em pessoas já em estado avançado da doença. De acordo com estimativas do Instituto Nacional do Câncer para 2016/2017, o Brasil deverá registrar no próximo ano 596 mil casos de câncer. O aumento na incidência do câncer tem associação com o envelhecimento da população, hábitos alimentares, excesso de peso, obesidade, consumo de bebidas alcoólicas e uso do tabaco (BRASIL, 2015).

A partir do século XX, o poder de intervenção dos profissionais de saúde cresceu enormemente, sem que ocorresse simultaneamente uma reflexão sobre o impacto dessa nova realidade na qualidade de vida dos enfermos. Aspectos culturais, associados aos fatores sociais, como a dificuldade do tratamento de um doente terminal em seu lar, levaram à morte institucionalizada. No mundo atual, mais de $70 \%$ dos óbitos ocorrem nos hospitais e, mais especificamente nas unidades de terapia intensiva (UTIs). Nessas unidades, tamanho é o arsenal tecnológico disponível que se torna quase impossível morrer sem a anuência do médico intensivista. Corrobora com essa afirmação, o fato de que os óbitos nas UTIs, a nível mundial, são precedidos em 30 a 50\% dos casos de decisões sobre a suspensão ou recusa de tratamentos considerados fúteis ou inúteis (KOVACS, 2014).

Ao longo da evolução humana, a percepção da morte foi se transformando e tomando uma proporção diferenciada na vida das pessoas. Para os nossos antepassados, a morte era percebida como uma fase natural da vida, onde o processo morte e morrer era assistido pelos familiares, permitindo o conforto e a presença dos entes queridos. Atualmente esse processo acontece nas instituições de saúde e a família, que assumia os cuidados, começa a transferi-los aos profissionais que atuam nas organizações hospitalares. Houve, portanto, uma transição de conceitos e percepções. A morte que antes era consumada e constatada nas residências dos doentes, passou a ser uma responsabilidade dos profissionais de saúde (BARBOSA, 2006).

A evolução da área das ciências da saúde como um todo é exponencial, trazendo, a cada dia, novas tecnologias diagnósticas e de tratamento. Como consequência desse progresso, observa-se uma maior sobrevida de pacientes com doenças crônicas e limitantes. Segundo HIN, National Cancer Institute, vários fatores podem afetar o prognóstico da doença, estes fatores incluem: o tipo de câncer e sua topografia, o estágio da doença (tamanho 
e disseminação), características das células tumorais, idade do paciente e resposta ao tratamento. Para estimar o prognóstico do câncer são utilizadas estatísticas que os pesquisadores coletaram ao longo de muitos anos sobre pessoas com o mesmo tipo de câncer. Vários tipos de estatísticas podem ser utilizadas para estimar o prognóstico. As estatísticas mais usadas incluem: sobrevida específica por câncer, sobrevida relativa e a sobrevida global.

Para pacientes com câncer o contato com o diagnóstico é a fase mais difícil. Sempre se necessita de suporte emocional para enfrentar o período de tratamento e as adaptações ao adoecer. $\mathrm{O}$ tratamento pode trazer desconforto, e a dor pode se manifestar como primeiro sintoma ou ainda ser ela consequente ao próprio tratamento (SILVA, 2008).

Dados estatísticos apontam para a gravidade do câncer, reafirmando os conteúdos simbólicos e imaginários que lhe são atribuídos. Trata-se de uma doença comumente relacionada à perda da integridade de seu portador, às mutilações físicas e por fỉm, à finitude da vida, sendo o período compreendido entre o início do tratamento e a tentativa de remissão da doença designado como "estado de guerra". Em oncologia notícias difíceis são constantemente transmitidas, tanto na fase inicial como no estágio final da doença (MACIEL, 2006).

Os cuidados paliativos consideram a família uma unidade de cuidado que também deve receber assistência durante todo o tempo de acompanhamento de seu paciente e até depois de seu óbito, no período do luto. O termo paliativo deriva do latim pallium, um manto usado pelos peregrinos durante suas viagens em direção aos santuários para protegê-los das intempéries. Em analogia, o cuidado paliativo tem o objetivo de proteger a pessoa doente durante seu último período de vida. No uso corrente, o termo paliativo tem uma conotação de inutilidade, ineficácia (MACIEL, 2006).

\subsection{O CUIDADO}

Desde que surge vida os cuidados existem, uma vez que é necessário cuidar da vida para que esta permaneça. Nenhum ser vivo pode escapar a esta imperiosa necessidade e as situações de cuidado podem ser efetivamente paradoxais, onde o que é fonte de vitalização e vivificação para um se choca com aquilo que cria obstáculo a vida para o outro (COLLIÉRE, 2003). 
O cuidado pode ser conceituado como o conjunto de procedimentos tecnicamente orientados para o bom êxito de certo tratamento, e deve ser centrado em ações de saúde para as mais diversas situações em que se necessita de uma ação terapêutica, ou seja, uma interação entre dois ou mais sujeitos visando ao alivio do sofrimento ou ao alcance do bemestar (COLLIÉRE, 2003).

O cuidado é a essência e objeto da enfermagem, mas só é possível se houver interação. Para que haja cuidado é preciso haver encontro, uma vez que somente através deste encontro há possibilidade de transformação (COLLIÉRE, 2003).

A história dos cuidados desenha-se em dois grandes eixos: assegurar a continuidade da vida e fazer recuar a morte. Para a autora o termo cuidado pode ser utilizado no singular e no plural, sendo oriundo do verbo soniare que significa "ocupar-se de". Cuidar é um dos raros verbos que se conjuga na forma passiva, prenominal e ativa: Ser cuidado... cuidar-se ... cuidar, sendo fato que estas três formas revelam as etapas da vida que ultrapassamos progressivamente sucedendo-se e sobrepondo-se. Já tratar é proveniente de tractare, palavra que originalmente significa negociar. O tratamento tem como objetivo modificar o domínio e a ação da doença, procurando detê-la. O tratamento tem como alvo a doença, portanto o cuidado não pode ser assimilado a tratar. Os cuidados e os tratamentos não são da mesma natureza. Os tratamentos não podem substituir o que assegura as funções vitais. Quanto mais um tratamento toma o lugar dos cuidados, mais se torna prejudicial (AYRES, 2005).

Podemos então concluir que nenhum tratamento pode substituir os cuidados e que até pode-se viver sem tratamentos, mas não se pode viver sem cuidados. O cuidado se constitui, simultaneamente, como um atributo e uma necessidade universal dos seres humanos (COLLIÉRE, 2003).

No contexto do cuidado paliativo, o "cuidar" é tratado como um verbo presente em todas as teorias de enfermagem, considerando que, em cuidados paliativos, cuidar significa estar ao lado de pessoas com perda de vitalidade, com dor, depressão e perda de autonomia. $\mathrm{O}$ enfermeiro é um profissional com enorme potencial para otimizar o cuidado, pois além de ser um excelente avaliador dos sintomas e suas intensidades, sabe lidar com as limitações que vão surgindo a cada dia (AYRES, 2005). 
Não podem ser considerados cuidados as tarefas de higiene desempenhadas de forma sistemática e rotineira. Cuidar é aprender a discernir o que necessita de estimulação, o que necessita de desenvolvimento de forças e o que necessita de capacidades de vida. Cuidar é discernir ainda o que necessita manter as capacidades existentes, o que necessita atenuar ou compensar as perdas e o que necessita de acompanhar o que é incerto ou se debilita. Esses cuidados, aliados a tratamentos ou não, requerem capacidade de discernimento de tudo o que ajuda a viver, contribuindo para passar e ultrapassar a etapa que se tem a vencer, até mesmo se esta etapa for a morte. Cuidar é discernir as preocupações e dificuldades encontradas pelas pessoas que precisam de cuidados (COLLIÉRE, 2003).

\subsection{O CUIDADO PALIATIVO}

A filosofia dos cuidados paliativos iniciou-se na Inglaterra, em 1967, a partir da iniciativa de Cicely Mary Strode Saunders. Ela foi assistente social, enfermeira e médica que disseminou uma nova maneira de cuidar dos pacientes que vivenciavam a terminalidade e a proximidade com a morte. Nessa filosofia os cuidados realizados tem o objetivo de compreender todas as necessidades do paciente, dentro dos limites possíveis, contemplando-o como um ser integral (ABREU, 2011).

A palavra paliativo que deriva do latim pallium, e significa manto. Não um manto qualquer, mas um manto que carrega uma simbologia e um significado. Em latim, Pallium ou pallia e o omoforium são vestimentas usadas pelo Papa e pelo bispo, respectivamente. Portanto observa-se uma profunda ligação desses termos históricos com o sagrado e a espiritualidade (ABREU, 2011).

Como acontece com muitas palavras, o termo paliativo tem um sentido real, etimológico, e um sentido que lhe é dado pelo senso comum. O sentido etimológico provém do adjetivo latino palliatus, que significa coberto com um pallium, o manto usado pelos gregos antigos. O significado que encontramos no dicionário não se distancia muito dessa raiz etimológica e figurativamente indica "o que serve para acalmar, atenuar ou aliviar momentaneamente um mal". Já na linguagem usada no dia-a-dia, o termo paliativo se distancia muito do seu sentido etimológico, relacionando-se à 'insignificante, medíocre, secundário'. É por isso que embora os termos cuidados paliativos estejam ligados ao sentido original de cobrir com um pallium, agasalhar, mitigar a dor e o sofrimento, muitas vezes são contaminados pelo senso comum (ABREU, 2011). 
Ao considerarmos a morte como algo absolutamente negativo, somos levados ao impulso de considerarmos negativo também aquilo que gravita em torno dela, a doença, a fragilidade, a velhice. E, simbolicamente, consideramos os frágeis, os doentes e os velhos como seres excessivamente próximos daquele momento de passagem que mais queremos afastar de nós (ABREU, 2011).

A Associação Brasileira de Cuidados Paliativos trás a definição do cuidado paliativo da OMS como uma abordagem que aprimora a qualidade de vida dos pacientes e famílias que enfrentam problemas associados com doenças ameaçadoras à vida, por meio de prevenção e alivio do sofrimento, possibilitadas por identificação precoce, avaliação correta e tratamento da dor, entre outros problemas de ordem física, psicossocial e espiritual (AYER, 2008).

Segundo Ayer (2008) o cuidado paliativo deve ser baseado em conhecimento científico inerente a várias especialidades e possibilidades de intervenção clínica e terapêutica nas diversas áreas de conhecimento da ciência médica. Porém, o trabalho de uma equipe de Cuidados Paliativos é regido por princípios claros, que podem ser evocados em todas as atividades desenvolvidas.

Os princípios são:

$\checkmark$ Fornecer alívio para dor e outros sintomas estressantes como astenia, anorexia, dispnéia e outras emergências oncológicas;

$\checkmark$ Reafirmar vida e a morte como processos naturais;

$\checkmark$ Integrar os aspectos psicológicos, sociais e espirituais ao aspecto clínico de cuidado do paciente;

$\checkmark$ Não apressar ou adiar a morte;

$\checkmark$ Oferecer um sistema de apoio para ajudar a família a lidar com a doença do paciente, em seu próprio ambiente;

$\checkmark$ Oferecer um sistema de suporte para ajudar os pacientes a viverem o mais ativamente possível até sua morte; 
$\checkmark$ Usar uma abordagem interdisciplinar para acessar necessidades clínicas e psicossociais dos pacientes e suas famílias, incluindo aconselhamento e suporte ao luto.

Os princípios do cuidado paliativo também foram publicados pela OMS em 1986 e reafirmados em 2002 (INCA, 2001). O tema cuidados paliativos é assunto negligenciado na maioria dos países, sendo necessária ação determinada, tanto social como política, com objetivo consistente de promover o bem estar e a qualidade de vida destes pacientes (QUILL, 2009).

Maciel (2006) nos traz uma reflexão trabalhada pela OMS desde 2002, em que é afirmado que os cuidados paliativos devem se iniciar o mais precocemente possível, de preferência a partir do diagnóstico de uma doença potencialmente letal. Na prática,sabe-se que nem sempre tal procedimento é possível. No entanto, o recomendável é que todos os serviços que se propõem a atender pacientes passíveis de inclusão estejam preparados para os cuidados paliativos. Isso possibilita, a qualquer momento, uma ação ou intervenção paliativa, de acordo com a necessidade do doente.

Em suma, os cuidados paliativos devem sempre existir em hospitais gerais de grande porte e onde se tratam câncer, idosos e pacientes crônicos. O que faz um paciente ser incluído num programa de cuidados paliativos é a percepção de que, além do tratamento curativo, existem sintomas e desconfortos que comprometem sua qualidade de vida e que precisam ser abordados com competência e seriedade por uma equipe especializada. O contato precoce com a equipe de cuidados paliativos possibilita um vínculo de confiança, imprescindível para que as decisões que nortearão o seu tratamento em final de vida sejam tomadas segundo os desejos e as características de cada doente. Isso significa, em última análise, o respeito ao direito de autonomia do doente. Quando o tratamento paliativo se torna preponderante, os doentes se caracterizam por um padrão de múltiplas necessidades e alta demanda, que variam de acordo com a natureza da doença de base (MACIEL, 2006).

Os complexos problemas que emergem com os cuidados no fim da vida nos colocam diante da necessidade de aprofundar o debate em torno deste momento crítico da existência humana (FLORIANI, 2008). 
Outro termo, já em desuso, é "paciente fora de possibilidade terapêutica" ou "FPT", o que também conduz a uma compreensão errônea, em que o termo terapêutico só é associado à cura: toda a gama de cuidados para garantir qualidade de vida é desconsiderada. Pacientes com doença avançada podem ter vários sofrimentos, $\mathrm{O}$ agravamento da doença traz vários sintomas físicos que, em conjunto, tornam a vida difícil. Acompanhando o declínio físico surgem sintomas de sofrimento em várias esferas, tais como: medo de ficar sozinho, tristeza pelo abandono dos planos da vida, perda das pessoas próximas, dependência, e o medo da morte. A assistência prestada ao paciente que apresenta esses agravos e sintomas não pode deixar de ser considerada como terapêutica (AYER, 2008).

Estar em Cuidados Paliativos não significa ser privado dos recursos diagnósticos e terapêuticos que a medicina pode oferecer. Deve-se usá-los de forma hierarquizada, levandose em consideração os benefícios que podem trazer e os malefícios que devem ser evitados. Começar precocemente a abordagem paliativa permite a antecipação dos sintomas, podendo preveni-los. A integração da equipe que promove o tratamento curativo possibilita a elaboração de um plano integral de cuidados, que perpasse todo o tratamento, desde o diagnóstico até a morte e o período após a morte do doente (PIVA, 2014).

Dessa forma, os cuidados paliativos constituem um campo interdisciplinar de cuidados totais, ativos e integrais, destinados a melhorar a qualidade de vida do paciente sem possibilidades de cura e dos seus familiares, por meio de avaliação correta e de tratamento adequados para o alívio da dor e dos sintomas decorrentes da fase avançada de uma doença, além de proporcionar suporte psicossocial e espiritual, em todos os estágios, desde o diagnóstico de uma doença incurável até o período de luto da família (PIVA, 2014).

Em quarenta anos de conhecimento e desenvolvimento dos cuidados paliativos, a prática está bem estruturada em apenas 35 países. Porém, outras 121 nações já sinalizam esforços para implantar políticas adequadas. O IOELC, International Observatory on End of Life Care, identificou no Brasil apenas 14 serviços e nenhuma iniciativa oficial. Esta realidade aparentemente já está diferente e tende a mudar muito rapidamente. Só no Estado de São Paulo, entre serviços conhecidos e estruturados, podemos contar com pelo menos 13 iniciativas. A julgar pela participação em congressos e divulgação de serviços, estima-se a existência de pelo menos 40 iniciativas no País. Muito pouco para nossa extensão continental. Porém, não se podem negar as iniciativas gerais que incluem (MACIEL, 2006). 
No contexto da prática clinica observa-se que após determinado período, por falência do tratamento ou recidiva, a doença evolui de forma progressiva e inversamente proporcional à condição clínica e capacidade funcional do doente. O declínio é perfeitamente visível, e os cuidados paliativos se tornam imperativos. Chega-se a um período no qual a morte é inevitável e uma cadeia de sinais e sintomas anunciam sua proximidade. Esse período, chamado de fase final da vida, ou terminalidade, requer atenção especial, vigilância intensa e uma terapêutica especializada e absolutamente voltada para o alívio dos sintomas do paciente (KOVACS, 2014).

Nesse momento a paliação se torna necessária e não se indicam os tratamentos invasivos e dolorosos, uma vez que estes podem apenas proporcionar o prolongamento do sofrimento. Nesse ponto, o paciente deve continuar a receber cuidados essenciais e suporte de vida, incluindo a atenção constante da família e ambiente afetivo. Nesta fase, na qual o doente tem muita dificuldade em expressar sofrimento e sintomas, deve-se desenvolver o poder de observação e comunicação silenciosa com o doente. O objetivo é perceber diferentes necessidades, proporcionando-lhe o necessário conforto. O processo final pode advir de uma complicação de difícil controle ou simplesmente falência funcional múltipla. Estas podem ser determinadas por danos preexistentes e acumuladas nas diferentes crises de necessidades (KOVACS, 2014).

Quando se fala em doença ativa, progressiva e ameaçadora à continuidade da vida significa que os cuidados paliativos podem e devem ser indicados na vigência de doenças crônicas em diferentes fases de evolução. Os cuidados paliativos devem ser iniciados quando há possibilidade de morte por evolução natural de um processo de adoecer, que pode se arrastar por anos. Só não é possível aplicar os princípios dos cuidados paliativos quando há morte súbita por doença, acidente ou violência. Porém, a diferença na amplitude dos cuidados e na sua pertinência depende da fase em que se encontra a doença e da história natural de cada uma delas (LYNN, 2005).

Outra definição para o cuidado paliativo envolve o exercício da arte do cuidar aliado ao conhecimento científico capaz de proporcionar o alívio do sofrimento relacionado à doença, tendo como foco a adequada avaliação e o manuseio dos sintomas do paciente e de seus familiares com a finalidade de trazer qualidade de vida. O cuidado paliativo adequado deve incluir além do manuseio dos sintomas, os domínios psiquiátricos, psicossociais e 
existenciais, protegendo os pacientes dos danos causados pela doença e do sofrimento aparente (FLORIANI, 2008).

O cuidado paliativo precisa integrar aspectos psicossociais e espirituais ao cuidado, oferecendo um sistema de suporte que auxilie o paciente a viver tão ativamente quanto possível. $\mathrm{O}$ ato de cuidar de pacientes na fase final das suas vidas é cada vez mais frequente. Não é possível explanar de forma sintética as particularidades apresentadas por estas pessoas. Mas vale a lição de que cada indivíduo tem a sua história de vida. Cada paciente não é um ser simplesmente biológico, e sim, alguém que tem a sua vida cronológica a ser considerada, incluindo seus terrenos cultural, religioso e social (MACIEL, 2006).

Cuidar de pacientes em cuidados paliativos exige muito mais do que conhecimentos técnico-científicos, requer a compreensão a fundo de sua individualidade, a partir de um relacionamento interpessoal de valorização da pessoa humana (MACIEL, 2006).

Diante do diagnóstico de cuidados paliativos pode-se observar o distanciamento da equipe de enfermagem. Esse distanciamento pode ser percebido pelo excesso de permissividade, redução no número de visitas ao leito, aceitação da finitude antes que a morte de fato aconteça, atenção por atender somente as necessidades básicas, entre outros. Esse comportamento pode se dar pelo próprio conceito equivocado do cuidar curativo. $\mathrm{O}$ enfermeiro tem como princípio fundamental em seu código de ética o comprometimento com a saúde e qualidade de vida da pessoa, família e coletividade e a filosofia de cuidados paliativos vem aprimorar o que já está enraizado na profissão, o cuidado (SILVA, 2008).

É errônea a suposição de que não há mais nada a se fazer pelo paciente sem possibilidades de cura, pois enquanto há vida, existe a necessidade do cuidado de enfermagem. Neste sentido, a atuação da equipe de enfermagem é primordial e indispensável para proporcionar o máximo de conforto ao paciente em cuidados paliativos, ajudando-o a vivenciar o processo de morrer com dignidade, para que utilize da melhor forma possível, o tempo que lhe resta. Isto significa ajudar o ser humano a buscar qualidade de vida (SILVA, 2008).

Observam-se a nível mundial grandes esforços na investigação de novos métodos e tecnologias para o tratamento do câncer. E verificamos os resultados desses esforços por meio de importantes descobertas, como novos medicamentos quimioterápicos, novas técnicas 
cirúrgicas e radioterápicas. O tratamento mais agressivo tem exposto o cliente oncológico à condições de maior criticidade e as internações em unidades de terapia intensiva tem sido mais frequentes (KOVACS, 2014).

\subsection{O PACIENTE ONCOLÓGICO CRÍTICO EM CUIDADOS PALIATIVOS}

Nos últimos anos, avanços nos cuidados dos pacientes com câncer possibilitaram maior probabilidade de controle ou cura da doença. Entretanto, o uso de tratamentos quimioterápicos e cirúrgicos mais agressivos implicou diretamente na maior utilização de leitos de UTI. Também, na última década, estudos têm demonstrado que os avanços recentes nos cuidados intensivos se traduziram na redução da mortalidade de pacientes críticos com câncer, mesmo em populações de maior risco como pacientes com sepse ou submetidos à ventilação mecânica (SALLUH, 2006).

Entretanto, a internação na UTI de pacientes com câncer com complicações agudas graves ainda é motivo de controvérsia entre os intensivistas e os oncologistas uma vez que o seu prognóstico é frequentemente considerado ruim a priori. Este conceito repetidamente gera recusa das internações dos pacientes nas UTI, em especial na realidade das instituições hospitalares públicas (SALLUH, 2006).

Uma avaliação ideal do mérito da internação de paciente com câncer na UTI necessita de complexa interação de fatores clínicos relacionados à complicação aguda, à neoplasia subjacente e às preferências e valores do paciente e seus familiares. Assim sendo, critérios atuais de admissão de pacientes oncológicos na UTI devem ser reavaliados (SALLUH, 2006).

Nesse contexto alguns aspectos são de alta relevância uma vez que a presença de comorbidades graves encontra-se associada à letalidade sendo a progressão do tumor um dos principais fatores de mau prognóstico em pacientes críticos com câncer (COSTA, 2008).

Os pacientes cirúrgicos, especialmente aqueles submetidos a cirurgias com intenção curativa, reconhecidamente têm melhor prognóstico quando comparados a pacientes clínicos e o benefício da internação na UTI é indiscutível. Por outro lado, a gravidade das disfunções orgânicas, o comprometimento da capacidade funcional e o estado da neoplasia (estadiamento 
e fase da doença) são os principais determinantes do seu prognóstico e devem ser consideradas na discussão, para critérios para admissão a UTI (SALLUH, 2006).

Cuidados paliativos na Unidade de Terapia Intensiva são cuidados prestados ao paciente crítico em estado terminal, quando a cura é inatingível e, portanto deixa de ser o foco da assistência. Nesta situação, o objetivo primário é o bem estar do paciente, permitindo-lhe uma morte digna e tranquila. A priorização dos cuidados paliativos e a identificação de medidas fúteis devem ser estabelecidas de forma consensual pela equipe multiprofissional em consonância com o paciente (se capaz), seus familiares ou seu representante legal. Após definidas, as ações paliativas, devem ser registradas de forma clara no prontuário do paciente. Durante o tratamento de um paciente terminal muitas das medidas curativas/restaurativas, podem configurar tratamento fútil, tais como: nutrição parenteral ou enteral, administração de drogas vasoativas, terapia renal substitutiva, instituição ou manutenção de ventilação mecânica invasiva e, inclusive, a internação ou permanência do paciente na UTI (SALLUH, 2006).

Caso venha a existir conflito durante a tomada de decisão de um tratamento paliativo, deve-se priorizar uma adequada comunicação entre os atores envolvidos no processo, pois, a má comunicação é uma das principais barreiras que gera conflitos no tratamento de um paciente em cuidados paliativos na UTI (SALLUH, 2006).

\subsubsection{COMPLICAÇÕES MAIS COMUNS NO PACIENTE ONCOLÓGICO EM CUIDADOS PALIATIVOS}

O término de uma terapia curativa para o câncer não significa o final de um tratamento ativo, mas mudanças em focos de tratamento. A OMS enfatiza que o tratamento ativo e o tratamento paliativo não são mutuamente excludentes e propõe que "muitos aspectos dos cuidados paliativos devem ser aplicados mais cedo, no curso da doença, em conjunto com o tratamento oncológico ativo" e são aumentados gradualmente como um componente dos cuidados do paciente do diagnóstico até a morte. A transição do cuidado ativo para o cuidado com intenção paliativa é um processo contínuo e sua dinâmica difere para cada paciente (OTTO, 2012).

Os cuidados paliativos devem incluir as investigações necessárias para o melhor entendimento e manejo de complicações e sintomas estressantes tanto relacionados ao 
tratamento quanto à evolução da doença. Apesar da conotação negativa ou passiva do termo paliativo, a abordagem e o tratamento paliativo devem ser eminentemente ativos, principalmente em pacientes portadores de câncer em fase avançada, onde algumas modalidades de tratamento cirúrgico e radioterápico são essenciais para alcance do controle de sintomas. Considerando a carga devastadora de sintomas físicos, emocionais e psicológicos que se avolumam no paciente com doença terminal, faz-se necessário um diagnóstico precoce e condutas terapêuticas antecipadas, dinâmicas e ativas, respeitando-se os limites do próprio paciente (OTTO, 2012).

As internações dos pacientes em cuidados paliativos em hospitais acontecem devido às complicações, sendo as mais comuns: dor não controlada, hemorragias, Infecções, náuseas e vômitos, bem como a desidratação (OTTO, 2012).

Tanto o tratamento cirúrgico, como o tratamento quimioterápico e radioterápico estão implicados no aparecimento de inúmeros efeitos colaterais. A pele, os cabelos, as unhas e as mucosas são estruturas que podem apresentar alterações decorrentes do estado fisiológico do paciente. A exérese cirúrgica do tumor pode acarretar sequelas locais, tanto estéticas como funcionais, tais como: cicatrizes atróficas, hipertróficas e queloidianas, hiperpigmentação e fibrose (OTTO, 2012).

As reações cutâneas desencadeadas por quimioterápicos não são raras, mas apresentam difícil manejo. As drogas quimioterápicas atuam sobre as células que apresentam alta taxa de multiplicação, agindo não somente sobre as células neoplásicas, mas também sobre qualquer célula do organismo com alto metabolismo. Desta maneira, a pele e seus anexos representam um dos maiores alvos do tratamento quimioterápico. O principal mecanismo de ação dos quimioterápicos é induzir a morte celular através da apoptose , sendo que os efeitos sobre o tecido cutâneo são, na maior parte, decorrentes de reações tóxicas e não alérgicas (OTTO, 2012).

A radioterapia ocasiona inúmeros efeitos sobre o tecido cutâneo, variando entre agudos (até seis meses após o início da terapia) ou crônicos (após seis meses do início da terapia) e leve, moderado ou grave, dependendo da localização, tamanho e profundidade do tumor irradiado (OTTO, 2012). 
Nos casos leves, pode ocorrer um discreto eritema e nos casos graves, pode haver necrose cutânea com risco aumentado de úlceras crônicas e degeneração maligna. A aparição das complicações a curto, médio ou longo prazo é, sem dúvida, um dos principais fatores limitantes do tratamento antineoplásico e, por meio da sua descrição, é possível formular estratégias apropriadas para melhor conduzi-las. Os efeitos colaterais decorrentes do tratamento quimioterápicos, radioterápico e/ou cirúrgico acarretam importantes consequências na qualidade de vida desses pacientes sendo, portanto, necessário um acompanhamento multidisciplinar com o objetivo de prevenir, minimizar e melhor entender esses efeitos adversos dos tratamentos oncológicos (OTTO, 2012).

\subsection{AS ESTRUTURAS CONCEITUAIS DA ENFERMAGEM}

Para que a atuação do Enfermeiro no contexto do cuidado paliativo se dê de forma coerente e eficaz, esse cuidado necessita ser sistematizado. Os referenciais teóricos de enfermagem dão sustentação ao processo de enfermagem e contribuem para a sistematização da assistência. O processo de enfermagem consiste numa referência para os profissionais que buscam um modelo de assistência de enfermagem que atenda o paciente em sua totalidade (FONSECA, 2002).

A fundamentação teórica em uma pesquisa serve para compreender, explicar e dar significado aos fatos que serão estudados pelo investigador. Esta fundamentação pode acontecer por meio de uma revisão bibliográfica inicial que trará familiarização e profundidade com o tema pesquisado (FONSECA, 2002). Em se tratando de um trabalho que se baseia em um referencial teórico, a descrição e compreensão do tema é essencial.

As teorias de enfermagem tem sido um tema dominante na literatura de enfermagem nos últimos 30 anos e tem estimulado o crescimento fenomenal da profissão, uma vez que muito do que se sabia sobre enfermagem não era escrito e a pesquisa para documentar a eficácia dos cuidados não era registrada. $\mathrm{O}$ desenho deste corpo substancial de conhecimentos de enfermagem tem como objetivos tornar a profissão reconhecida e dedicar cuidados profissionais aos pacientes. As autoras conceituam as teorias de enfermagem como um grupo de conceitos relacionados que provem de modelos de enfermagem. Estes modelos podem ser verbais ou esquemáticos e sugerem ações para conduzir a prática. $\mathrm{O}$ conceito é uma ideia ou imagem mental complexa de um fenômeno e consiste no mais importante componente da teoria. As teorias são compostas de definições, pressupostos, postulados e hipótese, sendo a 
última uma afirmação de relação testável. As teorias de enfermagem, de acordo com seu âmbito ou nível de abstração, podem ser classificadas como grandes teorias, teorias de médio alcance ou teorias práticas (TOMEY, 2004).

As grandes teorias utilizam raciocínio dedutivo, ou seja, aquele que parte do geral para o particular, onde duas ou mais afirmações conexas são usadas para delinear uma conclusão. Relata ainda que os trabalhos teóricos precisam ter clareza, simplicidade, generalidade, precisão empírica e consequências deriváveis e que a teoria confere significado ao conhecimento de modo a melhorar a prática seja descrevendo, explicando e antevendo fenômenos, desenvolvendo a capacidade analítica, orientando o pensamento critico e a tomada de decisão na prática profissional, ou ainda aumentando a autonomia do profissional (McEWEN, 2009).

São várias as teorias e referenciais que tem contribuído na assistência ou no processo de cuidar, dentre elas podemos destacar a teoria do Alcance de Metas de Imogene King. A partir do referencial teórico de Imogene King pode-se definir o processo de enfermagem como um processo de ação, reação e interação pelo qual o enfermeiro e cliente compartilham informações sobre suas percepções na situação de enfermagem. Pode-se definir ainda a saúde como um estado dinâmico no ciclo de vida de um ser humano que implica em ajustamentos contínuos a estressores, no ambiente interno e externo, através do uso de recursos próprios para alcançar o máximo potencial para a vida diária (VIEIRA, 2003) Os conceitos, teorias e pressupostos de King passaram por processo evolutivo cronológico como ilustra a figura 1.

Alguns conceitos essenciais para a enfermagem foram desenvolvidos ao longo do trabalho de King que determinou um Sistema Conceitual para a Enfermagem, tendo como pressuposto que o ser humano atua em sistemas sociais através de relacionamentos interpessoais, em termos de suas percepções, as quais influenciam sua vida e sua saúde (VIEIRA, 2003).

King definiu três sistemas como base do seu modelo teórico. O sistema pessoal, onde cada ser humano forma um sistema. Por interações, esses seres humanos formarão duplas, pequenos ou grandes grupos, constituindo assim um outro sistema, ao qual denomina de sistema interpessoal. Esses seres humanos agrupados estruturarão organizações de acordo com suas necessidades e interesses, formando um novo sistema, o sistema social. O referencial teórico de King permite ver o ser humano com a amplitude necessária para que 
sejam prestados cuidados capazes de atender ao paciente oncológico em cuidados paliativos (VIEIRA, 2003).

Figura 1 - Evolução da Teoria de Imogene King

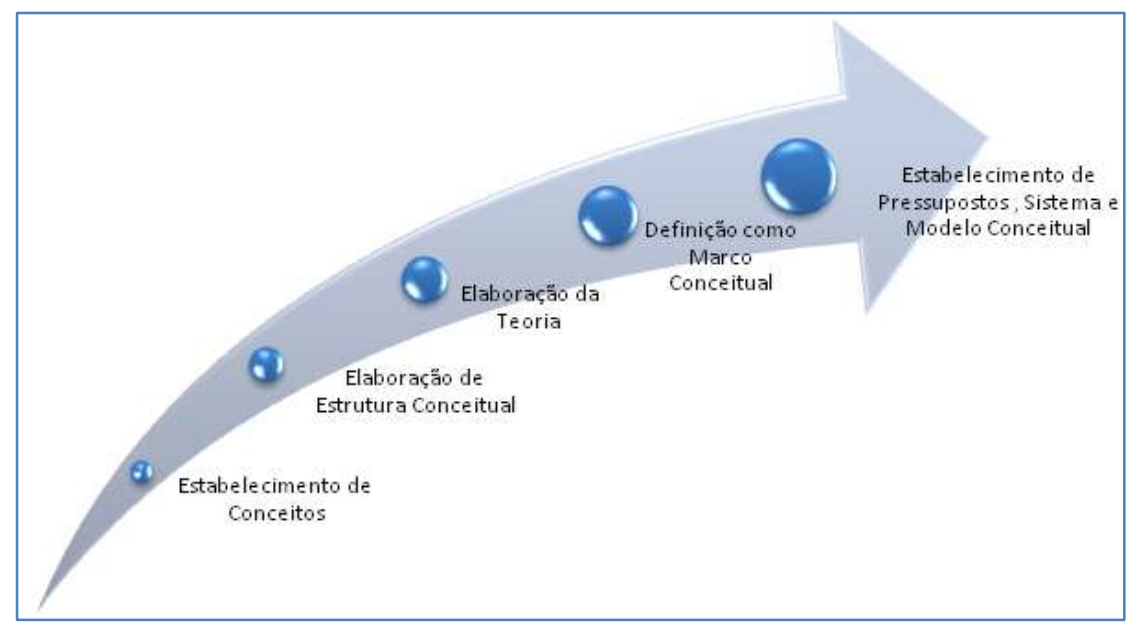

Fonte: o próprio autor

\subsection{A TEORIA DO ALCANCE DE METAS DE IMOGENE KING}

A escolha de um referencial teórico é essencial para embasar a prática diária das ações do enfermeiro. Neste trabalho optou-se pelo embasamento na teoria de enfermagem intitulada Teoria do Alcance de Metas proposta por Imogene King, em 1981, pois tal referencial possibilita o reconhecimento conjunto dos problemas apresentados pelo cliente em questão (indivíduo em cuidados paliativos), por meio das interações pessoais entre o enfermeiro e o indivíduo a quem se presta o cuidado de enfermagem. Esse cliente é considerado um ser atuante e participativo em seu cuidado, aumentando a probabilidade de resultados positivos no sentido a alcançar as metas de saúde estabelecidas também em conjunto. O termo cliente é utilizado, em substituição ao termo paciente, para dar a dimensão dinâmica desse ser (VIEIRA, 2003)

King desenvolveu quatro conceitos centrais para nortear os modelos conceituais e as teorias de enfermagem, sendo eles, o meio ambiente, saúde, ser humano e enfermagem (VIEIRA, 2003). 
Com a concepção de ser humano e o pressuposto geral de que estes em interação com o meio ambiente são o foco da enfermagem, cuja atribuição seria a de conduzi-los a um estado de saúde, ou seja, a estarem aptos para atuar em seus papéis sociais (VIEIRA, 2003).

King define a enfermagem como perceber, pensar, relacionar, julgar e atuar, tendo condutas direcionadas aos indivíduos que tem necessidade de cuidados. Para a autora esta situação requer um ambiente, onde enfermeiro e cliente estabeleçam uma relação para o enfrentamento de diferentes estados de saúde. A enfermagem é ainda definida como processo de ação, reação e interação onde enfermeiro e paciente compartilham suas percepções sobre a situação e através dessa comunicação identificam metas, problemas e interesses específicos. Quando o cliente participa junto ao profissional no estabelecimento de metas ocorre um processo de interação humana (VIEIRA, 2003).

King descreve que entender a forma como os seres humanos se relacionam com o ambiente para manter saúde é essencial para que o enfermeiro possa realizar prevenção, promoção da saúde e cuidado aos doentes. Durante a internação, um cliente precisa ser observado nos seus diferentes papéis: mãe, esposa e atuação na comunidade. Em cada situação a enfermagem tem um objetivo diferente. O conjunto de metas depende: da quantidade de doentes, das situações que levaram os doentes aos sistemas de cuidados a saúde e do local onde trabalham os enfermeiros. Os enfermeiros interagem com os clientes para obter informações sistemáticas sobre os eventos passados, bem como sobre os sinais e sintomas atuais. Interagem também para escutar dados sobre suas percepções definindo objetivos e tomando decisões sobre os meios a serem utilizados para eliminar uma doença ou resolver um problema. A tomada de decisão requer a colaboração do cliente e dos membros de sua família. Os enfermeiros utilizam seus conhecimentos e habilidades para ajudar as pessoas dos grupos a enfrentar seus problemas existenciais e a como saber diferentes maneiras para se adaptar às mudanças em suas atividades diárias (VIEIRA, 2003).

King descreve em sua teoria dos sistemas interatuantes que a maioria dos indivíduos começa sua vida fazendo parte de um grupo que é a família. Mediante as interações com os membros do grupo aprendem diferentes maneiras de satisfazer suas necessidades. Ao longo do seu crescimento e desenvolvimento os seres humanos assumem diferentes papéis em grupos distintos (VIEIRA, 2003). 
Para King a interação entre amigos ou membros de uma família pode se dar de forma verbal ou não verbal. E essas relações têm como objetivo principal a realização de um propósito determinado. Na enfermagem as metas são obtidas nas interações entre enfermeiro e cliente, quando ambas as partes exploram os meios para alcançá-las, estão de acordo com esses meios e mostram condutas para isto. Os resultados dessas interações são as satisfações que se tem ao realizar atividades diárias, bem como o êxito em desempenhar as atividades usuais. Os limites da enfermagem são os indivíduos e seus grupos interagindo com o meio ambiente (VIEIRA, 2003).

A teoria de King focaliza a percepção e cognição do indivíduo acerca da experiência que está vivenciando, sendo a intervenção dirigida para o processo contínuo de interação entre o indivíduo e os outros significantes. Tal teoria tem como finalidade alcançar objetivos predeterminados, em que a interação humana é a base da ação de enfermagem. Sua identificação conceitual ocorre através dos termos interação, transação, self, estresse, papel, crescimento e desenvolvimento, tempo, e espaço. A teoria tem como objeto, estabelecer uma relação interpessoal, intergrupal e social para alcançar objetivos de saúde ou ajustamento aos problemas de saúde do indivíduo compreendido como parte de um contexto biopsicossocial (VIEIRA, 2003). Os conceitos de cada sistema estão descritos nos quadros 1, 2 e 3.

A partir da identificação dos principais conceitos para enfermagem, King passou à formulação de uma estrutura conceitual, que sofreu uma evolução e aprimoramento de seus conceitos e que embasou o desenvolvimento de uma teoria geral para a enfermagem, a Teoria do Alcance de Metas. Na contínua evolução da estrutura conceitual, King amplia o marco conceitual inicial, definindo como foco central da estrutura conceitual o ser humano e seu comportamento, partindo dessa estrutura inicial, estabelece como pressuposto que o ser humano atua em sistemas sociais através de relacionamentos interpessoais, em termos de suas percepções, as quais influenciam sua vida e sua saúde (VIEIRA, 2003). 
Quadro 1: Sistema Pessoal de Imogene King: Conceitos, definições, características e implicações para a Enfermagem - Brasília, dezembro 2014 a julho 2015.

\begin{tabular}{|c|c|c|c|}
\hline Conceito & Definição & Características & $\begin{array}{c}\text { Implicações para a } \\
\text { Enfermagem }\end{array}$ \\
\hline Percepção & $\begin{array}{l}\text { Imagem da realidade dada pelo } \\
\text { individuo. } \\
\text { Processo de transformar } \\
\text { informações em dados sensoriais } \\
\text { da memória. } \\
\text { Relaciona-se com experiências } \\
\text { passadas, herança biológica, } \\
\text { antecedentes educativos e grupos } \\
\text { socioeconômicos. }\end{array}$ & $\begin{array}{l}\text { Universal, subjetiva, } \\
\text { pessoal, seletiva } \\
\text { orientada para o presente. }\end{array}$ & $\begin{array}{l}\text { - O enfermeiro deve } \\
\text { conhecer a percepção } \\
\text { para obtenção e } \\
\text { interpretação das } \\
\text { informações, fixação } \\
\text { mutua de objetivos e } \\
\text { exploração de meios } \\
\text { para alcança-los; } \\
\text { - Em algumas situações } \\
\text { a percepção pode estar } \\
\text { distorcida; }\end{array}$ \\
\hline $\mathbf{E u}$ & $\begin{array}{l}\text { Conjunto de pensamentos e } \\
\text { sentimentos que constituem a } \\
\text { consciência de uma pessoa, sua } \\
\text { existência individual e a sua } \\
\text { concepção de quem é. } \\
\text { Maneira como alguém se define } \\
\text { perante a si e aos outros. }\end{array}$ & $\begin{array}{l}\text { Sofre influências do } \\
\text { passado e especula acerca } \\
\text { do futuro, reativo por } \\
\text { natureza. }\end{array}$ & $\begin{array}{l}\text { - Ajuda a perceber o } \\
\text { outro com sensibilidade; } \\
\text { - O ambiente hospitalar } \\
\text { ameaça o "eu" do } \\
\text { paciente } \\
\text { - Entender como o } \\
\text { paciente percebe se eu e } \\
\text { seu estado de saúde }\end{array}$ \\
\hline $\begin{array}{l}\text { Imagem } \\
\text { Corporal }\end{array}$ & $\begin{array}{l}\text { Maneira pela qual as pessoas } \\
\text { percebem, não só o seu corpo, } \\
\text { mas também as reações dos outros } \\
\text { à sua aparência. } \\
\text { Pode mudar ao longo da vida com } \\
\text { base em experiências e percepções. }\end{array}$ & $\begin{array}{l}\text { Conceito extremamente } \\
\text { pessoal e subjetivo. }\end{array}$ & $\begin{array}{l}\text { - A forma como alguém } \\
\text { percebe seu corpo } \\
\text { influencia no modo de } \\
\text { vida. } \\
\text { - Muitas situações } \\
\text { podem alterar a Imagem } \\
\text { Corporal; } \\
\text { - As mudanças na } \\
\text { Imagem corporal estão } \\
\text { associadas a crises na } \\
\text { vida; } \\
\text { - É importante que os } \\
\text { enfermeiros entendam o } \\
\text { conceito de imagem } \\
\text { corporal e suas } \\
\text { alterações, para que } \\
\text { possam ajudar àqueles } \\
\text { que apresentam } \\
\text { alterações } \\
\text { autoimagem. }\end{array}$ \\
\hline
\end{tabular}


continuação

\begin{tabular}{|c|c|c|c|}
\hline Conceito & Definição & Características & $\begin{array}{l}\text { Implicações para a } \\
\text { Enfermagem }\end{array}$ \\
\hline $\begin{array}{c}\text { Crescimento e } \\
\text { Desenvolvimento }\end{array}$ & $\begin{array}{l}\text { Mudanças químicas e físicas que } \\
\text { acontecem com as pessoas. } \\
\text { Experiências similares, mas que } \\
\text { podem ter variações na } \\
\text { programação de cada individuo. } \\
\text { Influenciam nas condutas. }\end{array}$ & $\begin{array}{l}\text { Inclui mudanças celulares, } \\
\text { moleculares } \\
\text { comportamentais nos } \\
\text { indivíduos. }\end{array}$ & $\begin{array}{l}\text { - Os enfermeiros podem } \\
\text { ser os primeiros a } \\
\text { perceber alterações no } \\
\text { processo normal; } \\
\text { - Detecção de } \\
\text { interferências; } \\
\text { - Compreender o porquê } \\
\text { das condutas }\end{array}$ \\
\hline Tempo & $\begin{array}{l}\text { É a duração entre um } \\
\text { acontecimento e outro }\end{array}$ & $\begin{array}{l}\text { Universal, relacional, } \\
\text { unidirecional, subjetivo e } \\
\text { pode ser medido. }\end{array}$ & $\begin{array}{l}\text { - O enfermeiro realiza o } \\
\text { controle das atividades; } \\
\text { - Correlacionar as } \\
\text { rotinas com o tempo } \\
\text { biológico dos pacientes; } \\
\text { - Percepção do tempo; } \\
\text { - Turnos de trabalho, } \\
\text { cuidados } \\
\text { medicamentos; } \\
\text { - Estratégias: relógios, } \\
\text { calendários } \\
\text { informações. }\end{array}$ \\
\hline
\end{tabular}

Fonte: o próprio autor

Quadro 2: Sistema Interpessoal de Imogene King: Conceitos, definições, características e implicações para a Enfermagem - Brasília, dezembro 2014 a julho 2015.

\begin{tabular}{|c|c|c|c|}
\hline Conceito & Definição & Características & $\begin{array}{c}\text { Implicações para a } \\
\text { Enfermagem }\end{array}$ \\
\hline Papel & $\begin{array}{l}\text { Conjunto de comportamentos } \\
\text { esperados daqueles } \\
\text { que ocupam uma certa posição no } \\
\text { sistema social. } \\
\text { Tem relação com o "eu". } \\
\text { Uma pessoa pode desempenhar } \\
\text { vários papeis. }\end{array}$ & $\begin{array}{l}\text { Reciprocidade, aprende- } \\
\text { se a desenvolver, } \\
\text { complexo, tem a ver } \\
\text { com a situação. }\end{array}$ & $\begin{array}{l}\text { - O enfermeiro tem como } \\
\text { papel primário ajudar os } \\
\text { indivíduos a manter } \\
\text { equilíbrio entre os } \\
\text { sistemas e os grupos a } \\
\text { alcançar metas. } \\
\text { - Discrepâncias entre } \\
\text { expectativas e realidade; } \\
\text { - O mau entendimento de } \\
\text { um papel ou a percepção } \\
\text { distorcida deste pode } \\
\text { influenciar no resultado } \\
\text { do cuidado. }\end{array}$ \\
\hline
\end{tabular}


continuação

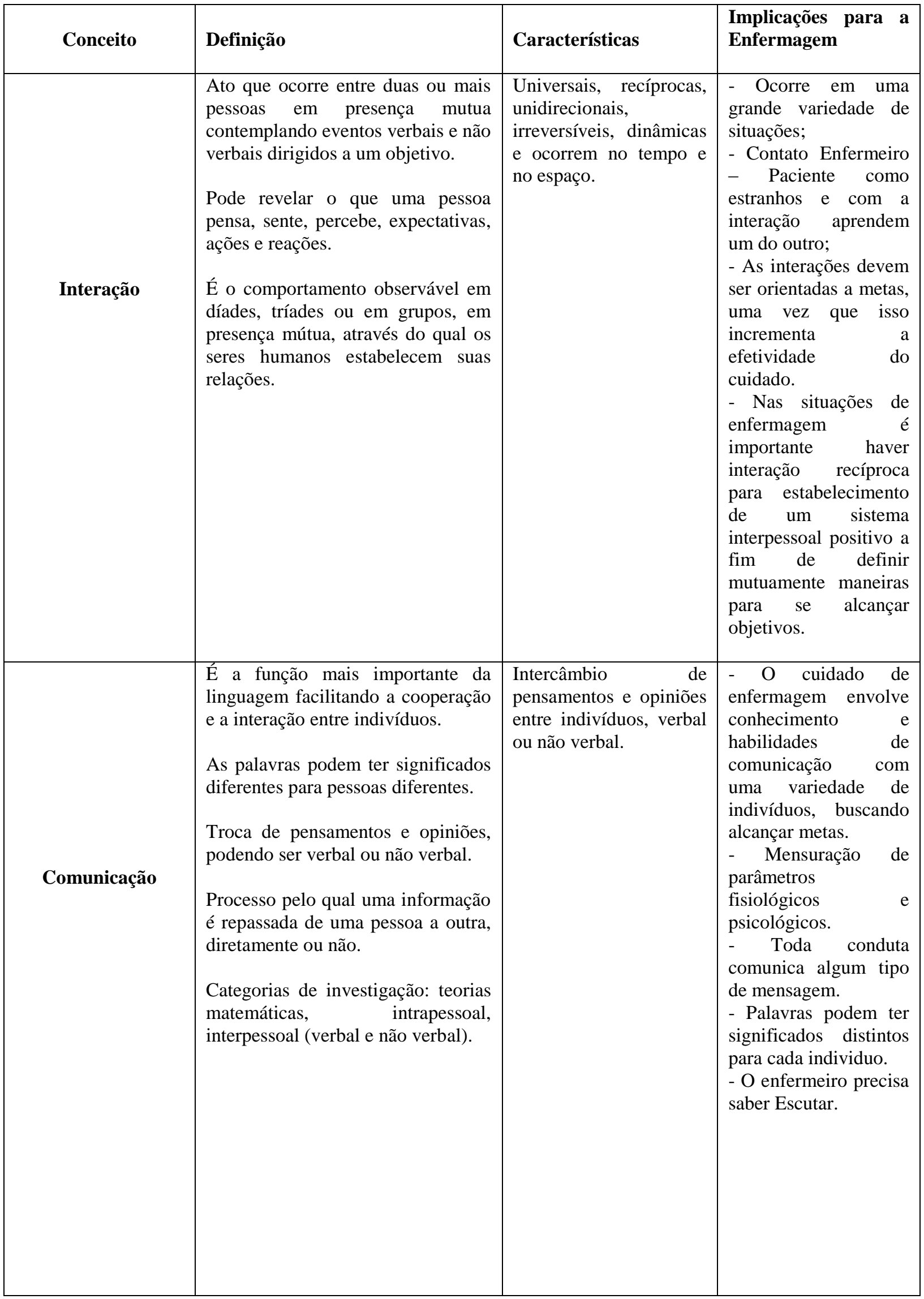


continuação

\begin{tabular}{|c|c|c|c|}
\hline Conceito & Definição & Características & $\begin{array}{l}\text { Implicações para a } \\
\text { Enfermagem }\end{array}$ \\
\hline Transação & $\begin{array}{l}\text { São condutas e comportamentos } \\
\text { humanos dirigidos a metas e ao } \\
\text { alcance de objetivos. } \\
\text { Relação entre o eu e o ambiente. } \\
\text { Tem valor quando a meta é } \\
\text { significativa e vale a pena ser } \\
\text { alcançada. }\end{array}$ & $\begin{array}{lr}\text { Gerada a partir de } \\
\text { interação, } & \text { reduz } \\
\text { estresse, são } & \text { únicas e } \\
\text { baseadas } & \text { em } \\
\text { experiência. } & \end{array}$ & $\begin{array}{l}\text { - É sempre necessária } \\
\text { por ocasião da } \\
\text { formação de díades no } \\
\text { sistema interpessoal. } \\
\text { - O enfermeiro deve } \\
\text { atuar ajudando os } \\
\text { indivíduos quando há } \\
\text { alteração no padrão } \\
\text { das transações, uma } \\
\text { vez que quando isso } \\
\text { ocorre algo é } \\
\text { desorganizado nas } \\
\text { habilidades } \\
\text { individuo para atuar. }\end{array}$ \\
\hline Estresse & $\begin{array}{l}\text { Um estado de dinamicidade no qual } \\
\text { indivíduos interagem com o } \\
\text { ambiente em busca de um } \\
\text { equilíbrio que propicie o } \\
\text { crescimento, desenvolvimento, bem } \\
\text { como desempenho efetivo de } \\
\text { papéis. }\end{array}$ & $\begin{array}{l}\text { Universalidade, } \\
\text { dimensão espaço- } \\
\text { temporal, subjetividade. }\end{array}$ & $\begin{array}{l}\text { - As enfermeiras estão } \\
\text { numa posição de } \\
\text { observadoras de } \\
\text { padrões de respostas a } \\
\text { estressores, pois, } \\
\text { identificadas as causas } \\
\text { da tensão, torna-se } \\
\text { possível a intervenção. } \\
\text { - A doença pode ser } \\
\text { produto do estresse. } \\
\text { - Causas do estresse } \\
\text { em hospitalizações, } \\
\text { doenças e ambientes } \\
\text { de trabalho. } \\
\text { - A tensão do paciente } \\
\text { cirúrgico pode ser } \\
\text { diminuída } \\
\text { estratégias por } \\
\text { enfermagem como } \\
\text { escutar, comunicação } \\
\text { interpessoal, } \\
\text { informações } \\
\text { apropriadas, estimula } \\
\text { a verbalização, } \\
\text { discussão } \\
\text { experiências e opções } \\
\text { distintas para } \\
\text { alcance de metas. }\end{array}$ \\
\hline
\end{tabular}

Fonte: o próprio autor 
Quadro 3: Sistema Social de Imogene King: Conceitos, definições, características e implicações para a Enfermagem - Brasília, dezembro 2014 a julho 2015.

\begin{tabular}{|c|c|c|c|}
\hline Conceito & Definição & Características & $\begin{array}{c}\text { Implicações para a } \\
\text { Enfermagem }\end{array}$ \\
\hline Organização & $\begin{array}{l}\text { Forma pela qual as atividades } \\
\text { contínuas são administradas para } \\
\text { alcançar metas }\end{array}$ & $\begin{array}{l}\text { Seres humanos } \\
\text { despendem maior parte } \\
\text { de sua vida nela }\end{array}$ & $\begin{array}{l}\text { Identificação e no } \\
\text { enfrentamento dos } \\
\text { conflitos entre a } \\
\text { organização e seus } \\
\text { papéis e funções } \\
\text { profissionais. }\end{array}$ \\
\hline Poder & $\begin{array}{l}\text { Processo através do qual uma ou } \\
\text { mais pessoas influenciam as demais } \\
\text { numa determinada situação }\end{array}$ & $\begin{array}{l}\text { Existe dentro } \quad \text { das } \\
\text { relações sociais }\end{array}$ & 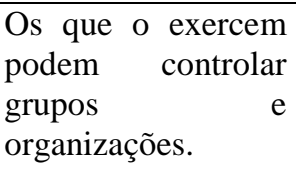 \\
\hline Autoridade & $\begin{array}{l}\text { Poder para tomar decisões que } \\
\text { guiam as ações do eu e de outros }\end{array}$ & Ativo e recíproco & $\begin{array}{l}\text { Sua apropriada } \\
\text { utilização em uma } \\
\text { organização } \\
\text { promove } \\
\text { satisfação ao } \\
\text { trabalhador, } \\
\text { eficiência, elevação } \\
\text { moral e facilita o } \\
\text { alcance de metas. }\end{array}$ \\
\hline Status & $\begin{array}{l}\text { Como a posição de um indivíduo } \\
\text { em um grupo é } \\
\text { percebida por outros indivíduos }\end{array}$ & E o prestígio & $\begin{array}{lr}\text { O papel de } \\
\text { enfermeira tem } \\
\text { mais prestígio que o } \\
\text { do auxiliar de } \\
\text { enfermagem e é } \\
\text { visto como de } \\
\text { maior status. }\end{array}$ \\
\hline Tomada de decisão & $\begin{array}{l}\text { A ação ou resposta humana é } \\
\text { decorrente de um processo de } \\
\text { tomada de decisão }\end{array}$ & $\begin{array}{l}\text { Situacionais e dirigidas } \\
\text { a metas }\end{array}$ & $\begin{array}{lr}\text { Constantemente, } \\
\text { enfermeira } \\
\text { paciente } \\
\text { decisões } & \text { tomam } \\
\text { metas a } & \text { sobre } \\
\text { alcançadas. } & \end{array}$ \\
\hline
\end{tabular}

Fonte: o próprio autor

Os elementos principais da teoria de King são os indivíduos que interagem num sistema de saúde para ajudarem e serem ajudados na manutenção ou no restabelecimento do estado de saúde. Portanto, encontrando-se no sistema interpessoal. King inter-relacionou esses conceitos mediante as seguintes proposições: as transações ocorrerão se estiver presente a precisão perceptiva (VIEIRA, 2003).

Para King se estas transações forem realizadas entre o enfermeiro e os indivíduos, as metas serão alcançadas, se as metas forem atingidas ocorrerá a satisfação e o atendimento eficiente de enfermagem, e se existirem transações entre a díade enfermeiro-indivíduo, o 
crescimento e desenvolvimento serão estimulados. Se as expectativas e o desempenho dos papéis, tal como percebidos pelo enfermeiro e pelo indivíduo, forem congruentes, haverá transações. Pode ocorrer o estresse nas interações enfermeiro e indivíduo se houver conflitos de papéis entre estes e se o enfermeiro comunicar informações adequadas aos indivíduos, embasadas em seus conhecimentos e habilidades, haverá uma fixação mútua de metas e estas serão atingidas (KING, 1981).

O sistema conceitual é composto por três sistemas interatuantes, o sistema pessoal, no qual insere a idéia de que cada ser humano forma um sistema, e de que por meio de interações, esses seres humanos formarão duplas, pequenos ou grandes grupos, constituindo assim outro sistema, ao qual denomina de sistema interpessoal. Esses seres humanos agrupados estruturarão organizações de acordo com suas necessidades e interesses, formando o sistema social (KING, 1981).

King descreve que o sistema pessoal do enfermeiro interage com o sistema pessoal do indivíduo formando uma díade, este é o sistema interpessoal (KING, 1981). Este sistema sofre influências dos sistemas sociais que os cercam como ilustrado nas figuras 2 e 3.

Figura 2 - Diagrama do Modelo Conceitual de Imogene King, 1981.

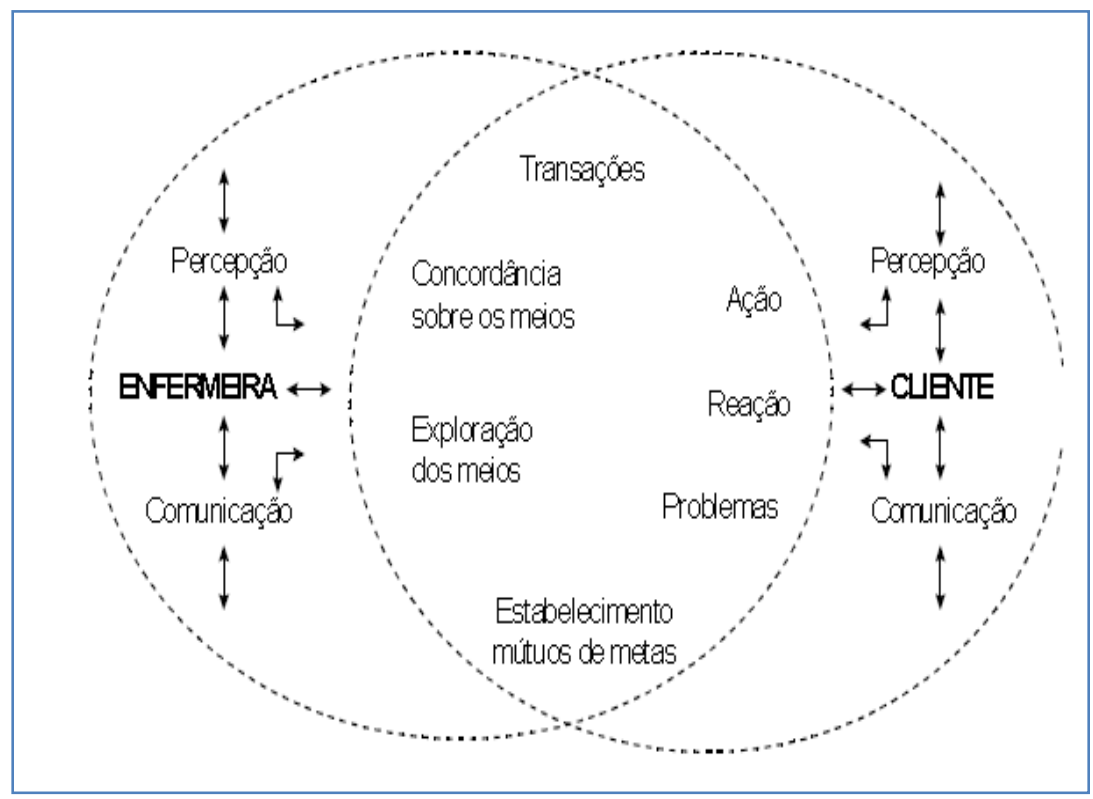

Fonte: KING, I.M. A theory for nursing: systems, concepts, process . 1981 
Figura 3 - Diagrama dos Sistemas Interatuantes de Imogene King, 1981

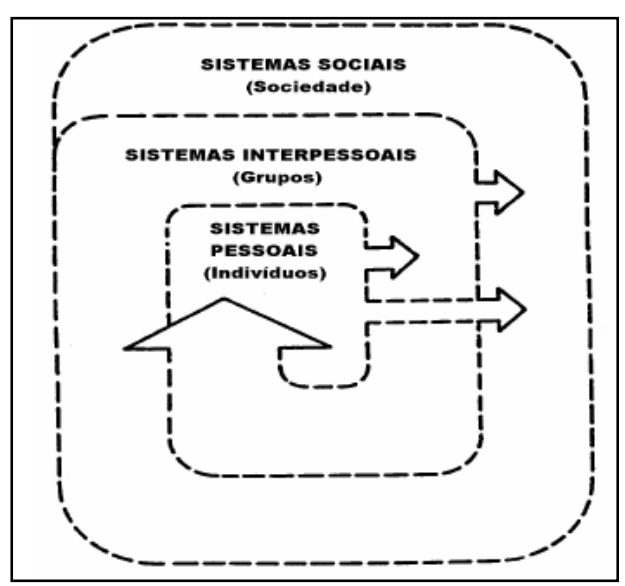

Fonte: KING, I.M. A theory for nursing: systems, concepts, process. 1981

A teoria de King foi desenvolvida durante os anos 70, momento muito propicio em que os enfermeiros buscavam identificar bases de conhecimento científico para orientar a prática da enfermagem.

Kubler-Ross, psiquiatra especialista num assunto tabu para as sociedades ocidentais - a morte - em seus estudos de caso disseca sobre as situações relacionais entre a equipe, os pacientes, seus familiares e entre os próprios profissionais, considerando a importância do conhecimento teórico de forma equiparada ao trabalho com a alma e o coração. A autora considera ainda como essenciais a interdisciplinaridade, os aspectos comunicacionais, o respeito à autonomia do paciente e a coparticipação da família para construção dos projetos terapêuticos singulares (MINAYO, 2013) Suas ideias vão ao encontro dos conceitos apresentados por King.

Nesse contexto torna-se primordial a aplicação de ferramentas que auxiliem a equipe de saúde a planejar o cuidado, através da percepção dos problemas. Nesse planejamento é de extrema relevância levar em consideração a condição clínica atual dos pacientes, bem como suas opiniões e as expectativas de seus familiares, uma vez que estes precisam ser tão cuidados e orientandos quanto o próprio paciente/cliente.

No campo da enfermagem, é introduzido no Brasil no ano de 1967 o conceito de diagnóstico de enfermagem norteando a sistematização da assistência. A aplicação de um método de assistência de enfermagem leva a uma melhor qualidade, individualizando o cuidado, e diferenciando o que é rotina do que é conhecimento específico da enfermagem. $\mathrm{O}$ 
processo de enfermagem descrito por King é um método de intervenção para a assistência ao paciente que permite ao enfermeiro maior cientificidade às suas ações. $O$ processo de enfermagem descrito por King é composto de cinco fases: coleta de dados, lista de problemas, lista de metas, plano e registro da evolução.

Atualmente o processo é descrito também com cinco etapas que são: coleta de dados, diagnóstico, planejamento, implementação e avaliação (NANDA-I, 2015). Embora a nomenclatura possa ser diferente, a proposta de King está de acordo com as etapas hoje descritas.

$\mathrm{Na}$ fase de avaliação verifica-se o quanto as metas foram alcançadas. O processo de enfermagem é o caminho para que o enfermeiro ajude o cliente a alcançar suas metas por meio da interação proposital (NANDA-I, 2015).

\subsection{O PROCESSO DE ENFERMAGEM}

Nos dias atuais, a comunidade científica de enfermagem tem voltado estudos para o cuidar sistematizado e, em especial, para os sistemas de classificação dos fenômenos de enfermagem.

King definiu o processo de enfermagem como um método usado pelos enfermeiros para levantar dados, planejar, implementar e avaliar o cuidado prestado. Para sua realização são necessárias habilidades especiais para a coleta de dados, para se comunicar e capacidade de codificar esses dados, identificando objetivos e os meios para alcançá-los. Para a autora o processo de enfermagem pode ser concebido como a aplicação prática de sua teoria, o qual pode ser implementado pela utilização de dois instrumentos desenvolvidos por ela (VIEIRA, 2003).

O primeiro instrumento é resultante de uma adaptação feita pela autora do Problems and Prospect desenvolvido por Weed em 1969, este sistema foi chamado por ela de Registro de Enfermagem Orientado por Metas (GONR), e consiste num modelo de organizar e documentar os dados obtidos. O modelo é composto por seis elementos básicos. Os dados básicos corresponderiam ao levantamento de dados, composto por todas as informações obtidas sobre a pessoa no momento da admissão no serviço de saúde e que deve ser constantemente atualizado. A lista dos diagnósticos de enfermagem corresponde ao 
julgamento clínico da enfermeira sobre as informações obtidas. Segundo a autora, esta lista de problemas pode ser um diagnóstico ou não, sendo atualizada com novas informações constantemente, podendo surgir novos problemas e os velhos serem resolvidos. Esta lista serve como um guia para coleta constante de dados acerca do problema identificado, para identificar um diagnóstico de enfermagem e para planejar os cuidados de enfermagem imediatos ao indivíduo, documentando os problemas identificados e aqueles resolvidos pelo cuidado de enfermagem prestado (KING, 1981).

King desenvolveu também outro elemento que é a lista de metas, que são metas estabelecidas mutuamente com o cliente ou com a família proporcionando a continuidade do cuidado de enfermagem. Essa ação representa uma aproximação sistemática para auxiliar o indivíduo a alcançar o seu bem estar, além de propiciar um meio de interação entre o enfermeiro e o indivíduo, para estabelecer metas conjuntas, explorar formas de atingir essas metas. Isso possibilita a participação do indivíduo nas decisões sobre seu cuidado. Essa interação demonstra o cuidado de enfermagem individualizado. Os objetivos servem como um guia para os enfermeiros no acompanhamento de qualquer alteração de nova informação que o indivíduo possa vir a apresentar (VIEIRA, 2003).

A prescrição de enfermagem é o elemento seguinte deste registro de enfermagem, o qual está baseada na avaliação do problema. Outro elemento que compõe o registro de enfermagem é um impresso para evolução, destinado ao registro das informações e cuidados rotineiros do indivíduo, como último elemento tem-se o sumário de alta, no qual se registra o alcance ou não das metas propostas, bem como são descritas as metas futuras (VIEIRA, 2003).

O processo de enfermagem de King compreende cinco etapas:

1. Interação inicial: contato inicial que induz uma reação entre o enfermeiro e o paciente. É extremamente influenciada pela percepção que um tem do outro e pela comunicação estabelecida entre eles;

2. Diagnóstico/Lista de problemas: detecção das necessidades de cuidado dos seres humanos com vistas a alcançar a saúde, devendo ser confirmado com os pacientes; 
3. Estabelecimento de metas comuns à díade enfermeiro-paciente, com base nos diagnósticos detectados e em comum acordo das partes;

4. Exploração e viabilização de meios para alcançar as metas traçadas devendo haver concordância entre ambas as partes sobre estes meios;

5. Evolução: avaliação contínua do alcance de metas, ressaltando fatores intervenientes nos três sistemas, pessoal, interpessoal e social, para desenvolver no paciente a capacidade de enfrentar problemas, desenvolvendo-se bem nos papéis cotidianos.

Esse processo será permeado de ação e reação, uma vez que, os indivíduos são seres reagentes, e pautado no diagnóstico e na busca da resolução dos problemas, que somente será alcançada se ocorrer uma interação efetiva enfermeiro-paciente. Assim, a aplicação do processo de enfermagem, metodologia de trabalho capaz de melhorar grandemente a qualidade da assistência de enfermagem prestada, deve ser o objetivo do enfermeiro (KING, 1981).

Atualmente o processo de enfermagem tem sido descrito em cinco etapas (DOENGES, 2011) e muito do que King já descrevia, continua sendo aplicado e até incrementado ao longo dos últimos anos.

Ao se comparar o trabalho de King e o sistema de classificação dos diagnósticos da NANDA-I, JESUS (1992) propôs uma distribuição desses diagnósticos com as categorias diagnósticas de Doenges \& Moorhouse (DOENGES, 2011). Essa distribuição contemplou os sistemas de King, os rótulos diagnósticos da NANDA-I daquela época e as categorias de divisão diagnósticas de Doenges e Moorhouse. Tal classificação proposta no trabalho de Jesus (1992) considerou dentro do sistema pessoal 10 categorias de divisão diagnóstica, que foram: Alimentação/Hidratação, Eliminação, Sexualidade, Atividade/Repouso, Higiene, Respiração, Circulação, Dor/Conforto, Segurança e Neuro-sensorial. Para o sistema interpessoal duas categorias foram consideradas: Integridade do ego e Ensino/Aprendizagem. Já para o sistema social apenas a categoria Interação Social (JESUS, 1992).

A concepção da Enfermagem como ciência, determina que esteja pautada em uma ampla estrutura teórica, aplicada à prática por meio do Processo de Enfermagem, que é um instrumento metodológico que favorece o cuidado e documenta a prática profissional, sendo 
constituído por etapas inter-relacionadas, de acordo com a estrutura teórica utilizada (VIEIRA, 2003)

A utilização das etapas do processo de enfermagem favoreceu o desenvolvimento de sistemas de classificação de enfermagem para os elementos da prática profissional: diagnóstico, resultado e intervenções de enfermagem. Os sistemas de classificação são instrumentos tecnológicos que nos fornecem uma linguagem padronizada a ser utilizada no processo de enfermagem e na documentação da prática profissional (CARPENITO, 1999).

Caracteriza-se a primeira geração do processo de enfermagem àquela onde o raciocínio clínico se dá pela identificação de problemas que deverão ser solucionados à luz dos referenciais teóricos que possibilitaram a sua identificação e que apoiarão as ações de enfermagem para solucioná-los. A segunda geração está atrelada ao uso de Classificações de Diagnósticos, onde o raciocínio clínico faz-se pela formulação de hipóteses diagnósticas, que serão afirmadas ou refutadas se as metas/objetivos declarados forem, ou não, alcançados. A utilização de Classificações de Intervenções pode, ou não, ser adotada nesta geração. Na terceira geração do Processo de Enfermagem, as três classificações necessariamente são utilizadas: Diagnósticos, Resultados e Intervenções. O raciocínio clínico baseia-se na avaliação de um resultado inicial, advindo do estabelecimento de indicadores de resultados para o suposto diagnóstico identificado e o seu progresso ou ausência de progresso é julgado após as intervenções realizadas (NANDA-I, 2015).

Deste modo, conhecer as classificações, utilizá-las, pesquisá-las e divulgá-las torna-se imperioso no mundo globalizado, onde evidências científicas ditam condutas aos profissionais da área da saúde. Classificações de Diagnósticos, Intervenções e Resultados têm sido construídas em diferentes países desde a década de 1970 e vêm se modificando e aperfeiçoando por meio de pesquisas (CARPENITO, 1999).

A primeira conferência norte-americana para discussão dos diagnósticos de enfermagem foi realizada em 1973 na St. Louis University. As conferências continuaram a serem realizadas, quando em 1980 foram gerados, refinados e classificados os termos diagnósticos. Em decorrência deste processo, em 1982, foi criada a então chamada North American Nursing Diagnosis Association (NANDA). A NANDA, até 2000, classificava os diagnósticos de enfermagem de acordo com a Taxonomia I, que era estruturada por nove categorias a partir do modelo conceitual dos Padrões de Respostas Humanas (trocar, 
comunicar, relacionar, valorizar, escolher, mover, perceber, conhecer, sentir). Em 2000 foi definida a Taxonomia II, contendo 13 domínios, 106 classes e 155 diagnósticos (NANDA-I, 2015).

No ano de 2002 essa associação norte-americana tornou-se internacional, passando a ser conhecida como NANDA-I. Desde então, a Taxonomia II da NANDA-I vem sendo aperfeiçoada, com a inclusão de novos diagnósticos (COSSA, 2011).

O termo diagnóstico de enfermagem é definido pela NANDA-I como "um julgamento clínico sobre a resposta de um indivíduo, uma família ou uma comunidade com relação a problemas de saúde reais ou potenciais/ processos de vida que fornecem a base para uma terapia definitiva que busca alcançar resultados nos quais a enfermagem é necessária" (NANDA-I, 2015).

A NIC, por sua vez, foi construída por pesquisadores da Universidade de Iowa, tendo sido lançada em 1992. Segundo a NIC, a intervenção de enfermagem é "qualquer tratamento baseado no julgamento e no conhecimento clínico que um enfermeiro realiza para melhorar os resultados do paciente/cliente”. As intervenções NIC estão vinculadas aos diagnósticos de enfermagem da NANDA-I (BULECHEK, 2010).

Os resultados das intervenções, NOC (Nursing Outcomes Classification), é a descrição do resultado atual frente à escolha do resultado desejado (estado final). Assim, o estado atual pode ser comparado ao final, após uma intervenção de enfermagem para determinar a eficácia da assistência realizada (MOORHEAD, 2010).

Ainda sobre os sistemas de classificação desenvolvidos existe a Classificação Internacional para a Prática da Enfermagem (CIPE), coordenado pelo CIE (Conselho Internacional de Enfermagem). A CIPE é definida como um sistema unificado da linguagem de enfermagem, uma terminologia instrumental para a prática, que facilita a combinação cruzada de termos locais com as terminologias existentes (CIPE, 2007).

Essa linguagem unificada é considerada como um marco importante para articular a contribuição que a Enfermagem traz para a saúde e a atenção à saúde, em todo o mundo, fomentando a harmonização com outras classificações utilizadas no trabalho dos grupos de normalização em saúde e em enfermagem. A CIPE denominada como uma terminologia 
combinatória traz a possibilidade de construção de um vocabulário especializado na área da Enfermagem (CIPE, 2007).

O processo de enfermagem possibilita ainda conhecer as causas dos problemas, os fatores com os quais os problemas se relacionam e a forma como eles se evidenciam.

A identificação dos diagnósticos de enfermagem e dos problemas colaborativos que os enfermeiros tratam com maior frequência, em determinadas populações, podem fornecer dados muito úteis para o auxilio na tomada de decisão e planejamento de recursos necessários para o cuidado (NEVES, 2003).

Nesse contexto, a classificação da NANDA-I aborda domínios, classes e diagnósticos que permitem ao enfermeiro através do julgamento clínico, conhecer o paciente, identificar seus problemas reais e potenciais, e relacioná-los às intervenções de enfermagem (TANNURE, 2010).

Nessa perspectiva recebe destaque a necessidade de sistematizar a prática, embasandoa em conhecimento científico. A prática de enfermagem sistematizada baseada no Modelo Conceitual dos Sistemas Interatuantes, na Teoria do Alcance de Metas de Imogene King e nos diagnósticos de enfermagem pode favorecer a identificação das necessidades de cuidado manifestadas ou referidas pelos pacientes em cuidados paliativos em sua totalidade trazendo excelência ao cuidado de enfermagem e favorecendo a participação ativa do paciente no seu cuidado (VIEIRA, 2003).

Portanto, com a expectativa de aumento na incidência de doenças oncológicas e com o crescente avanço tecnológico, estima-se que haverá maior sobrevida desses doentes, mesmo diante do diagnóstico paliativo. Assim, os enfermeiros precisam aprimorar seus conhecimentos, desenvolver o raciocínio clínico e habilidades de comunicação e percepção, para que consigam exercer uma prática baseada em evidências através de embasamento teórico que direcione a prática.

Desta forma, este trabalho objetiva identificar os diagnósticos de enfermagem mais frequentes nos pacientes portadores de doenças oncológicas em cuidados paliativos, tendo como referencial o Sistema Conceitual e a Teoria do Alcance de Metas de Imogene King. Foi 
ainda utilizada a Taxonomia II dos diagnósticos de enfermagem da NANDA-I (NANDA, 2015).

Acredita-se que este estudo contribuirá para as discussões nessa área, a partir da descrição de conteúdos que possam subsidiar o cuidado de enfermagem adequado a estes pacientes proporcionando-lhes melhores condições de suportar as situações vivenciadas nesta fase de final da vida (NANDA-I, 2015).

Crê-se na relevância desta pesquisa pela necessidade de fundamentar as ações para o cuidado de enfermagem tendo como meta a ajudar o indivíduo a manter sua saúde para que, dessa maneira, ele possa desempenhar bem seus papéis.

A teoria de King regulamenta uma base teórica para o processo de enfermagem e fornece conhecimento básico de enfermagem como um processo de interações que conduzem a transações. 


\section{OBJETIVOS DA PESQUISA}

\subsection{OBJETIVO GERAL}

O presente estudo tem como objetivo identificar os diagnósticos de enfermagem mais frequentes dirigidos a um grupo de pacientes oncológicos críticos inclusos em protocolo de cuidados paliativos.

\subsection{OBJETIVOS ESPECÍFICOS}

- Caracterizar os clientes oncológicos críticos em cuidados paliativos quanto ao perfil socioeconômico-demográfico e aos aspectos relativos à topografia da doença oncológica;

- Identificar o perfil diagnóstico dos clientes oncológicos críticos em protocolo de cuidados paliativos com fundamentação na Teoria do Alcance de Metas de King, utilizando a taxonomia II de NANDA-I;

- Listar e descrever as características definidoras mais frequentes dos diagnósticos de enfermagem reais identificados na amostra;

- Listar e descrever os fatores relacionados aos diagnósticos de enfermagem reais mais frequentes identificados na amostra;

- Listar e descrever os fatores de risco dos diagnósticos de enfermagem de vulnerabilidade (de risco) mais frequentes identificados na amostra;

- Discutir os diagnósticos mais frequentes na amostra estudada. 


\section{METODOLOGIA DA PESQUISA}

\subsection{PLANO DE INVESTIGAÇÃO}

$\mathrm{Na}$ definição do plano de investigação o caminho metodológico traçado possui características da Corrente de Pensamento Positivista Lógica. O positivismo lógico é definido como o formulador do celebre princípio da verificação, onde é considerado verdadeiro aquilo que é empiricamente verificável, concluindo que toda informação sobre o mundo deve ser confrontada com o dado e que a teoria deve apresentar concordância geral com o dado na experiência por meio de variáveis. A variável permite medir as relações entre os fenômenos, testar hipóteses e estabelecer generalizações (GIL, 2007). O estudo enfatiza a relação entre clientes oncológicos em cuidados paliativos e os diagnósticos de enfermagem que serão objetivamente medidos, e centra sua atenção em fatos observáveis para exprimir a realidade. O estudo privilegia a estatística e trabalha com o raciocínio lógico dedutivo, tendo como base do conhecimento as relações de causa e efeito (BURNS, 2004).

\subsection{NATUREZA DO ESTUDO}

No contexto da declaração dos objetivos, o propósito desse estudo de natureza quantitativo é aplicar a teoria de Imogene King como base conceitual para verificar a relação entre a variável independente paciente oncológico crítico em cuidados paliativos com a variável dependente diagnósticos de enfermagem. A pesquisa foi realizada em um Hospital Privado do Distrito Federal.

Considerou-se nesta pesquisa cliente oncológico como o doente com diagnóstico de câncer, sendo o câncer uma doença crônica com efeitos físicos e emocionais. A reabilitação do cliente com câncer é um processo contínuo que tem como finalidade maximizar a capacidade do cliente dentro das limitações impostas pela doença e pelo tratamento, através da avaliação das condições da qualidade de vida e do planejamento para a melhor terapêutica a ser aplicada.

Quanto à definição de cuidado paliativo, adotou-se como sendo a abordagem ou tratamento que melhora a qualidade de vida de pacientes e familiares diante de doenças que ameacem a continuidade da vida, através do avalio e controle da dor (OMS, 2002). 
Utilizou-se a definição de diagnósticos de enfermagem adotada pela NANDA-I, qual seja, o julgamento clínico sobre as respostas do indivíduo, da família ou comunidade a problemas de saúde/processos vitais reais ou potenciais e proporciona a base para seleção de intervenções para atingir resultados (NADA-I, 2015).

\subsection{TIPO DE ESTUDO}

Trata-se de uma pesquisa de natureza quantitativa, com caminho metodológico de estudo exploratório descritivo, que contemplará a definição da prevalência de diagnósticos de enfermagem para pacientes com câncer em cuidados paliativos hospitalizados, evidenciando a frequência simples e percentual de suas categorias, respectivos fatores relacionados e características definidoras, bem como fatores de risco.

O estudo será exploratório, uma vez que se inicia no aprofundamento dos limites de uma realidade específica buscando antecedentes e maior conhecimento para posterior planejamento descritivo. A fase exploratória consiste inicialmente em breve análise dos estudos já realizados, bem como a relevância e suas deficiências, e posteriormente no levantamento de possíveis problemas.

O estudo descritivo, tem como foco o desejo de conhecer. Pretende descrever com exatidão os fatos e fenômenos presentes na realidade do cuidado de enfermagem aos pacientes oncológicos em cuidados paliativos, objetivando proporcionar maior familiaridade com o problema, com vistas a torná-lo mais explícito o que poderá contribuir para melhorias na qualidade do cuidado de Enfermagem.

\subsection{DEFINIÇÃO DO PROBLEMA DE PESQUISA}

Quais são os diagnósticos de enfermagem, seus fatores relacionados, fatores de risco e características definidoras mais frequentes em uma população de clientes críticos portadores de doenças oncológicas em protocolo de cuidados paliativos internados em Hospital Privado do Distrito Federal?

\subsection{DELIMITAÇÃO DO PROBLEMA DE PESQUISA}

A delimitação consiste na definição do problema pelo pesquisador. Essa delimitação se fez influenciada diretamente pelo contato do pesquisador com seu meio de interesse prático 
vivenciado no dia-a-dia. Quando o problema é delimitado dessa maneira observa-se que durante a execução da pesquisa, o pesquisador em alguns momentos mergulha em outras situações que podem distanciá-lo do objeto, mas esse distanciamento é necessário para que possa apreciar a dimensão cientifica dos fenômenos, uma vez que seu pensamento deve ser guiado por formulações conceituais que integram as teorias (GIL, 2007).

\subsection{FORMULAÇÃO DO PROBLEMA DE PESQUISA}

Após a delimitação do problema foi realizada a formulação do problema utilizando como premissas a precisão e a clareza. Esta formulação ressalta as relações entre os fenômenos. Assim, a questão fundamental foi: Quais são os diagnósticos de enfermagem, suas características definidoras, fatores relacionados e fatores de risco, predominantes em clientes oncológicos críticos, em cuidados paliativos, considerando seu perfil socioeconômico-demográfico, aspectos relativos à topografia da doença oncológica e suas respostas aos problemas de saúde ou potencialidades?

\subsection{FUNDAMENTAÇÃO TEÓRICA DA PESQUISA}

Após a delimitação do problema selecionou-se a base para fundamentação teórica a partir de aprofundamento no tema e revisão bibliográfica com o objetivo de selecionar subsídios para apoio na análise da realidade e explicação da relação entre as variáveis selecionadas. A avaliação bibliográfica possibilitou avaliação dos esforços, métodos, dificuldades, disponibilidade de recursos humanos e materiais disponíveis, possibilidade de realização da pesquisa e a utilidade dos resultados.

Uma teoria é um sistema de constructos abstratos e de suas relações mútuas, que pretende explicar aspectos particulares de conduta em face de predições verificáveis a respeito desta. A Teoria de Enfermagem selecionada para esse estudo foi a Teoria do Alcance de Metas de Imogene King que tem como base a relação entre enfermeiro e cliente para o estabelecimento, de forma conjunta, dos meios para resolução de problemas reais e/ou potenciais apresentados. Os conceitos e pressupostos da Teoria de King fundamentam o significado dessa pesquisa, uma vez que adaptam-se à dimensão do problema de pesquisa apresentado possibilitando significado aos fatos investigados, explicando aspectos da realidade, permitindo a interpretação dos fatos observados e ainda abrindo perspectivas para futuras pesquisas (TOMEY, 2004) 
O estudo em questão estabelece ainda relação entre variáveis. A variável na pesquisa quantitativa pode ser entendida como aquilo que se deseja medir. São as características observáveis.

\subsection{LOCAL DO ESTUDO}

O estudo foi realizado em um Hospital privado do Distrito Federal localizado na Asa Sul onde a pesquisadora atua no cargo de gerente de enfermagem.

Segundo relatório do sistema Tasy, o hospital possui 227 leitos, sendo destes 74 destinados a terapia intensiva adulto e infantil. Segundo dados de Janeiro a Dezembro de 2013, a Instituição tem perfil predominantemente cirúrgico, realizando em média 1000 procedimentos ao mês. Das cirurgias realizadas, em média 30\%, envolvem pacientes com doenças oncológicas. O Hospital possui 153 leitos de internação, sendo uma Unidade de Internação de 14 leitos destinada exclusivamente à Oncologia.

\subsection{CARACTERIZAÇÃO DA AMOSTRA E CRITÉRIOS DE INCLUSÃO E EXCLUSÃO}

Foi definida amostra estatisticamente válida, constituída por pacientes Oncológicos críticos em Cuidados Paliativos atendidos em um Hospital privado Geral do Distrito Federal. A definição da amostra foi feita após levantamento de dados expressos em relatório da Comissão Interna de óbitos, que informou sobre o universo geral de pacientes oncológicos em cuidados paliativos atendidos na instituição. Foi realizado um estudo retrospectivo, para verificar a quantidade de paciente com diagnóstico de câncer e inclusos em protocolo de cuidados paliativos internados no local do estudo no ano de 2013. O estudo contou com o apoio de relatórios retirados do sistema hospitalar SMART e com informações do censo de controle diário da enfermagem. O sistema SMART consiste num conjunto de métodos desenvolvidos para diversos segmentos comerciais que atua em soluções integradas de softwares. Após esse levantamento foi definida amostra. Esse processo contou com a validação por profissional com experiência estatística e clinica.

No ano de 2013 o hospital campo para a pesquisa realizou internação de 72 pacientes em cuidados paliativos. A amostra é definida como parte representativa da população ou parte dos elementos de uma população possíveis de observação de uma variável de interesse. 
Define ainda amostragem como o processo de seleção da amostra. A técnica de amostragem é feita com a finalidade de economia financeira, redução no tempo de observação, melhorar a qualidade dos dados levantados e consequentemente ter resultados mais satisfatórios (BARBETTA, 2006).

A inclusão dos clientes foi realizada independente de sexo, e considerou-se os critérios: idade igual ou maior que 18 anos, estarem internados durante o momento da coleta de dados com o diagnóstico médico de câncer, em tratamento paliativo (ou seja, incluído no protocolo de cuidados paliativos) com tempo superior a 24 horas e que aceitassem participar do estudo mediante a assinatura do Termo de Consentimento Livre e Esclarecido, TCLE, segundo parecer do Comitê de Ética em Pesquisa (Apêndice A). Os clientes com critérios para inclusão que não pudessem interagir poderiam participar, após o consentimento de seu familiar responsável, também mediante assinatura do Termo de Consentimento.

O Protocolo de Cuidados Paliativos realizado na instituição hospitalar, campo da pesquisa, apresentava como finalidade normatizar a identificação do paciente em cuidados paliativos sem terapêutica modificadora da doença, bem como o registro desta condição em prontuário levando em conta princípios bioéticos de beneficência, não maleficência, autonomia e justiça. Para inclusão do cliente nesse protocolo este deveria apresentar um ou mais dos seguintes critérios: presença de doença avançada, progressiva e incurável; falta de possibilidades razoáveis de respostas a tratamentos específicos; presença de inúmeros problemas ou sintomas intensos, múltiplos, multifatoriais; prognóstico de vida inferior a seis meses.

O protocolo tinha ainda como princípio importante o respeito à autonomia do paciente e/ou familiares, onde caso a família durante a fase de terminalidade desejasse que o paciente fosse encaminhado à UTI (devido sua dificuldade em lidar com esse momento) esse desejo seria respeitando sendo o paciente encaminhado para medidas de conforto até o óbito. Na UTI a prioridade era o controle da dor e dos sintomas para o alívio do sofrimento seguindo de princípios e metas que visassem o respeito às necessidades e anseios individuais. Todo paciente em cuidado paliativo era acompanhado pelo serviço de psicologia hospitalar para suporte e atendimento a ele e aos seus familiares.

Durante o cuidado paliativo esforços eram feitos no sentido de promover que as pessoas significativas estivessem próximas ao paciente, garantir que a equipe de saúde se 
sentisse útil para o paciente, atuar para que indivíduo e seus familiares estivessem sempre cientes das modificações do quadro clínico compreendendo o que estava sendo feito no cuidado e porque, e atuar com foco no controle do sofrimento e da dor.

Foram considerados critérios de exclusão os indivíduos internados na unidade que não estivessem no protocolo de cuidados paliativos ou que não aceitassem participar do estudo, ou tivessem solicitada suspensão do consentimento para participar do estudo ou que evoluíssem para o óbito em até 24 horas após a admissão.

A coleta dos dados ocorreu de dezembro de 2014 a julho de 2015. Durante o período da coleta de dados foram admitidos no local da pesquisa 40 pacientes sendo a amostra avaliada composta de 34 indivíduos. Os 6 pacientes não avaliados tiveram óbito com tempo menor que 24 horas após a admissão, não atendendo aos critérios de inclusão, visto que a abordagem aos familiares para preenchimento do TCLE, bem como a avaliação do paciente pelo pesquisador ficaria impossibilitada. A amostra avaliada possui margem de confiança de $99 \%(\mathrm{z}=2,58)$ e margem de erro de $1,5 \%(\mathrm{e})$, e o p valor igual a 0,0049 . Sendo $e$ o erro amostral, $z$ a distribuição normal padrão e $p$ a significância estatística. Os dados estatísticos apresentados validam a amostra selecionada para a presente pesquisa, onde a análise de 30 indivíduos já poderia conferir à pesquisa amostra estatisticamente válida.

\subsection{PROCEDIMENTO PARA COLETA DE DADOS}

Para a coleta de dados foi realizada entrevista com observação de dados objetivos e subjetivos, exame físico e consulta ao prontuário, mediante um roteiro de coleta de dados desenvolvido com fundamentação nos requisitos de cuidados paliativos (Apêndice B).

O roteiro de coleta de dados passou por processo de refinamento realizado por profissionais com experiência no cuidado paliativo a pacientes oncológicos, domínio na Teoria do Alcance de Metas de Imogene King e experiência na utilização do Processo de Enfermagem na prática clínica e na pesquisa. Assim, o instrumento de coleta foi avaliado por três peritos com critérios de experiência clinica pré-definidos. Os critérios foram: experiência assistencial à pacientes oncológicos por tempo igual ou superior a 3 anos, possuir especialização em oncologia clínica e atuar em instituição hospitalar lotado em setor onde estivesse implementado o Processo de Enfermagem e houvesse internação de pacientes oncológicos em cuidados paliativos há no mínimo 1 ano. 
Após a avaliação do instrumento pelos peritos, foi realizado um teste piloto com nove pacientes com perfil semelhante ao perfil objetivado no estudo, que estavam internados em enfermaria.

Após esta avaliação os juízes sugeriram alterações como: inclusão do registro de dispositivos invasivos, situação psicológica e social dos familiares, inclusão de campo para registro de exames laboratoriais e de imagem alterados, bem como registro de presença ou não de doença metastática e tratamento oncológicos anteriormente realizados. Todas as sugestões foram aceitas tendo em vista a relevância das informações sugeridas para construção dos diagnósticos de enfermagem.

Os pacientes foram selecionados através da busca ativa diária e relatório de pacientes internados por CID, Código Internacional de Doenças, retirado pelo sistema Tasy. Esse é um sistema para gestão hospitalar que tem como objetivo facilitar o fluxo de informações entre todos os setores da empresa e integrar todos os processos hospitalares. Esta integração elimina dados redundantes e retrabalho, garantindo a confiabilidade das informações e proporcionando aos gestores uma visão global da organização. É uma solução em tecnologia da informação desenvolvida pela Philips. Os ganhos com implantação desse sistema são: as organizações de saúde adquirem maior integração de processos, pessoas e informações; maior produtividade, rentabilidade, melhor gestão do seu negócio e principalmente maior segurança ao paciente.

Assim, os pacientes com diagnóstico de neoplasia eram investigados através da análise em prontuário para verificação do registro de inclusão no protocolo de cuidados paliativos. $\mathrm{O}$ tempo médio gasto para coleta de dados foi de 45 minutos por paciente, sendo 20 minutos de avaliação física e 25 minutos para busca de dados em prontuário e entrevista com familiares. Os clientes ou seus familiares foram abordados previamente para entender o objetivo e aplicabilidade do estudo aceitando participar por meio de assinatura do TCLE.

Após a coleta de dados foi realizada a identificação dos Diagnósticos de Enfermagem, utilizando o processo de raciocínio diagnóstico, o qual incluiu as etapas de análise e síntese dos dados coletados do paciente. Segundo Tannure (2010) para a elaboração do raciocínio, necessita-se do "assessment", ou seja, sintetizar, interpretar e analisar os dados coletados, considerando que os mesmos devem ser colhidos corretamente, pois esta ação indicará a 
conduta assistencial do processo e o mau julgamento e/ou diagnóstico errôneo poderá afetar a qualidade da assistência bem como a segurança do paciente.

Após a coleta e processamento de dados segundo o modelo conceitual adotado, foi realizada a formulação da declaração do diagnóstico por meio do sistema de classificação da NANDA-I, confirmação do diagnóstico, registro e documentação. A fase de análise e síntese para definição dos diagnósticos de enfermagem foi revisada e validada por profissional perito em diagnósticos de enfermagem. O perito tem atuação na docência em enfermagem, em especial com o processo de enfermagem e experiência também na área clínica, com mestrado e doutorado na área de diagnósticos de enfermagem.

Finalizada a coleta de dados, análise, síntese, identificação dos diagnósticos de enfermagem e relação com fatores relacionados ou fatores de risco foi realizada a caracterização socioeconômica da amostra estudada, identificação do perfil diagnóstico, listagem e descrição das características definidoras mais frequentes dos diagnósticos de enfermagem reais e listagem e descrição dos fatores de risco dos diagnósticos de enfermagem de risco mais frequentes.

A etapa final consistiu na discussão dos fatores relacionados mais frequentes nos diagnósticos de enfermagem reais predominantes na amostra estudada e análise dos diagnósticos quanto à frequência simples e percentual de suas categorias, respectivos fatores relacionados e características definidoras/fatores de risco.

\subsection{INSTRUMENTO DE COLETA DOS DADOS}

Ainda em relação ao instrumento para coleta de dados foi utilizado um instrumento como base o Sistema Conceitual por King com fundamentação nos três sistemas que são a base de modelo: sistema pessoal, interpessoal e social. Isso permitiu uma abordagem do paciente pautada em visão holística e na classificação da Taxonomia II da NANDA-I. No instrumento foram agrupados dados para cada um dos sistemas descritos e identificados os elementos que pudessem caracterizar os diagnósticos de enfermagem (evidências clínicas, fatores relacionados e fatores de risco).

O instrumento de coleta (Apêndice B) foi elaborado após revisão bibliográfica sobre o cuidado, o processo de enfermagem e suas etapas, bem como sobre a aplicabilidade do 
Modelo Conceitual e da Teoria do Alcance de Metas de Imogene King. Após esta revisão, o instrumento construído para coleta esteve direcionado ao cliente oncológico com anamnese e exame físico, divididos dentro dos três sistemas interatuantes. O instrumento contou também com uma parte para identificação dos diagnósticos de enfermagem, fatores relacionados e características definidoras.

A organização dos registros foi estruturada de modo a utilizar, sempre que possível, a checagem do tipo check-list, com espaços em branco para possíveis complementações de informações relevantes. $\mathrm{O}$ instrumento foi composto por três partes:

Questões relativas ao sistema pessoal: identificação (incluindo identificação, idade, procedência, ocupação, escolaridade, dependência financeira, data da admissão, motivo da internação, diagnóstico oncológico, tratamentos prévios, comorbidades), hábitos de vida (tabagismo, etilismo, uso de drogas ilícitas, padrão alimentar, dificuldade em mastigar ou deglutir, uso de sondas, peso atual, estatura, padrão de eliminações intestinais e vesicais, padrão de sono, nível de dependência para alimentação, higiene, deambulação e mobilidade, avaliação do padrão respiratório e necessidade de oxigênio suplementar, presença de náuseas/vômitos ou dor, história de quedas, presença de alergias, presença de edemas, presença de lesões e avaliação neuro-sensorial). Inclui ainda avaliação sobre a percepção (sobre a doença e tratamento), a imagem corporal e self, tempo e espaço.

Questões relativas ao sistema interpessoal: questões que abordam a integridade do ego no que se refere à doença, equipe de saúde, possíveis barreiras à comunicação, o relacionamento familiar, o papel desempenhado na família, preocupações a cerca da hospitalização e a percepção do cliente sobre as suas necessidades.

Questões relacionadas ao sistema social: questões relativas à habitação, composição e relação familiar, estado civil, papel desempenhado na família, crença/ religião, necessidade de participação na comunidade, serviços de saúde (acessibilidade e uso), crença e prática religiosa e outras necessidades biopsicossociais.

Foram utilizadas 6 escalas de avaliação. Para avaliação do risco de úlcera por pressão foi utilizada a escala de Braden, para risco de queda a escala de Morse, foram utilizadas duas escalas de dor (escala visual e analógica e escala comportamental), Escala de ansiedade (Ham - A) e escala de estresse percebido (PSS 14). Foi utilizado ainda o APACHE II (Acute 
Physiology and Chronic Health Evalution) para avaliação e classificação do índice de gravidade dos clientes inclusos na pesquisa.

As variáveis avaliadas no APACHE II são: temperatura axilar, pressão arterial média, frequência cardíaca, frequência respiratória, pressão de oxigênio com fração de oxigênio maior que $50 \%, \mathrm{pH}$ arterial ou bicarbonato de sódio, sódio sérico, potássio sérico, creatinina sérica, hematócrito, quantidade de leucócitos, pontuação na escala de Glasgow, idade, presença de doenças crônicas e natureza dos procedimento cirúrgicos (emergência ou eletivo) se houver (KNAUS, 1985).

Os pacientes críticos reúnem todas as condições para desenvolver úlcera por pressão, pois muitas vezes estão acamados, imobilizados e/ou com má perfusão tecidual. Optou-se neste estudo por utilizar a escala de Braden por ter sido submetida a diversos estudos e testes de confiabilidade e validade em diferentes populações, e além disso, foi validada também para a Língua Portuguesa. A escala de Braden é composta de 6 subclasses que refletem: grau de percepção sensorial, umidade, atividade física, nutrição, mobilidade, fricção e cisalhamento. Todas as subclasses são graduadas de 1 a 4, exceto fricção e cisalhamento, cuja variação é de 1 a 3 . O grau de risco varia de 6 a 23, e pacientes adultos hospitalizados com escores de 16 ou abaixo são considerados de risco para a aquisição de úlcera por pressão. Em população mais velha, os graus 17 ou 18 já podem ser considerados críticos (PARANHOS, 1999).

$\mathrm{Na}$ amostra estudada, que foi composta por 34 clientes, $100 \%$ deles apresentaram risco para úlcera por pressão presente, esses riscos foram categorizados em baixo, moderado, alto e severo, como ilustrado na figura 4. 
Figura 4 - Escala de Braden, 1999.

\begin{tabular}{|c|c|c|c|c|}
\hline \multicolumn{5}{|c|}{ AVALIAÇÃO DO GRAU DE RISCO } \\
\hline \multicolumn{5}{|c|}{ ESCALA DE BRADEN * } \\
\hline Percepção sensorial & $\begin{array}{l}\text { 1. Totalmente } \\
\text { limitado }\end{array}$ & 2. Muito limitado & $\begin{array}{l}\text { 3. Levemente } \\
\text { limitado }\end{array}$ & $\begin{array}{l}\text { 4. Nenhuma } \\
\text { limitação }\end{array}$ \\
\hline Umidade & $\begin{array}{l}\text { 1. Completamente } \\
\text { molhada }\end{array}$ & 2. Muito molhada & $\begin{array}{l}\text { 3. Ocasionalmente } \\
\text { molhada }\end{array}$ & $\begin{array}{l}\text { 4. Raramente } \\
\text { molhada }\end{array}$ \\
\hline Atividade & 1. Acamado & $\begin{array}{l}\text { 2. Confinado à } \\
\text { cadeira }\end{array}$ & $\begin{array}{l}\text { 3. Anda } \\
\text { ocasionalmente }\end{array}$ & $\begin{array}{l}\text { 4. Anda } \\
\text { freqüentemente }\end{array}$ \\
\hline Mobilidade & 1. Totalmente imóvel & $\begin{array}{l}\text { 2. Bastante } \\
\text { limitado }\end{array}$ & $\begin{array}{l}\text { 3. Levemente } \\
\text { limitado }\end{array}$ & $\begin{array}{l}\text { 4. Não apresenta } \\
\text { limitações }\end{array}$ \\
\hline Nutrição & 1. Muito pobre & $\begin{array}{l}\text { 2. Provavelmente } \\
\text { inadequado }\end{array}$ & 3. Adequado & 4. Excelente \\
\hline $\begin{array}{l}\text { Fricção e } \\
\text { Cisalhamento }\end{array}$ & 1. Problema & $\begin{array}{l}\text { 2. Problema em } \\
\text { potencial }\end{array}$ & $\begin{array}{l}\text { 3. Nenhum } \\
\text { problema }\end{array}$ & \\
\hline
\end{tabular}

Fonte: PARANHOS, W. Avaliação de risco para úlceras de pressão por meio da Escala de Braden, na língua portuguesa. 1999

Para auxiliar na identificação do risco de quedas optou-se por utilizar a escala de quedas de Morse. Esta escala foi publicada por Morse em 1989 e é composta por seis critérios para a avaliação do risco de quedas: história recente de quedas, diagnóstico secundário, necessidade de auxílio na deambulação, terapia endovenosa/dispositivo endovenoso salinizado ou heparinizado, marcha e estado mental. Cada critério avaliado recebeu uma pontuação que variou de zero a 30 pontos, totalizando um escore de risco, cuja classificação é a seguinte: 0 a 24 pontos - sem risco; 25 a 50 pontos - baixo risco; acima de 50 pontos - alto risco, como nos mostra a figura 5 (URBANETTO, 2013). 
Figura 5 - Escala de risco de quedas de Morse, 2013

\begin{tabular}{|c|c|}
\hline Item & Definiçào Operacional \\
\hline \multicolumn{2}{|l|}{ 1. Histórico de quedas } \\
\hline Nào & Se o paciente não tem histónia de quedas nos ûltimos três meses. \\
\hline Sim & $\begin{array}{l}\text { Se o paciente caiu durante o periodo da internação hospitalar ou se tem historico recente (até } \\
\text { trés meses) de quedas por causas fisiologicas, tais como convulsốes ou marcha comprometida } \\
\text { antes da admissào hospitalar. }\end{array}$ \\
\hline \multicolumn{2}{|l|}{ 2. Diagnóstico secundário } \\
\hline Nảo & Se no prontuārio do paciente apresentar apenas um diagnöstico médico. \\
\hline Sim & Se no prontuario do paciente apresentar mais de um diagnóstico médico. \\
\hline \multicolumn{2}{|l|}{ 3. Auxilio na deambulação } \\
\hline $\begin{array}{l}\text { Nenhum/Acamado/Auxiliado por Profissional } \\
\text { da Saude }\end{array}$ & $\begin{array}{l}\text { Se o paciente deambula sem equipamento auxiliar (muleta, bengala ou andador), ou } \\
\text { Se deambula com a ajuda de um membro da equipe de satide, ou ainda } \\
\text { Se usa cadeira de rodas ou se está acamado e náo sai da cama sozinho. }\end{array}$ \\
\hline Muletas Bengala/Andador & Se o paciente utiliza muletas, bengala ou andador. \\
\hline Mobiliario/Parede & Se o paciente se movimenta apoiando-se no mobiliario/paredes. \\
\hline \multicolumn{2}{|c|}{ 4. Terapia endovenosa/dispositivo endovenoso salinizado ou heparinizado } \\
\hline Nào & $\begin{array}{l}\text { Se o paciente nào usa dispositivo endovenoso. } \\
\text { Nota: quando o paciente usa dispositivo totalmente implantado, considera-se pontuação zero, } \\
\text { quando năo estiver em uso. }\end{array}$ \\
\hline $\operatorname{Sim}$ & $\begin{array}{l}\text { Se o paciente usa dispositivo endovenoso com infusăo continua ou não (salinizado ou } \\
\text { heparinizado). }\end{array}$ \\
\hline \multicolumn{2}{|r|}{ se } \\
\hline $\begin{array}{l}\text { Normal/ Sem deambulaşâo, Acamado, Cadeira } \\
\text { de Rodas }\end{array}$ & $\begin{array}{l}\text { Uma marcha normal é caracterizada pelo andar de cabeça ereta, braços balançando } \\
\text { livremente ao lado do corpo e passos largos, sem hesitaçao. Tambem recebe a mesma } \\
\text { pontuaçẫo se o paciente esta acamado e/ou usa cadeira de rodas (sem deaunbulação). }\end{array}$ \\
\hline Fraca & $\begin{array}{l}\text { Os passos sẫo curtos e podem ser vacilantes. Quando a marcha é fraca, embora o paciente } \\
\text { incline-se para frente enquanto caminha, é capaz de levantar a cabeça sem perder o } \\
\text { equilibrio. Além disso, caso ele faça uso de algum mobiliário como apoio, este apoio se da de } \\
\text { maneira leve somente para se sentir seguro, nào para se manter ereto. }\end{array}$ \\
\hline Comprometida/Cambaleante & 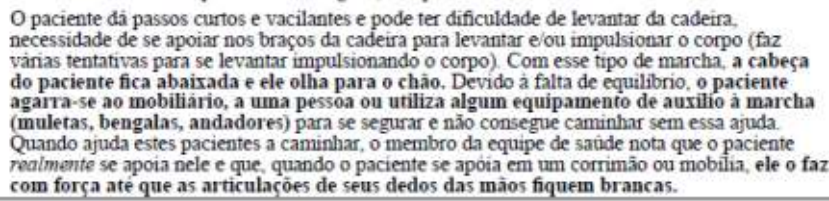 \\
\hline \multicolumn{2}{|l|}{ 6. Estado mental } \\
\hline $\begin{array}{l}\text { Orientado/ Capaz quanto à sua capacidade/ } \\
\text { limitação }\end{array}$ & $\begin{array}{l}\text { Ao perguntar ao paciente "Vocè é capaz de ir ao banheiro sozinho ou precisa de ajuda?" } \\
\text { verifique se a resposta é consistente com as informaçóes constantes no prontuário efou com sua } \\
\text { avaliação. Em caso positivo, o paciente é classificado como capaz. }\end{array}$ \\
\hline Superestima capacidade/ Esquece limitaçôes & 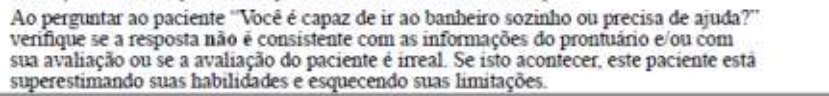 \\
\hline
\end{tabular}

Fonte: Urbanetto JS, Morse Fall Scale: tradução e adaptação transcultural para a língua portuguesa. 2013

Para avaliação da dor optou-se por utilizar duas escalas de avaliação a depender do grau de nível de consciência dos pacientes em questão. A escala visual analógica (EVA), que consiste em ferramenta auxiliar na aferição da intensidade da dor do paciente consciente, onde ele mesmo realiza a avaliação da sua dor. Embora a avaliação da dor tenha um componente subjetivo, procurou-se selecionar um instrumento para uniformizar a avaliação dos pacientes. A EVA é constituída por uma linha de $10 \mathrm{~cm}$ que tem, em geral, como extremos as frases “ausência de dor e dor insuportável". Apesar das vantagens já apontadas, idosos e crianças, às vezes, sentem dificuldades em utilizá-la devido à abstração necessária para sua compreensão. Nessa população específica, existem instrumentos propostos que usam outros recursos visuais como desenhos representando expressões faciais. $\mathrm{O}$ avaliador questiona o paciente quanto ao seu grau de dor sendo que 0 significa ausência total de dor e 10 o nível de dor máxima suportável pelo paciente, como ilustrado na figura 6 (ONA, 2002). 
Figura 6 - Escala visual analógica, 2013

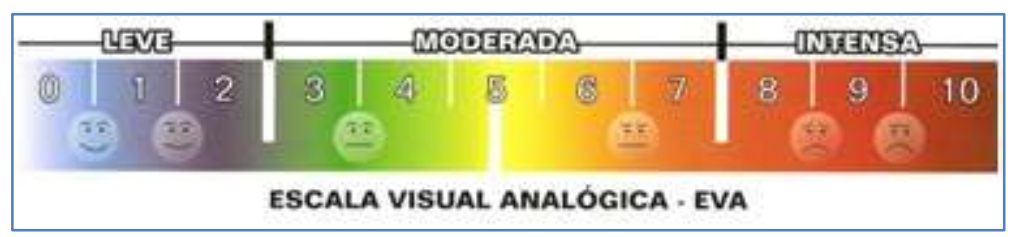

Fonte: Manual ONA - Organização Nacional de Acreditação - 2013

Em situações onde o paciente é incapaz de se comunicar, devem-se utilizar outros métodos. Neste estudo optou-se por usar a escala comportamental (Behavioral Pain Scale BPS) com escores de 3 a 12, através da observação da expressão facial, de movimentos do corpo, de tensão muscular e sincronia com o ventilador como ilustra a figura 7. O BPS, é de fácil aplicação, é usado para avaliar a dor de paciente sedado ou em ventilação mecânica. Se o escore for > 6, é considerado inaceitável. A expressão facial é o item que mais contribui para a avaliação da dor, seguida de movimentos dos membros e da aceitação da ventilação. São comportamentos de dor: careta, testa franzida, rigidez, retração, pálpebras cerradas apertadas, nariz franzido, lábio superior levantado, verbalização, punhos cerrados. A aceitação da ventilação mecânica pode ser afetada por hipoxemia, broncoespasmo e secreção (AHLERS, 2010).

Figura 7 - Escala Behavioral Pain Scale - BPS

\begin{tabular}{|l|}
\hline Expressão facial \\
Relaxada: 1 \\
Parcialmente tensa: 2 \\
Totalmente tensa: 3 \\
Fazendo careta: 4 \\
Movimentos dos membros superiores \\
Relaxado: 1 \\
Parcialmente flexionado: 2 \\
Totalmente flexionado: 3 \\
Totalmente contraido: 4 \\
Ventilação mecânica \\
Tolerando movimentos: 1 \\
Tossindo, mas tolerando durante a maior parte do tempo: 2 \\
Lutando contra ventilador: 3 \\
Impossibilidade de controle do ventilador: 4 \\
\hline
\end{tabular}

Fonte: Ahlers SJ - The use of the Behavioral Pain Scale. 2010

Para avaliação da presença de ansiedade, bem como o seu nível caso estivesse presente, optou-se pela utilização da Escala de Avaliação de Ansiedade de Hamilton (HamA). A escala compreende 14 grupos de sintomas, subdivididos em dois grupos, sete 
relacionados a sintomas de humor ansioso e sete relacionados a sintomas físicos de ansiedade. Cada item é avaliado segundo uma escala que varia de 0 a 4 de intensidade $(0=$ ausente; $2=$ leve; 3 =média; 4 = máxima). A soma dos escores obtidos em cada item resulta em um escore total, que varia de 0 a 56. A elaboração desta escala baseou-se no princípio de que quanto mais grave for a manifestação de uma patologia, maior será o número de sintomas característicos que se apresentam. Se o número de sintomas for relativamente alto, a contagem dos sintomas torna-se um instrumento quantificador útil, confiável e de boa validade.

Para avaliação da presença de estresse, optou-se pela utilização da Escala de Estresse Percebido, ilustrada na figura 8. A Escala de Percepção de Estresse (PSS 14) é uma medida global de estresse que se propõe avaliar o grau em que um indivíduo aprecia as suas situações de vida como estressantes. A ferramenta possui 14 itens com opções de resposta que variam de zero a quatro ( $0=$ nunca; $1=$ =quase nunca; $2=$ às vezes; $3=$ quase sempre $4=$ sempre). As questões com conotação positiva $(4,5,6,7,9,10$ e 13$)$ têm sua pontuação somada invertida, da seguinte maneira, $0=4,1=3,2=2,3=1$ e $4=0$. As demais questões são negativas e devem ser somadas diretamente. A soma da pontuação das questões fornece escores que podem variar de zero a 56 (LUFT, 2007). Esta escala é aplicável apenas à clientes conscientes e orientados.

Figura 8 - A Escala de Percepção de Estresse (PSS 14), 2007.

\begin{tabular}{||l|l|l|l|l|l|l||}
\hline Neste último mês, com que freqüência... & 0 & 1 & 2 & 3 & 4 \\
\hline 1 & $\begin{array}{l}\text { Você tem ficado triste por causa de algo que aconteceu } \\
\text { inesperadamente? }\end{array}$ & & & & \\
\hline 2 & $\begin{array}{l}\text { Você tem se sentido incapaz de controlar as coisas importantes em } \\
\text { sua vida? }\end{array}$ & 0 & 1 & 2 & 3 & 4 \\
\hline 3 & Você tem se sentido nervoso e "estressado"? & 0 & 1 & 2 & 3 & 4 \\
\hline 4 & Você tem tratado com sucesso dos problemas difíceis da vida? & 0 & 1 & 2 & 3 & 4 \\
\hline 5 & $\begin{array}{l}\text { Você tem sentido que está lidando bem as mudanças importantes } \\
\text { que estão ocorrendo em sua vida? }\end{array}$ & 0 & 1 & 2 & 3 & 4 \\
\hline 6 & $\begin{array}{l}\text { Você tem se sentido confiante na sua habilidade de resolver } \\
\text { problemas pessoais? }\end{array}$ & 0 & 1 & 2 & 3 & 4 \\
\hline 7 & $\begin{array}{l}\text { Você tem sentido que as coisas estão acontecendo de acordo com } \\
\text { a sua vontade? }\end{array}$ & 0 & 1 & 2 & 3 & 4 \\
\hline 8 & $\begin{array}{l}\text { Você tem achado que não conseguiria lidar com todas as coisas } \\
\text { que você tem que fazer? }\end{array}$ & 0 & 1 & 2 & 3 & 4 \\
\hline 9 & Você tem conseguido controlar as irritações em sua vida? & 0 & 1 & 2 & 3 & 4 \\
\hline 10 & Você tem sentido que as coisas estão sob o seu controle? & 0 & 1 & 2 & 3 & 4 \\
\hline 11 & $\begin{array}{l}\text { Você tem ficado irritado porque as coisas que acontecem estão } \\
\text { fora do seu controle? }\end{array}$ & 0 & 1 & 2 & 3 & 4 \\
\hline 12 & $\begin{array}{l}\text { Você tem se encontrado pensando sobre as coisas que deve } \\
\text { fazer? }\end{array}$ & 0 & 1 & 2 & 3 & 4 \\
\hline 13 & Você tem conseguido controlar a maneira como gasta seu tempo? & 0 & 1 & 2 & 3 & 4 \\
\hline 14 & $\begin{array}{l}\text { Você tem sentido que as dificuldades se acumulam a ponto de } \\
\text { você acreditar que não pode superá-las? }\end{array}$ & 0 & 1 & 2 & 3 & 4 \\
\hline \hline
\end{tabular}

Fonte: Luft, CDB; Sanches, S de O; Mazo, GZ; Andrade, A. Versão brasileira da Escala de Estresse Percebido: tradução e validação para idosos. 2007 


\subsection{ANÁLISE DOS DADOS}

A análise dos dados foi conduzida por estatística descritiva, de acordo com a proposta do estudo. A apresentação dos dados encontra-se no formato de tabelas de frequência, tabelas de medidas descritivas e gráficos.

Foram utilizados métodos de estatística descritiva com a finalidade de descrever e resumir os dados com o objetivo de descrever o fenômeno. Após a definição do problema, planejamento de como seriam levantadas as informações e coleta direta dos dados primários, realizou-se a apuração.

$\mathrm{Na}$ apuração estatística realizou-se contagem e agrupamento dos dados com posterior condensação e tabulação. As variáveis foram analisadas quanto às frequências relativa e absoluta, utilizando-se o método de estatística descritiva, com a média das variáveis pertinentes.

Os dados apurados foram apresentados na formar tabular e gráfica. Esse gerenciamento do banco de dados foi realizado com o auxílio do Microsoft Excel $^{\circledR} 2007$.

\subsection{CONSIDERAÇÕES ÉTICAS E LEGAIS}

O estudo foi submetido do Comitê de Ética em Pesquisa com Seres Humanos da Faculdade de Ciências da Saúde da Universidade de Brasília sob protocolo de $\mathrm{n}^{0}$ CAAE 34271514.3.0000.0030 (Anexo A) obtendo aprovação e submetido ainda a Diretoria geral da Instituição hospitalar com protocolo CAAE 34271514.3.3001.5057, obtendo êxito também em sua aprovação.

Todos os participantes (clientes e/ou familiares) foram esclarecidos sobre os objetivos do estudo, procedimentos a serem realizados, confiabilidade dos dados e sobre os riscos ao participar da pesquisa. Também foram esclarecidos sobre a possibilidade de sua retirada da pesquisa a qualquer momento, sem qualquer prejuízo ao seu cuidado, em atendimento às normas da Resolução 466/2012 do Conselho Nacional de Saúde, do Ministério da Saúde, que regulamenta as pesquisas envolvendo os seres humanos no Brasil. 


\section{RESULTADOS}

A apresentação dos resultados desse trabalho será feita em três etapas.

Inicialmente será feita a caracterização socioeconômico-demográfica dos pacientes que fizeram parte da amostra, bem como os aspectos relativos à topografia da doença, em seguida a identificação dos diagnósticos de enfermagem. Serão também apresentadas as características definidoras e os fatores relacionados dos diagnósticos de enfermagem mais frequentes.

Como informado anteriormente, a coleta de dados ocorreu no período de dezembro de 2014 a julho de 2015, quando foram admitidos, no local da pesquisa, 40 clientes, dos quais 34 fizeram parte da amostra estudada por atenderem os critérios de inclusão na pesquisa.

\subsection{Caracterização dos clientes oncológicos críticos em protocolo de cuidados paliativos quanto ao perfil socioeconômico-demográfico}

A Tabela 1 apresenta a caracterização dos pacientes oncológicos críticos em cuidados paliativos atendidos na instituição estudada.

Tabela 1: Caracterização dos clientes oncológicos críticos em protocolo de cuidados paliativos quanto ao perfil socioeconômico-demográfico na amostra estudada ( $\mathrm{n}=34)$ - Brasília, dezembro 2014 a julho 2015.

\begin{tabular}{lcc}
\hline Caracterização & N & \% \\
\hline Sexo & & \\
Feminino & 17 & 50 \\
Masculino & 17 & 50 \\
& & \\
Faixa etária & & \\
30 a 45 & 1 & 2,9 \\
46 a 60 & 4 & 11,8 \\
61 a 75 & 11 & 32,4 \\
76 a 90 & 15 & 44,1 \\
Mais de 90 & 3 & 8,8 \\
& & \\
Escolaridade & & \\
Ensino fundamental incompleto & 12 & 35,3 \\
Ensino fundamental completo & 17 & 50 \\
Ensino médio completo & 2 & 5,9 \\
\hline
\end{tabular}


continuação

\begin{tabular}{lcc}
\hline Caracterização & $\mathbf{N}$ & $\mathbf{\%}$ \\
\hline Ensino médio incompleto & 1 & 2,9 \\
Ensino superior & 2 & 5,9 \\
& & \\
Renda familiar & 3 & 8,8 \\
Menor que 1 salário mínimo & 7 & 20,6 \\
Entre 1 a 2 salários mínimos & 21 & 61,8 \\
Maior que 2 e até 5 salários mínimos & 3 & 8,8 \\
Maior que 5 salários mínimos & & \\
& & \\
Estado civil & 3 & 8,8 \\
Solteiro & 32 & 64,7 \\
Viúvo & 26,5 \\
Casado
\end{tabular}

Fonte: o próprio autor

Em relação ao sexo, 17 (50\%) foram do sexo masculino e 17 (50\%) do sexo feminino. Quanto à faixa etária, a idade média da amostra foi de 74,4 anos, $15(44,1 \%)$ tinham entre 76 e 90 anos, 11 (26\%) tinham idades entre 61 e 75 anos, $4(11,8 \%)$ entre 45 e 60 anos ou mais, $3(8,8 \%)$ tinham mais de 90 anos e $1(2,9 \%)$ tinha idade menor que 45 anos, como mostra a figura 9.

Figura 9: Histograma de idade dos clientes oncológicos críticos em cuidados paliativos $(n=34)$ - Brasília, dezembro 2014 a julho 2015.

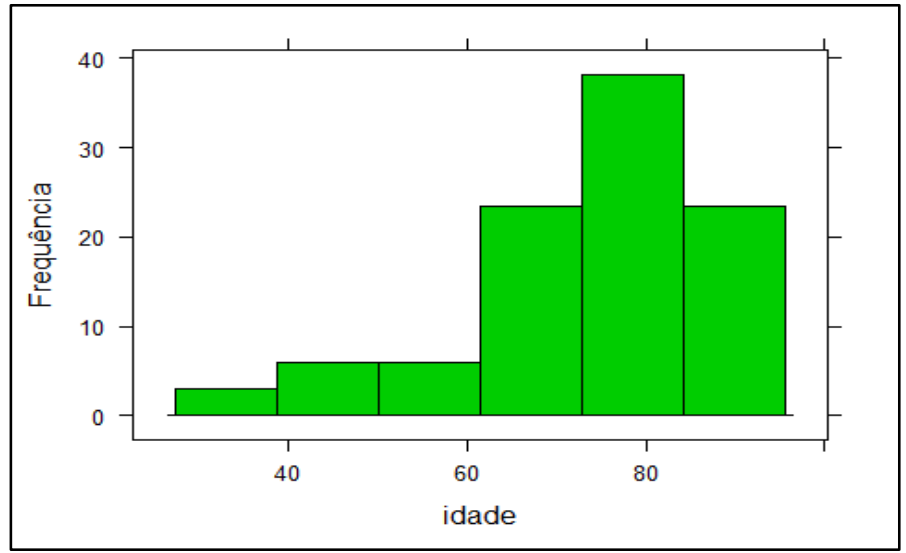

Fonte: o próprio autor 
Em relação à escolaridade, observou-se que 17 (50\%) clientes possuíam ensino fundamental completo, 12 (35,3\%) não concluíram o ensino fundamental, 2 (5,9\%) realizaram o ensino médio completo, 2 (5,9\%) possuíam ensino superior e $1(2,9 \%)$ não concluiu o ensino médio. Em relação à renda familiar 21 (61,8\%) clientes apresentavam renda entre 2 e 5 salários mínimos, 7 (20,6\%) possuíam renda entre 1 e 2 salários mínimos, 3 (8,8\%) renda menor que 1 salário mínimo e $3(8,8 \%)$ apresentavam renda familiar equivalente à mais de 5 salários mínimos.

Em relação ao estado civil $22(64,7 \%)$ dos clientes eram viúvos, 9 (26,5\%) eram casados e $3(8,8 \%)$ eram solteiros, como apontado na tabela1.

\subsection{Caracterização dos fatores condicionantes à internação hospitalar dos pacientes oncológicos críticos em protocolo de cuidados paliativos}

A Tabela 2 apresenta os resultados gerais da internação dos pacientes avaliados, com relação ao tempo de permanência, tipo de alta hospitalar, doenças pré-existentes, local de internação e hábitos de vida.

Tabela 2: Caracterização dos fatores condicionantes à internação hospitalar dos pacientes oncológicos críticos em protocolo de cuidados paliativos na amostra estudada $(n=34)$ - Brasília, dezembro 2014 a julho 2015.

Caracterização fatores condicionantes

$\mathbf{N}$

$\%$

Tempo de permanência

$\begin{array}{lcc}2 \text { a } 10 \text { dias } & 21 & 61,8 \\ 11 \text { a } 20 \text { dias } & 7 & 20,7 \\ 21 \text { a } 30 \text { dias } & 3 & 8,8 \\ 31 \text { a } 60 \text { dias } & 1 & 2,9 \\ 61 \text { a } 100 \text { dias } & 1 & 2,9 \\ \text { Mais de } 100 \text { dias } & 1 & 2,9\end{array}$

Tipo de alta

Óbito

$32 \quad 94,1$

Alta

$2 \quad 5,9$

Local de Internação

Unidade de Terapia Intensiva $\quad 32 \quad 94,1$

Enfermaria

2

5,9 
continuação

\begin{tabular}{lcc} 
Caracterização fatores condicionantes & $\mathbf{N}$ & $\mathbf{\%}$ \\
\hline Hábitos de vida & & \\
Tabagista & 12 & 35,3 \\
Etilista & 3 & 8,8 \\
& & \\
Doenças Pré-existentes & & \\
Hipertensão Arterial sistêmica & 18 & 34,6 \\
Insuficiência renal & 15 & 28,8 \\
Diabetes mellitus & 10 & 19,2 \\
Cardiopatias & 7 & 13,5 \\
DPOC & 2 & 3,8 \\
\hline
\end{tabular}

Fonte: próprio autor

Em relação ao tempo de internação no momento da avaliação da coleta de dados, variou-se de dois dias à mais de 100 dias, conforme tabela 2, com o tempo médio de 16,2 dias.

Observou-se que 21 clientes $(61,8 \%)$ tiveram tempo de internação entre 2 e 10 dias, 7 clientes $(20,7 \%)$ ficaram internados por período entre 11 e 20 dias, 03 clientes $(8,8 \%)$ tiveram internação por período entre 21 e 30 dias, 1 (2,9\%) cliente ficou internados por período entre 61 e 100 dias e $1(2,9 \%)$ cliente esteve internado por mais de 100 dias.

Em relação ao desfecho da internação, 34 clientes $(94,1 \%)$ evoluíram para o óbito durante e a internação e apenas $2(5,9 \%)$ tiveram alta para casa aos cuidados de empresas de homecare.

Em relação ao local em que o paciente estava internado no momento da avaliação e coleta de dados, 34 clientes $(94,1 \%)$ estavam em unidade de terapia intensiva e apenas 2 $(5,9 \%)$ estavam internados em unidade aberta, enfermaria.

Quanto aos hábitos e o estilo de vida, na amostra estudada, 12 (35,3\%) eram tabagistas e $3(8,8 \%)$ eram etilistas. 
Foi realizada ainda análise do perfil dos clientes da amostra no que se refere à presença de comorbidades. Observou-se que 18 clientes $(34,6 \%)$ eram portadores de hipertensão arterial sistêmica, 15 (28,8\%) eram renais crônicos, 10 (19,2\%) eram diabéticos, 7 $(13,5 \%)$ possuíam alguma cardiopatia e $2(3,8 \%)$ eram portadores de doença pulmonar crônica obstrutiva, como pode ser observado na tabela 2 .

Em relação à topografia da doença oncológica observou-se prevalência das neoplasias pulmonares $(17,6 \%)$, seguido das neoplasias de sistema nervoso central $(14,7 \%)$, mama $(11,8 \%)$, próstata $(11,8 \%)$, bexiga $(8,8 \%)$, cólon $(8,8 \%)$, renal $(5,9 \%)$, útero $(5,9 \%)$. As neoplasias gástricas, hepáticas, ósseas, ovarianas e de tireoide apresentaram frequência de 2,9\% cada, como ilustrado na figura 10.

Figura 10: Topografia da doença oncológica dos clientes oncológicos críticos em cuidados paliativos $(\mathrm{n}=$ 34) - Brasília, dezembro 2014 a julho 2015.

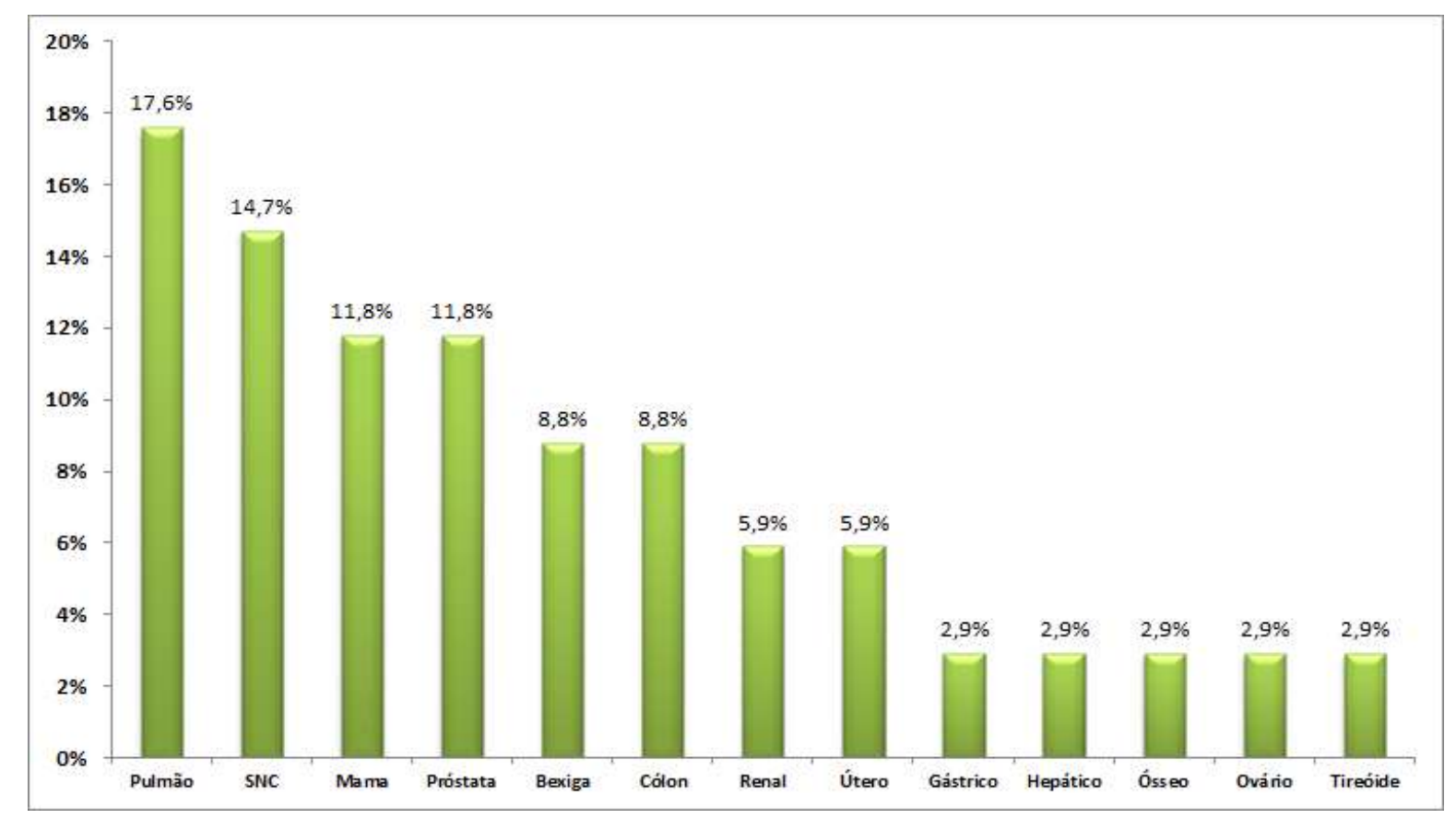

Fonte: o próprio autor

$\mathrm{Na}$ amostra estudada 26 clientes (76,5\%) possuíam algum tipo de metástase, enquanto $8(23,5 \%)$ não tinham doença metastática diagnosticada, como descrito na tabela 3. Em relação à localização da mestástase, 14 clientes $(41,2 \%)$ possuíam mestástase em região pulmonar, 12 indivíduos (35,3\%) apresentavam metástase óssea e 8 clientes (23,5\%) tinham diagnóstico de mestástase em região hepática. 
Tabela 3: Caracterização de frequência sobre a existência de metástase nos clientes oncológicos críticos em protocolo de cuidados paliativos na amostra estudada $(n=34)$ - Brasília, dezembro 2014 a julho 2015.

\begin{tabular}{ccc}
\hline $\begin{array}{c}\text { Existência de } \\
\text { Metástase }\end{array}$ & $\mathrm{N}$ & $\%$ \\
\hline Sim & 26 & 76,5 \\
Não & 8 & 23,5 \\
Total & 34 & 100,0 \\
\hline
\end{tabular}

Fonte: o próprio autor.

$\mathrm{Na}$ amostra estudada $27(79,4 \%)$ dos clientes fizeram tratamento quimioterápico, 25 $(73,5 \%)$ tiveram tratamento oncológico cirúrgico e 11 (32,4\%) já haviam feito sessões de radioterapia como descrito na tabela 4 .

Tabela 4: Tratamentos prévios aos quais foram submetidos os pacientes oncológicos críticos em protocolo de cuidados paliativos na amostra estudada $(n=34)$ - Brasília, dezembro 2014 a julho 2015.

\begin{tabular}{lcc}
\hline Tratamento oncológico prévio* & N & $\%$ \\
\hline Quimioterapia & & \\
Sim & 27 & 79,4 \\
Não & 7 & 20,6 \\
& & \\
Cirurgia & & \\
Sim & 25 & 73,5 \\
Não & 9 & 26,5 \\
& & \\
Radioterapia & & 67,6 \\
Não & 23 & 32,4 \\
Sim & 11 & \\
\end{tabular}

*Em relação ao tratamento observou-se na totalidade dos clientes a presença de terapias combinadas, sendo a combinação de cirurgia, radioterapia e quimioterapia presente em 11 clientes (32,3\%), cirurgia e radioterapia realizadas em conjunto em $26,5 \%$ e a combinação de cirurgia e quimioterapia realizadas em 14 clientes $(41,2 \%)$.

Fonte: o próprio autor.

$\mathrm{Na}$ amostra estudada Foram aplicadas escalas para a avaliação de risco de úlcera por pressão, risco de queda, avaliação da dor, avaliação de ansiedade e avaliação de percepção de estresse como descrito na tabela 5. 
Tabela 5: Escalas de avaliação aplicadas aos pacientes oncológicos críticos em protocolo de cuidados paliativos na amostra estudada - Brasília, dezembro 2014 a julho 2015.

\begin{tabular}{|c|c|c|}
\hline Escalas de avaliação & $\mathbf{N}$ & $\%$ \\
\hline \multicolumn{3}{|l|}{ Escala de Braden $(n=34)$} \\
\hline Alto risco para úlcera por pressão & 27 & 79,4 \\
\hline Moderado risco para úlcera por pressão & 7 & 20,6 \\
\hline \multicolumn{3}{|l|}{ Escala de Morse $(n=34)$} \\
\hline Alto risco para quedas & 28 & $\begin{array}{l}82,4 \\
17,6\end{array}$ \\
\hline Moderado risco para quedas & 6 & \\
\hline \multicolumn{3}{|l|}{ Escala Verbal analógica de Dor $(\mathbf{n}=2)$} \\
\hline Dor moderada & 1 & 50 \\
\hline Dor severa & 1 & 50 \\
\hline \multicolumn{3}{|l|}{ Escala comportamental $(\mathrm{BPS})(\mathrm{n}=32)$} \\
\hline Dor presente & 22 & 68,8 \\
\hline Dor ausente & 10 & 31,2 \\
\hline \multicolumn{3}{|c|}{ Escala de Avaliação de Ansiedade (Ham-A) (n=2) } \\
\hline Ansiedade presente & 1 & 50 \\
\hline Ansiedade ausente & 1 & 50 \\
\hline \multicolumn{3}{|l|}{ Escala de Percepção de Estresse (PSS 14) $(n=2)$} \\
\hline Estresse percebido & 2 & 100 \\
\hline
\end{tabular}

Fonte: o próprio autor

Em relação às escalas aplicadas pôde-se observar que na avaliação segundo Braden para o risco de úlcera por pressão, 79,4\% apresentavam alto risco e 20,6\% tinham moderado risco. Não foram observados clientes com baixo risco ou risco ausente.

$\mathrm{Na}$ aplicação da escala de Morse para avaliação do risco de quedas, 82,4\% dos avaliados apresentaram alto risco para quedas e 17,6\% estavam em situação de risco moderado. 
Com relação às escalas para avaliação da dor, foram utilizadas a escala EVA para pacientes conscientes e a BPS para pacientes sedados ou com nível de consciência alterado. Para a EVA foram avaliados dois clientes, sendo observado em um cliente (50\%) dor moderada e em outro (50\%) dor severa. Na aplicação da BPS observou-se em 22 clientes $(64,7 \%)$ dor presente pelas características comportamentais e em 10 clientes $(29,4 \%)$ não apresentavam dor no momento da avaliação.

Sobre a escala de avaliação de ansiedade, esta aplica-se apenas à pacientes conscientes. Sendo assim, esta foi aplicada à apenas dois clientes da amostra estudada, sendo identificado em um cliente (50\%) ansiedade presente e no outro cliente (50\%) ausência de ansiedade. A escala não pode ser aplicada em 32 clientes devido alteração do nível de consciência, confusão mental ou uso contínuo de medicamentos sedativos.

A escala de percepção de estresse não pode ser aplicada em 32 clientes em decorrência da alteração do nível de consciência, confusão mental ou uso contínuo de medicamentos sedativos. Nos clientes em a escala foi aplicada, dois, em ambos foram identificados agentes estressores.

\subsection{Perfil diagnóstico dos clientes oncológicos críticos em protocolo de cuidados} paliativos

A taxonomia da NANDA-I possibilitou o levantamento de 718 diagnósticos de enfermagem ao todo na amostra estudada (34 clientes), com média de 21,11 diagnósticos por paciente. Destes obteve-se um total de 51 diagnósticos diferentes, sendo 38 deles diagnósticos reais e 13 de vulnerabilidade, como apresentado nas tabelas 6 e 7.

Tabela 6: Diagnósticos de enfermagem reais mais frequentes nos pacientes oncológicos críticos em protocolo de cuidados paliativos na amostra estudada $(n=34)$ - Brasília, dezembro 2014 a julho 2015.

\begin{tabular}{l|c|c}
\hline \multicolumn{1}{c}{ Diagnósticos de enfermagem } & \multicolumn{2}{c}{ Frequência } \\
\cline { 2 - 3 } & $\mathrm{N}$ & $\%$ \\
\hline Déficit no autocuidado & 34 & 100 \\
Deglutição prejudicada & 34 & 100 \\
Mobilidade física prejudicada & 34 & 100 \\
Proteção ineficaz & 34 & 100 \\
Eliminação urinária prejudicada & 32 & 94,1 \\
Comunicação verbal prejudicada & 31 & 91,2 \\
Processos familiares disfuncionais & 30 & 88,2 \\
\hline
\end{tabular}


continuação

\begin{tabular}{|c|c|c|}
\hline \multirow{2}{*}{ Diagnósticos de enfermagem } & \multicolumn{2}{|c|}{ Frequência } \\
\hline & $\mathrm{N}$ & $\%$ \\
\hline Dentição prejudicada & 30 & 88,2 \\
\hline Incontinência intestinal & 27 & 79,4 \\
\hline Pesar (família) & 29 & 85,3 \\
\hline Tristeza crônica (família) & 29 & 85,3 \\
\hline Ventilação espontânea prejudicada / Padrão resp. ineficaz & 26 & 76,5 \\
\hline Dor aguda & 23 & 67,6 \\
\hline Volume de líquidos excessivo & 20 & 58,8 \\
\hline Disposição para religiosidade melhorada (família) & 16 & 47,1 \\
\hline Perfusão renal ineficaz & 14 & 41,2 \\
\hline Integridade tissular prejudicada & 12 & 35,3 \\
\hline Conflito de decisão (família) & 12 & 35,3 \\
\hline Desobstrução ineficaz de vias aéreas & 10 & 29,4 \\
\hline Nutrição alterada: menos que as necessidades corporais & 8 & 23,5 \\
\hline Diarreia & 7 & 20,6 \\
\hline Constipação & 5 & 14,7 \\
\hline Troca de gases prejudicada & 5 & 14,7 \\
\hline Hipertermia & 2 & 5,9 \\
\hline Mucosa oral prejudicada & 2 & 5,9 \\
\hline Volume de líquidos deficiente & 2 & 5,9 \\
\hline Ansiedade relacionada à morte (família) & 2 & 5,9 \\
\hline Distúrbio da imagem corporal & 2 & 5,9 \\
\hline Náusea & 2 & 5,9 \\
\hline Atividade de recreação deficiente & 1 & 2,9 \\
\hline Confusão aguda & 1 & 2,9 \\
\hline Débito cardíaco diminuído & 1 & 2,9 \\
\hline Hipotermia & 1 & 2,9 \\
\hline Insônia & 1 & 2,9 \\
\hline Integridade da pele prejudicada & 1 & 2,9 \\
\hline Memória prejudicada & 1 & 2,9 \\
\hline Obesidade & 1 & 2,9 \\
\hline Desesperança (família) & 1 & 2,9 \\
\hline
\end{tabular}

Fonte: o próprio autor

Encontra-se na Tabela 7 os dados relativos à distribuição dos diagnósticos de enfermagem de vulnerabilidade, ou seja, dos diagnósticos de risco elaborados junto à clientela estudada. 
Tabela 7: Diagnósticos de enfermagem de vulnerabilidade mais frequentes nos pacientes oncológicos críticos em protocolo de cuidados paliativos na amostra estudada ( $n=34)$ - Brasília, dezembro 2014 a julho 2015.

\begin{tabular}{l|c|c}
\hline \multirow{2}{*}{\multicolumn{1}{c|}{ Diagnósticos de enfermagem }} & \multicolumn{2}{c}{ Frequência } \\
\cline { 2 - 3 } & $\mathrm{N}$ & $\%$ \\
\hline Risco de aspiração & 34 & 100 \\
Risco de quedas & 34 & 100 \\
Risco de sangramento & 33 & 97,1 \\
Risco de síndrome do desuso & 32 & 94,1 \\
Risco de olho seco & 31 & 91,2 \\
Risco de integridade da pele prejudicada & 21 & 61,8 \\
Risco de perfusão tissular cerebral ineficaz & 3 & 8,8 \\
Risco de infecção & 2 & 5,9 \\
Risco de choque & 1 & 2,9 \\
Risco de confusão aguda & 1 & 2,9 \\
Risco de desequilíbrio eletrolítico & 1 & 2,9 \\
Risco de nutrição desequilibrada menos que as necessidades & 1 & 2,9 \\
Risco de volume de líquidos desequilibrado & 1 & 2,9 \\
& \multicolumn{2}{c}{} \\
\hline
\end{tabular}

Fonte: o próprio autor

Dos diagnósticos de enfermagem identificados na amostra estudada, 20 deles apresentaram frequências superiores à 50\%, sendo 14 diagnósticos reais e 6 diagnósticos de risco ou vulnerabilidade. Os diagnósticos com frequências iguais a 100\% foram: Déficit no autocuidado, Deglutição prejudicada, Mobilidade física prejudicada, Proteção ineficaz, Risco de quedas e Risco de aspiração. O diagnóstico Risco de sangramento esteve presente em 33 clientes $(97,1 \%)$. Os diagnósticos de Eliminação urinária prejudicada, Risco de síndrome do desuso apresentarem-se em 32 (94,1\%) dos clientes avaliados no estudo. Comunicação verbal prejudicada e Risco de olho seco estiveram presentes em 31 clientes (91,2\%); Processos familiares disfuncionais e Dentição prejudicada em 30 clientes (88,2\%); Pesar e Tristeza crônica foram identificados em 29 clientes (85,3\%); a Incontinência intestinal apresentou-se em 27 clientes (79,4\%); Ventilação espontânea prejudicada/Padrão respiratório ineficaz em 26 (76,5\%); Dor aguda em 23 clientes (67,6\%); Risco de integridade da pele prejudicada esteve presente em 21 clientes $(61,8 \%)$ da amostra; e diagnóstico Volume de líquidos excessivo esteve presente em 20 clientes $(58,8 \%)$ da amostra. 
Observou-se que 31 diagnósticos de enfermagem apresentaram frequência menor que $50 \%$ na amostra estudada, sendo que 24 foram diagnósticos reais e sete diagnósticos de risco. Foram eles: disposição para religiosidade melhorada $(47,1 \%)$, perfusão renal ineficaz (41,2\%), conflito de decisão (família) (35,3\%), nutrição alterada: menos que as necessidades corporais (23,5\%), Desobstrução ineficaz das vias aéreas $(29,4 \%)$, integridade tissular prejudicada $(20,7 \%)$, diarreia $(20,3 \%)$, constipação $(14,7 \%)$, troca de gases prejudicada $(14,7 \%)$, risco de perfusão tissular cerebral ineficaz $(8,8 \%)$, mucosa oral prejudicada $(5,9 \%)$, volume de líquidos deficiente $(5,9 \%)$, ansiedade relacionada à morte $(5,9 \%)$, distúrbio da imagem corporal $(5,9 \%)$, náusea $(5,9 \%)$, risco de infecção $(5,9 \%)$, hipertermia $(3,4 \%)$, atividade de recreação deficiente $(2,9 \%)$, obesidade $(2,9 \%)$, débito cardíaco diminuído $(2,9 \%)$, hipotermia $(2,9 \%)$ insônia $(2,9 \%)$, integridade da pele prejudicada $(2,9 \%)$, confusão aguda $(2,9 \%)$, memória prejudicada $(2,9 \%)$, desesperança $(2,9 \%)$, risco de choque $(2,9 \%)$, risco de confusão aguda (2,9\%), risco de desequilíbrio eletrolítico $(2,9 \%)$, risco de nutrição desequilibrada menos que as necessidades $(2,9 \%)$, risco de volume de líquidos desequilibrado $(2,9 \%)$.

$\mathrm{Na}$ perspectiva dos três sistemas mencionados por King, observou-se que os diagnósticos encontrados contemplaram todos os sistemas propostos, e estão divididos de forma percentual na tabela 8 (a seguir) e ilustrados na figura 11.

Tabela 8: Distribuição dos diagnósticos de enfermagem reais da NANDA-I, conforme os sistemas de King, na amostra estudada $(n=34)$ - Brasília, dezembro 2014 a julho 2015.

\begin{tabular}{l|l|cr}
\hline \multirow{2}{*}{ Sistemas } & \multicolumn{2}{c}{ Diagnósticos de enfermagem } & \multicolumn{2}{c}{ Frequência } \\
\cline { 3 - 4 } & & $\mathrm{N}$ & $\%$ \\
\hline \multirow{2}{*}{} & Déficit no autocuidado & 34 & 100 \\
& Deglutição prejudicada & 34 & 100 \\
& Mobilidade física prejudicada & 34 & 100 \\
& Proteção ineficaz & 34 & 100 \\
& Risco de aspiração & 34 & 100 \\
& Risco de quedas & 34 & 100 \\
& Risco de sangramento & 33 & 97,1 \\
& Eliminação urinária prejudicada & 32 & 94,1 \\
& Risco de síndrome do desuso & 32 & 94,1 \\
& Risco de olho seco & 31 & 91,2 \\
& Dentição prejudicada & 30 & 88,2 \\
& Incontinência intestinal & 27 & 79,4 \\
& Ventilação espontânea prejudicada / Padrão resp.ineficaz & 26 & 76,5 \\
& Dor aguda & 23 & 67,6 \\
\hline
\end{tabular}

continua 
Continuação

\begin{tabular}{|c|c|c|c|}
\hline \multirow{2}{*}{ Sistemas } & \multirow{2}{*}{ Diagnósticos de enfermagem } & \multicolumn{2}{|c|}{ Frequência } \\
\hline & & $\mathrm{N}$ & $\%$ \\
\hline & Risco de integridade da pele prejudicada & 21 & 61,8 \\
\hline & Volume de líquidos excessivo & 20 & 58,8 \\
\hline & Perfusão renal ineficaz & 14 & 41,2 \\
\hline & Desobstrução ineficaz de vias aéreas & 10 & 29,4 \\
\hline & Integridade tissular prejudicada & 12 & 20,7 \\
\hline & Nutrição alterada: menos que as necessidades corporais & 8 & 23,5 \\
\hline & Diarreia & 7 & 20,6 \\
\hline & Constipação & 5 & 14,7 \\
\hline & Troca de gases prejudicada & 5 & 14,7 \\
\hline & Risco de perfusão tissular cerebral ineficaz & 3 & 8,8 \\
\hline & Hipertermia & 2 & 5,9 \\
\hline & Mucosa oral prejudicada & 2 & 5,9 \\
\hline & Risco de infecção & 2 & 5,9 \\
\hline & Volume de líquidos deficiente & 2 & 5,9 \\
\hline & Distúrbio da imagem corporal & 2 & 5,9 \\
\hline & Náusea & 2 & 5,9 \\
\hline & Confusão aguda & 1 & 2,9 \\
\hline & Débito cardíaco diminuído & 1 & 2,9 \\
\hline & Hipotermia & 1 & 2,9 \\
\hline & Insônia & 1 & 2,9 \\
\hline & Integridade da pele prejudicada & 1 & 2,9 \\
\hline & Memória prejudicada & 1 & 2,9 \\
\hline & Obesidade & 1 & 2,9 \\
\hline & Risco de choque & 1 & 2,9 \\
\hline & Risco de confusão aguda & 1 & 2,9 \\
\hline & Risco de desequilíbrio eletrolítico & 1 & 2,9 \\
\hline & Risco de nutrição desequilibrada menos que as necessidades & 1 & 2,9 \\
\hline & Risco de volume de líquidos desequilibrado & 1 & 2,9 \\
\hline \multirow{7}{*}{ Interpessoal } & Processos familiares disfuncionais (família) & 30 & 88,2 \\
\hline & Pesar (família) & 29 & 85,3 \\
\hline & Tristeza crônica (família) & 29 & 85,3 \\
\hline & Ansiedade relacionada à morte (família) & 2 & 5,9 \\
\hline & Atividade de recreação deficiente & 1 & 2,9 \\
\hline & Desesperança (família) & 1 & 2,9 \\
\hline & Comunicação verbal prejudicada & 31 & 91,2 \\
\hline \multirow{2}{*}{ Social } & Disposição para religiosidade melhorada (família) & 16 & 47,1 \\
\hline & Conflito de decisão (família) & 12 & 35,3 \\
\hline
\end{tabular}

Fonte: o próprio autor 
Figura 11: Distribuição dos diagnósticos de enfermagem segundo os Sistemas Pessoal, Interpessoal e Social dos clientes oncológicos críticos em cuidados paliativos (n= 34) - Brasília, dezembro 2014 a julho 2015.

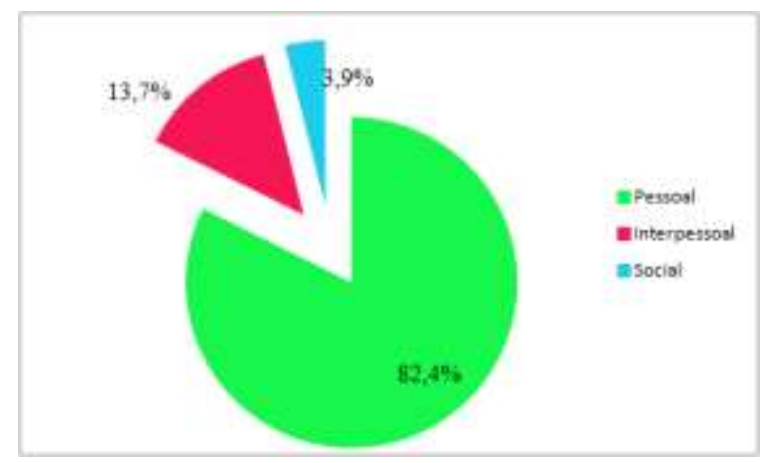

Fonte: o próprio autor

Conforme pode ser observado na tabela 8 e na figura 11, houve prevalência dos diagnósticos vinculados ao sistema pessoal, 42 diagnósticos $(82,4 \%)$, seguido do sistema interpessoal com 7 diagnósticos $(13,7 \%)$ e do sistema social, dois diagnósticos representando 3,9\%. A maior prevalência foi de diagnósticos do sistema pessoal.

A Tabela 9 apresenta a distribuição dos diagnósticos de enfermagem da NANDA-I por domínios, conforme a taxonomia atual da NANDA-I.

Tabela 9: Distribuição dos diagnósticos de enfermagem reais da NANDA-I, por domínios, na amostra estudada $(n=34)$ - Brasília, dezembro 2014 a julho 2015.

Distribuição dos diagnósticos de enfermagem reais da NANDA-I por domínio

\section{Promoção da saúde}

Proteção ineficaz

Atividade de recreação deficiente

\section{Total Diagnósticos arrolados $\quad 35$}

\section{Nutrição}

Deglutição prejudicada

100,0

Volume de líquidos excessivo

$\begin{array}{ll}34 & 100,0 \\ 20 & 83,3\end{array}$

Nutrição alterada: menos que as necessidades corporais

8

Volume de líquidos deficiente

23,5

Obesidade

2,9

12,9 
continuação

\section{Distribuição dos diagnósticos de enfermagem reais da NANDA-I}

$\mathbf{N}$

$\%$

\section{Eliminação e troca}

Eliminação urinária prejudicada

Incontinência intestinal

Diárreia

Constipação

Troca de gases prejudicada
94,1

79,4

20,6

14,7

14,7

Total Diagnósticos arrolados

Atividade /Repouso

Déficit no auto cuidado (alimentação, banho, higiene intima, vestir-se)

$\begin{array}{cc}34 & 100,0 \\ 34 & 100,0 \\ 26 & \\ & 76,5 \\ 14 & 41,2 \\ 1 & 2,9 \\ 1 & 2,9\end{array}$

Total Diagnósticos arrolados

\section{Percepção / Cognição}

Comunicação verbal prejudicada

Confusão aguda

12,9

Memória prejudicada

Total Diagnósticos arrolados

\section{Autopercepção}

Distúrbio da imagem corporal

Desesperança

\section{Papéis e relacionamentos}


continuação

\begin{tabular}{lcc}
\hline $\begin{array}{l}\text { Distribuição dos diagnósticos de enfermagem reais da NANDA-I } \\
\text { por domínio }\end{array}$ & N & \% \\
\hline Enfrentamento / Tolerância ao estresse & & \\
$\quad$ Pesar (família) & 29 & 85,3 \\
Tristeza crônica (família) & 29 & 85,3 \\
Ansiedade relacionada a morte (família) & 2 & 5,9 \\
$\quad$ Total Diagnósticos arrolados & $\mathbf{6 0}$
\end{tabular}

\section{Princípios da vida}

$\begin{array}{lll}\text { Disposição para religiosidade melhorada (família) } & 16 & 47,1 \\ \text { Conflito de decisão (família) } & 12 & 35,3\end{array}$

Total Diagnósticos arrolados $\quad 28$

$\begin{array}{lcc}\text { Segurança e proteção } & & \\ \text { Dentição prejudicada } & 30 & 88,2 \\ \text { Integridade tissular prejudicada } & 12 & 35,3 \\ \text { Desobstrução ineficaz de vias aéreas } & 10 & 29,4 \\ \text { Hipertermia } & 2 & 5,9 \\ \text { Mucosa oral prejudicada } & 2 & 5,9 \\ \text { Hipotermia } & 1 & 2,9 \\ \text { Integridade da pele prejudicada } & 1 & 2,9\end{array}$

Total Diagnósticos arrolados $\quad \mathbf{5 8}$

\section{Conforto}

$\begin{array}{lll}\text { Dor aguda } & 23 & 67,6\end{array}$

$\begin{array}{lll}\text { Náuseas } & 2 & 5,9\end{array}$

Total Diagnósticos arrolados 25

Fonte: o próprio autor

No domínio Promoção da Saúde são descritos na NANDA-I 12 diagnósticos. No estudo foram identificados apenas dois reais, a Proteção ineficaz (100\%) e a Atividade de recreação deficiente $(2,9 \%)$.

No domínio Nutrição são descritos na NANDA-I 21 diagnósticos. No estudo foram identificados apenas cinco reais, sendo eles: Deglutição prejudicada (100\%), Volume de líquidos excessivo (83,3\%), Nutrição alterada: menos que as necessidades corporais $(23,5 \%)$, Volume de líquidos deficiente $(5,9 \%)$ e Obesidade $(2,9 \%)$. 
No domínio Eliminação e troca são descritos na NANDA-I 19 diagnósticos. No estudo foram identificados apenas cinco, sendo eles: Eliminação urinária prejudicada $(94,1 \%)$, Incontinência intestinal (79,4\%), Diárreia (20,6\%), Constipação $(14,7 \%)$ e Troca de gases prejudicada $(14,7 \%)$.

No domínio Atividade/Repouso são descritos na NANDA-I 35 diagnósticos. No estudo foram identificados apenas 6 reais, sendo eles: Déficit no autocuidado (100\%), Mobilidade física prejudicada (100\%), Ventilação espontânea prejudicada/ Padrão respiratório ineficaz (76,5\%), Perfusão renal ineficaz (41,2\%), Débito cardíaco diminuído (2,9\%) e Insônia $(2,9 \%)$.

No domínio Percepção/Cognição são descritos na NANDA-I 12 diagnósticos. No estudo foram identificados três reais, sendo eles a Comunicação verbal prejudicada $(91,2 \%)$, Confusão aguda (2,9\%) e Memória prejudicada $(2,9 \%)$.

No domínio Autopercepção são descritos na NANDA-I 11 diagnósticos. No estudo foram identificados apenas dois, sendo eles o Distúrbio da imagem corporal $(5,9 \%)$ e a Desesperança $(2,9 \%)$.

No domínio Papéis e relacionamentos são descritos na NANDA-I 15 diagnósticos. No estudo foram identificados apenas um, Processos familiares disfuncionais $(88,2 \%)$.

No domínio Enfrentamento/Tolerância ao estresse são descritos na NANDA-I 37 diagnósticos. No estudo foram identificados apenas três, sendo eles: Pesar (85,3\%), Tristeza crônica $(85,3 \%)$ e Ansiedade relacionada à morte (5,9\%).

No domínio Princípios da vida são descritos na NANDA-I 12 diagnósticos. No estudo foram identificados apenas dois, sendo eles a Disposição para religiosidade melhorada $(47,1 \%)$ e o Conflito de decisão $(35,3 \%)$.

No domínio Segurança e proteção são descritos na NANDA-I 45 diagnósticos. No estudo foram identificados 7 diagnósticos reais, sendo eles a Dentição prejudicada $(88,2 \%)$, Integridade tissular prejudicada (35,3\%), Desobstrução ineficaz de vias aéreas $(29,4 \%)$, Hipertermia (5,9\%), Mucosa oral prejudicada (5,9\%), Hipotermia $(2,9 \%)$ e Integridade da pele prejudicada $(2,9 \%)$.

No domínio Conforto são descritos na NANDA-I 13 diagnósticos. No estudo foram identificados apenas dois, sendo eles a Dor aguda $(67,6 \%)$ e a Náusea $(5,9 \%)$.

Quanto aos diagnósticos de vulnerabilidade e suas relações com os domínios da NANDA-I, os resultados estão apresentados na tabela 10, a seguir. 
Tabela 10: Distribuição dos diagnósticos de enfermagem de risco da NANDA-I, por domínios, na amostra estudada (n=34) - Brasília, dezembro 2014 a julho 2015.

\begin{tabular}{lll}
\hline $\begin{array}{l}\text { Distribuição dos diagnósticos de enfermagem de risco da NANDA-I por } \\
\text { domínio }\end{array}$ & $\mathbf{N}$ & $\mathbf{\%}$ \\
\hline & & \\
Nutrição & 1 & 2,9 \\
$\quad$ Risco de nutrição desequilibrada menos que as necessidades & 1 & 2,9 \\
$\quad$ Risco de volume de líquidos desequilibrado & 1 & 2,9
\end{tabular}

Total Diagnósticos arrolados 3

\section{Atividade /Repouso}

Risco de síndrome do desuso

Risco de perfusão tissular cerebral ineficaz

Total Diagnósticos arrolados

\section{Percepção / Cognição}

Risco de confusão aguda

Total Diagnósticos arrolados

\section{Segurança e proteção}

Risco de aspiração
Risco de quedas
Risco de sangramento
Risco de olho seco
Risco de integridade da pele prejudicada
Risco de infecção
Risco de choque

$\begin{array}{cc}34 & 100,0 \\ 34 & 100,0 \\ 33 & 97,1 \\ 31 & 91,2 \\ 21 & 61,8 \\ 2 & 5,9 \\ 1 & 2,9\end{array}$

Total Diagnósticos arrolados

\section{Fonte: o próprio autor}

No domínio Nutrição são descritos na NANDA-I 12 diagnósticos. No estudo foram identificados apenas três diagnósticos de risco, o Risco de nutrição desequilibrada menos que as necessidades corporais (2,9\%), o Risco de volume de líquidos desequilibrado (2,9\%) e o Risco de desequilíbrio eletrolítico (2,9\%).

No domínio Atividade / Repouso são descritos na NANDA-I 35 diagnósticos. No estudo foram identificados apenas dois diagnósticos de risco, o Risco de síndrome do desuso $(94,1 \%)$ e o Risco de perfusão tissular cerebral ineficaz $(8,8 \%)$. 
No domínio Percepção / Cognição são descritos na NANDA-I 12 diagnósticos. No estudo foi identificado apenas um diagnóstico de risco dentro deste domínio, o Risco de confusão aguda $(2,9 \%)$.

No domínio Segurança e proteção são descritos na NANDA-I 45 diagnósticos. No estudo foram identificados 7 diagnósticos de risco, sendo eles o Risco de aspiração (100\%), Risco de quedas (100\%), Risco de sangramento (97,1\%), Risco de olho seco (91,2\%), o Risco de integridade da pele prejudicada $(61,8 \%)$, Risco de infecção $(5,9 \%)$ e Risco de choque $(2,9 \%)$.

$\mathrm{Na}$ Tabela 11 são apresentadas as características definidoras dos diagnósticos de maior prevalência na amostra estudada.

Tabela 11: Distribuição das frequências das características definidoras para os diagnósticos de enfermagem com frequências iguais ou superiores a 50\%, segundo a NANDA-I - Brasília, dezembro 2014 a julho 2015.

\begin{tabular}{|c|c|c|c|}
\hline \multirow{2}{*}{ Diagnóstico } & \multirow{2}{*}{ Características definidoras } & \multicolumn{2}{|c|}{ Frequência } \\
\hline & & $\mathrm{N}$ & $\%$ \\
\hline $\begin{array}{l}\text { Déficit no autocuidado }(\mathrm{n}=34) \\
\text { (alimentação, banho, higiene } \\
\text { intima, vestir-se) }\end{array}$ & $\begin{array}{l}\text { Capacidade prejudicada de realizar } \\
\text { atividades de autocuidado } \\
\text { Capacidade prejudicada de ingerir / engolir } \\
\text { alimentos }\end{array}$ & 34 & $\begin{array}{l}100,0 \\
100,0\end{array}$ \\
\hline \multirow[t]{2}{*}{ Deglutição prejudicada $(\mathrm{n}=34)$} & Dificuldade para deglutir & 34 & 100,0 \\
\hline & Incapacidade de limpar a cavidade oral & 34 & 100,0 \\
\hline $\begin{array}{l}\text { Mobilidade física prejudicada } \\
(\mathrm{n}=34)\end{array}$ & Redução das habilidades motoras & 34 & 100,0 \\
\hline \multirow[t]{8}{*}{ Proteção ineficaz $(n=34)$} & Prejuízo neurosensorial & 29 & 85,3 \\
\hline & Imobilidade & 28 & 82,4 \\
\hline & Alteração da coagulação & 16 & 47,1 \\
\hline & Dispnéia & 12 & 35,3 \\
\hline & Deficiência na imunidade & 12 & 35,3 \\
\hline & Úlcera por pressão & 8 & 23,5 \\
\hline & Desorientação & 4 & 11,8 \\
\hline & Fraqueza & 2 & 5,9 \\
\hline $\begin{array}{l}\text { Eliminação urinária prejudicada } \\
(\mathrm{n}=32)\end{array}$ & Incontinência urinária & 32 & 100,0 \\
\hline
\end{tabular}


continuação

\begin{tabular}{|c|c|c|c|}
\hline \multirow{2}{*}{ Diagnóstico } & \multirow{2}{*}{ Características definidoras } & \multicolumn{2}{|c|}{ Frequência } \\
\hline & & $\mathrm{N}$ & $\%$ \\
\hline \multirow[t]{2}{*}{$\begin{array}{l}\text { Comunicação verbal prejudicada } \\
(\mathrm{n}=31)\end{array}$} & Não consegue falar & 31 & 100,0 \\
\hline & Ausência de contato visual & 29 & 93,5 \\
\hline \multirow[t]{4}{*}{$\begin{array}{l}\text { Processos familiares } \\
\text { disfuncionais }(n=30)\end{array}$} & $\begin{array}{l}\text { Habilidade insuficiente para solucionar } \\
\text { problemas }\end{array}$ & 20 & 66,7 \\
\hline & Padrão contraditório de comunicação & 12 & 40,0 \\
\hline & $\begin{array}{l}\text { Incapacidade de lidar experiências } \\
\text { traumáticas de forma construtiva }\end{array}$ & 10 & 33,3 \\
\hline & Expressão inapropriada de raiva & 5 & 16,7 \\
\hline \multirow[t]{3}{*}{ Dentição prejudicada $(n=30)$} & Halitose & 24 & 80,0 \\
\hline & Ausência de dentes & 26 & 46,7 \\
\hline & Dentes desgastados & 12 & 40,0 \\
\hline \multirow[t]{4}{*}{ Pesar $(n=29)$} & Sofrimento psicológico & 29 & 100,0 \\
\hline & Desespero & 20 & 69,0 \\
\hline & Desorganização & 14 & 48,3 \\
\hline & Afastamento & 5 & 17,2 \\
\hline \multirow[t]{2}{*}{ Tristeza crônica $(n=29)$} & Relato de sentimentos negativos & 21 & 72,4 \\
\hline & Tristeza & 12 & 41,4 \\
\hline \multirow[t]{3}{*}{ Incontinência intestinal $(n=27)$} & Odor fecal & 27 & 100,0 \\
\hline & Manchas de fezes (fralda) & 27 & 100,0 \\
\hline & Passagem constante de fezes amolecidas & 20 & 74,1 \\
\hline \multirow{4}{*}{$\begin{array}{l}\text { Ventilação espontânea } \\
\text { prejudicada / Padrão } \\
\text { resp.ineficaz }(\mathrm{n}=26)\end{array}$} & Padrão respiratório anormal & 26 & 100,0 \\
\hline & Uso de musculatura acessória para respirar & 18 & 69,2 \\
\hline & Dispnéia & 10 & 38,5 \\
\hline & Frequência cardíaca aumentada & 3 & 11,5 \\
\hline
\end{tabular}


Continuação

\begin{tabular}{|c|c|c|c|}
\hline \multirow{2}{*}{ Diagnóstico } & \multirow{2}{*}{ Características definidoras } & \multicolumn{2}{|c|}{ Frequência } \\
\hline & & $\mathrm{N}$ & $\%$ \\
\hline \multirow[t]{3}{*}{ Dor aguda $(n=23)$} & $\begin{array}{l}\text { Evidência de dor usando lista padronizada } \\
\text { (escala) }\end{array}$ & 21 & 91,3 \\
\hline & Expressão facial & 21 & 91,3 \\
\hline & $\begin{array}{l}\text { Autorrelato de intensidade usando escala } \\
\text { padronizada }\end{array}$ & 2 & 8,7 \\
\hline \multirow[t]{5}{*}{$\begin{array}{l}\text { Volume de líquidos excessivo } \\
(\mathrm{n}=20)\end{array}$} & Edema & 18 & 90,0 \\
\hline & Hematócrito diminuído & 16 & 80,0 \\
\hline & Hemoglobina diminuída & 16 & 80,0 \\
\hline & Dispnéia & 10 & 50,0 \\
\hline & Desequilíbrio eletrolítico & 8 & 40,0 \\
\hline
\end{tabular}

Fonte: o próprio autor.

Para o diagnóstico de Proteção ineficaz, que esteve presente em 100\% da amostra, foram identificadas as características definidoras diversas, entre elas as com maior prevalência destacam-se o prejuízo neurosensorial, em 29 clientes $(85,3 \%)$, a imobilidade em 28 clientes (82,4\%), a alteração da coagulação em 16 clientes (47,1\%), a dispnéia em 12 clientes $(35,3 \%)$ e a deficiência na imunidade em 12 clientes $(35,3 \%)$. Houve ainda outras características definidoras levantadas, como apresentado na tabela 8 , embora com frequência menor que $30 \%$.

Para a Deglutição prejudicada, presente também em $100 \%$ da amostra, as características definidoras encontradas foram a dificuldade para deglutir (100\%), bem como a incapacidade de limpar a cavidade oral (100\%).

As características definidoras de maior prevalência para o diagnóstico de Déficit no autocuidado, presente também em $100 \%$ da amostra, foram a incapacidade de realizar atividades de autocuidado presente em 34 clientes (100\%) e a capacidade prejudicada de realizar atividades de autocuidado e a capacidade prejudicada de ingerir/engolir alimentos identificada em 34 clientes (100\%).

Observou-se que $100 \%$ da amostra apresentou o diagnóstico de Mobilidade física prejudicada, tendo como característica definidora a redução das habilidades motoras em 34 clientes $(100 \%)$. 
Para o diagnóstico de Eliminação urinária prejudicada, a característica definidora foi a Incontinência, presente em 32 clientes.

Observou-se que para o diagnóstico de Comunicação verbal prejudicada, as características definidoras de maior prevalência foram: não consegue falar, observado em 31 clientes e a ausência de contato visual presente em 29 clientes.

Nos clientes que apresentaram familiares com diagnóstico de Processos familiares disfuncionais (30 clientes), observou-se como característica definidora: habilidades insuficientes para solucionar problemas $(66,7 \%)$, o padrão de comunicação contraditória (40\%), a incapacidade de lidar com experiências traumáticas $(33,3 \%)$ e a expressão inapropriada de raiva $(16,7 \%)$.

Nos clientes que apresentaram o diagnóstico de Dentição prejudicada, as características definidoras observadas foram a halitose (80\%), a ausência de dentes $(46,7 \%)$ e a presença de dentes desgastados.

Observou-se que para o diagnóstico de Pesar, as características definidoras de maior prevalência foram: sofrimento psicológico, observado nas famílias de 29 clientes, o desespero presente em 20 famílias, a desorganização observada em 14 famílias e o afastamento que esteve presente na família de cinco clientes.

Nos clientes que apresentaram familiares com diagnóstico de Tristeza crônica (29 clientes), observou-se como características definidoras: o relato de sentimento negativos $(72,4 \%)$ e a tristeza $(41,4 \%)$.

Nos clientes que apresentaram diagnóstico de Incontinência intestinal (27 clientes), observou-se como características definidoras: o odor fecal (100\%), as manchas de fezes (100\%) observadas nas fraldas ou bolsas de colostomia, bem como a passagem constante de fezes amolecidas $(74,1 \%)$.

Observou-se que para o diagnóstico de Ventilação espontânea prejudicada/Padrão respiratório ineficaz, as características definidoras de maior prevalência foram: padrão respiratório anormal, presente em 26 clientes, uso de musculatura acessória para respirar observada em 18 clientes, dispnéia presente em 10 clientes e frequência cardíaca aumentada que foi observada em três clientes.

Observou-se que para o diagnóstico de Dor aguda, presente em 23 clientes, foram elaboradas as características definidoras: evidência de dor usando lista padronizada $(91,3 \%)$, expressão facial $(91,3 \%)$ e ainda o autorrelato de intensidade usando escala padronizada $(8,7 \%)$. 
Nos clientes que apresentaram o diagnóstico de Volume de líquido excessivo (20 clientes), observou-se como características definidoras: o edema (90\%), o hematócrito diminuído (80\%), a hemoglobina diminuída (80\%), a dispnéia (50\%) e ainda o desequilíbrio eletrolítico $(40 \%)$.

Nas Tabelas 12 e 13 estão apresentados os fatores relacionados e os fatores de risco para os diagnósticos mais prevalentes na amostra estudada.

Tabela 12: Distribuição das frequências dos fatores relacionados para os diagnósticos de enfermagem com frequências iguais ou superiores à 50\%, segundo a NANDA-I - Brasília, dezembro 2014 a julho 2015.

\begin{tabular}{|c|c|c|c|}
\hline \multirow{2}{*}{ Diagnóstico } & \multirow{2}{*}{ Fatores relacionados } & \multicolumn{2}{|c|}{ Frequência } \\
\hline & & $\mathrm{N}$ & $\%$ \\
\hline \multirow[t]{2}{*}{ Déficit no autocuidado $(\mathrm{n}=34)$} & Prejuízo neuromuscular & 29 & 85,3 \\
\hline & Prejuízo perceptivo & 5 & 14,7 \\
\hline \multirow[t]{3}{*}{ Deglutição prejudicada $(n=34)$} & Alteração na função cognitiva & 30 & 88,2 \\
\hline & $\begin{array}{l}\text { História de alimentação por sonda } \\
\text { Obstrução mecânica (entubação, } \\
\text { traqueostomia) }\end{array}$ & 29 & 85,3 \\
\hline & Condição respiratória & 26 & 76,5 \\
\hline
\end{tabular}

Mobilidade física prejudicada

$$
(n=34)
$$

Prejuízos neuromusculares

Agente farmacológico

Prejuízo sensório-perceptivo
29

29

5
85,3

85,3

14,7

\begin{tabular}{llcc} 
Proteção ineficaz $(\mathrm{n}=34)$ & Câncer & 34 & 100,0 \\
& Regime de tratamento & 28 & 82,4 \\
& Extremo de idade & 28 & 82,4 \\
& Perfil sanguíneo anormal & 21 & 61,8 \\
& Distúrbios imunológicos & 15 & 44,1 \\
& Nutrição inadequada & 9 & 26,5 \\
\hline Eliminação urinária prejudicada & Dano sensório-motor & 32 & 94,1 \\
$(\mathrm{n}=32)$ & Infecção no trato urinário & 4 & 11,8 \\
\hline
\end{tabular}


continuação

\begin{tabular}{|c|c|c|c|}
\hline \multirow{2}{*}{ Diagnóstico } & \multirow{2}{*}{ Fatores relacionados } & \multicolumn{2}{|c|}{ Frequência } \\
\hline & & $\mathrm{N}$ & $\%$ \\
\hline \multirow[t]{3}{*}{$\begin{array}{l}\text { Comunicação verbal prejudicada } \\
(n=31)\end{array}$} & Prejuízo no sistema nervoso central & 31 & 91,2 \\
\hline & Regime de tratamento & 29 & 85,3 \\
\hline & $\begin{array}{l}\text { Barreira física (entubação ou } \\
\text { traqueostomia) }\end{array}$ & 29 & 85,3 \\
\hline $\begin{array}{l}\text { Processos familiares disfuncionais } \\
(\mathrm{n}=30)\end{array}$ & $\begin{array}{l}\text { Habilidade insuficiente de solucionar } \\
\text { problemas }\end{array}$ & 30 & 88,2 \\
\hline \multirow[t]{2}{*}{ Dentição prejudicada $(\mathrm{n}=30)$} & $\begin{array}{l}\text { Dificuldade de acesso a cuidados } \\
\text { dentários profissionais }\end{array}$ & 12 & 35,3 \\
\hline & Economicamente desfavorecido & 10 & 29,4 \\
\hline Pesar $(n=29)$ & $\begin{array}{l}\text { Antecipação da perda de pessoa } \\
\text { significativa }\end{array}$ & 29 & 85,3 \\
\hline \multirow[t]{2}{*}{ Tristeza crônica $(n=29)$} & Morte de uma pessoa amada & 29 & 85,3 \\
\hline & Crise no controle da enfermidade & 22 & 64,7 \\
\hline \multirow{6}{*}{ Incontinência intestinal (n=27) } & $\begin{array}{l}\text { Déficit no autocuidado (higiene } \\
\text { intima) }\end{array}$ & 27 & 79,4 \\
\hline & Imobilidade & 27 & 79,4 \\
\hline & Agentes farmacológicos & 27 & 79,4 \\
\hline & Lesão colorretal & 4 & 11,8 \\
\hline & Diárreia crônica & 4 & 11,8 \\
\hline & Alteração na função cognitiva & 2 & 5,9 \\
\hline \multirow{5}{*}{$\begin{array}{l}\text { Ventilação espontânea prejudicada } \\
\text { / Padrão resp.ineficaz }(n=26)\end{array}$} & Doença pulmonar & 28 & 84,6 \\
\hline & $\begin{array}{l}\text { Dano musculoesquelético, neurológico } \\
\text { e fadiga respiratória }\end{array}$ & 26 & 76,5 \\
\hline & Infecção* & 26 & 76,5 \\
\hline & Prejuízo neuromuscular & 26 & 76,5 \\
\hline & Alteração no metabolismo & 12 & 35,3 \\
\hline
\end{tabular}


continuação

\begin{tabular}{|c|c|c|c|}
\hline \multirow{2}{*}{ Diagnóstico } & \multirow{2}{*}{ Fatores relacionados } & \multicolumn{2}{|c|}{ Frequência } \\
\hline & & $\mathrm{N}$ & $\%$ \\
\hline Dor aguda $(n=23)$ & Agente lesivo & 23 & 67,6 \\
\hline $\begin{array}{l}\text { Volume de líquidos excessivo } \\
(\mathrm{n}=20)\end{array}$ & Mecanismo regulador comprometido & 20 & 58,8 \\
\hline
\end{tabular}

Fonte: o próprio autor

Tabela 13: Distribuição das frequências dos fatores de risco para os diagnósticos de enfermagem com frequências iguais ou superiores à 50\%, segundo a NANDA-I - Brasília, dezembro 2014 a julho 2015.

\begin{tabular}{|c|c|c|c|}
\hline \multirow{2}{*}{ Diagnóstico } & \multirow{2}{*}{ Fatores de Risco } & \multicolumn{2}{|c|}{ Frequência } \\
\hline & & $\mathrm{N}$ & $\%$ \\
\hline \multirow[t]{3}{*}{ Risco de aspiração $(n=34)$} & Capacidade de deglutição prejudicada & 34 & 100,0 \\
\hline & Alimentação enteral & 29 & 85,3 \\
\hline & Resíduo gástrico aumentado & 8 & 23,5 \\
\hline \multirow{3}{*}{ Risco de quedas $(\mathrm{n}=34)$} & Neoplasia & 34 & 100,0 \\
\hline & Mobilidade prejudicada & 30 & 88,2 \\
\hline & Idade acima de 65 anos & 26 & 76,4 \\
\hline \multirow[t]{2}{*}{ Risco de sangramento $(n=33)$} & Regime de tratamento & 29 & 85,3 \\
\hline & Função hepática prejudicada & 12 & 35,3 \\
\hline \multirow[t]{2}{*}{$\begin{array}{l}\text { Risco de síndrome do desuso } \\
(\mathrm{n}=32)\end{array}$} & Imobilização & 29 & 85,3 \\
\hline & Nível de consciência alterada & 5 & 14,7 \\
\hline \multirow[t]{3}{*}{ Risco de olho seco $(n=31)$} & Regime de tratamento & 29 & 85,3 \\
\hline & Ventilação mecânica & 29 & 85,3 \\
\hline & Envelhecimento & 28 & 82,4 \\
\hline \multirow{5}{*}{$\begin{array}{l}\text { Risco de integridade da pele } \\
\text { prejudicada }(n=21)\end{array}$} & $\begin{array}{l}\text { Fatores mecânicos (pressão, } \\
\text { imobilidade) }\end{array}$ & 21 & 61,8 \\
\hline & Pressão sobre saliência óssea & 21 & 61,8 \\
\hline & $\begin{array}{l}\text { Pontuação obtida na Escala de } \\
\text { Braden* }\end{array}$ & 21 & 61,8 \\
\hline & Extremos de idade & 21 & 61,8 \\
\hline & Nutrição inadequada & 8 & 23,5 \\
\hline
\end{tabular}

* Fator de risco fora da Taxonomia NANDA-I

Fonte: o próprio autor 
Para o diagnóstico de Déficit no autocuidado os fatores relacionados observados foram a prejuízo neuromuscular, presente em 29 clientes $(85,3 \%)$ diagnosticados e o prejuízo cognitivo presente em cinco clientes $(14,7 \%)$.

Quanto à Deglutição prejudicada, todos os fatores observados apresentaram-se com frequência maior que 50\%: alteração na função cognitiva, induzida por sedativos $(88,2 \%)$, a história de alimentação por sonda $(85,3 \%)$, a obstrução mecânica relacionada à intubação ou traqueotomia $(85,3)$, bem como a condição respiratória $(76,5 \%)$.

$\mathrm{Na}$ Mobilidade física prejudicada os fatores de maior prevalência foram os prejuízos neuromusculares $(85,3 \%)$ e o uso agentes farmacológicos $(85,3 \%)$.

No que se refere aos fatores relacionados observou-se que o diagnóstico de enfermagem de Proteção ineficaz, presente em 100\% da amostra, apresentou como fatores de maior prevalência o câncer (100\%), o regime de tratamento, em especial sedativos e anticoagulantes $(82,4 \%)$, o extremo de idade $(82,4 \%)$ e perfil sanguíneo anormal $(61,8 \%)$. Fatores como os distúrbios imunológicos e nutrição inadequada foram identificados na amostra, porém com frequência menor que $50 \%$.

Nos clientes que apresentaram o diagnóstico de Eliminação urinária prejudicada foram identificados o dano sensório-motor, induzido pela sedação (100\%) e as infecções no trato urinário $(12,5 \%)$.

No diagnóstico de Comunicação verbal prejudicada os fatores identificados foram o prejuízo no sistema nervoso central $(100 \%)$, o regime de tratamento $(93,5 \%)$ e a barreira física imposta pela via aérea artificial $(93,5 \%)$.

O diagnóstico de Processos familiares disfuncionais apresentou como fator relacionado a habilidade insuficiente de solucionar problemas em $100 \%$ dos clientes nos quais esse diagnóstico esteve presente.

Para os clientes que apresentaram o diagnóstico de enfermagem de Dentição prejudicada foram observados como fatores a dificuldade de acesso aos cuidados dentários profissionais (40\%) e o fato de serem economicamente desfavorecidos $(33,3 \%)$.

Em relação ao diagnóstico de Pesar, relacionado aos membros da família do cliente avaliados, o fator relacionado que esteve presente foi a antecipação da perda de pessoa significativa identificados em 29 famílias (100\%).

Assim como o diagnóstico de Pesar, o diagnóstico de Tristeza crônica esteve presente também nos familiares, tendo como fatores relacionados: morte de uma pessoa amada (proximidade) $(100 \%)$ e a crise no controle da enfermidade $(75,9 \%)$. 
Em relação ao diagnóstico de Incontinência intestinal os fatores relacionados foram o déficit no autocuidado para higiene íntima (100\%), imobilidade (100\%), agentes farmacológicos $(100 \%)$, lesão colorretal $(14,8 \%)$, diarreia crônica $(14,8 \%)$ e alteração na função cognitiva $(7,4 \%)$.

Sobre a Ventilação espontânea prejudicada/Padrão respiratório ineficaz que esteve presente em 27 clientes, os fatores relacionados identificados foram: dano musculoesquelético, neurológico e fadiga respiratória (100\%), o prejuízo neuromuscular (100\%), a infecção (fator que também não está na taxonomia NANDA-I) esteve presente em $100 \%$ dos clientes que possuíam esse diagnóstico. Outros fatores foram a doença pulmonar $(84,6 \%)$ e fatores metabólicos $(46,2 \%)$

Para os clientes diagnosticados com Dor aguda, o fator relacionado para $100 \%$ dos casos foi a presença de agente lesivo.

Sobre o Volume de líquido excessivo o fator relacionado observado em 100\% dos casos foi a presença de mecanismo regulador comprometido.

Os fatores de risco identificados para os clientes com diagnóstico de Risco de aspiração foram a capacidade de deglutição prejudicada (100\%), a alimentação enteral $(85,3 \%)$ e a presença de resíduo gástrico aumentado $(23,5 \%)$.

Para os clientes nos quais foram evidenciados o diagnóstico Risco de queda, os fatores de risco identificados foram a neoplasia (100\%), a Mobilidade física prejudicada $(88,2 \%)$ e a idade maior que 65 anos $(76,4 \%)$.

Já os fatores de risco para os clientes que apresentaram Risco de sangramento foram o regime de tratamento $(87,9 \%)$ e em menor frequência a função hepática prejudicada $(36,4 \%)$.

Para o diagnóstico de Síndrome do desuso os fatores de risco identificados foram a imobilização $(90,6 \%)$ e o nível de consciência alterado $(15,6 \%)$.

Com relação ao diagnóstico de Risco de olho seco, que esteve presente em 31 clientes, os aspectos de vulnerabilidade observados foram o regime de tratamento $(93,5 \%)$, a ventilação mecânica $(93,5 \%)$, e o envelhecimento $(90,3 \%)$.

Em relação ao diagnóstico de Risco de integridade da pele prejudicada os fatores de risco observados em $100 \%$ dos diagnosticados foram fatores mecânicos, pressão sobre saliência ósseas, extremo de idade, nutrição inadequada e escala de Braden, sendo que a última não consta na taxonomia NANDA-I. O fator estado nutricional desequilibrado esteve presente em $38,1 \%$ dos clientes. 


\section{DISCUSSÃO}

O cuidado de enfermagem vai muito além do cuidado técnico. Cuidar de alguém implica importar-se com a pessoa, envolver-se com ela. $\mathrm{O}$ cuidado paliativo tem por objetivo melhorar a qualidade de vida dos pacientes que se encontram sem possibilidade de cura. É um cuidado voltado para prevenir e aliviar o sofrimento, através do tratamento da dor e outros sintomas físicos, psicossociais e espirituais utilizando os benefícios da evolução técnicocientífica, e privilegiando os princípios éticos (SADALA, 2009).

A impossibilidade de cura não significa a deteriorização da relação enfermeiropaciente, mas, sim, o estreitamento dessa atenção, a qual, certamente, trará benefícios para ambos. Como ser ativo no seu tratamento, o paciente pode participar dos processos de decisão e dos cuidados voltados para si (SADALA, 2009).

Atuar na manutenção da qualidade de vida do paciente com câncer exige o desenvolvimento de meios para que o cuidado de enfermagem seja sensível e permita a manutenção da saúde e o confronto. O enfermeiro está presente em todas as diferentes etapas: prevenção, diagnóstico e tratamentos prolongados. Esta participação envolve não somente administrar a dor, a insuficiência respiratória, a ansiedade e a depressão, mas o compartilhar com o paciente e sua família as decisões do cuidar (SANTOS, 2007).

A enfermagem é cuidado contínuo com a finalidade de acolher, preservar e dar condições físicas, mentais, espirituais para um desprendimento livre e sereno. É de extrema importância considerar as capacidades e necessidades do paciente e de sua família, coexperimentando e apoiando o processo vivido através do respeito ao outro com olhar voltado para o cliente de forma individualizada, considerando sua unicidade, uma vez que cada indivíduo é um ser singular (SANTOS, 2007). Nesse contexto observa-se a relevância do processo de enfermagem.

Nessa perspectiva, a discussão dos resultados encontrados visa fornecer subsídios na investigação dos diagnósticos de enfermagem dos pacientes criticamente doentes sem possibilidades terapêuticas, auxiliando os profissionais de enfermagem na identificação de problemas ou potencialidades que posteriormente servirão como base para o planejamento do cuidado à essa clientela. 
A análise dos resultados desse trabalho será apresentada a seguir.

Inicialmente será discutida a caracterização sócio demográfica dos pacientes selecionados para o estudo, em seguida a identificação dos diagnósticos de enfermagem e após será feita a discussão daqueles que apresentaram frequência maior que 50\% na amostra estudada.

\subsection{Caracterização dos clientes oncológicos críticos em protocolo de cuidados paliativos quanto ao perfil socioeconômico-demográfico}

Em relação ao sexo na amostra estudada, houve distribuição equitativa entre os sexos feminino e masculino. Embora os achados mostrem uma distribuição igualitária entre os sexos, segundo o Instituto Nacional do Câncer, a incidência geral do câncer diminuiu para os homens de 1,8\% ao ano entre 2007 e 2011. As taxas para as mulheres mantiveram-se estáveis entre 1998 e 2011. Dentro dessas tendências houve variação racial/étnica, e alguns tipos de câncer têm taxas crescentes. A estimativa para 2014 e 2015 é de doenças neoplásicas na proporção de 52\% em homens e 48,\% entre as mulheres (INCA, 2015).

Estudos descritivos de natureza observacional têm registrado os padrões vigentes da doença. Em relação à idade, com poucas exceções, o câncer tem prevalência maior nos homens do que nas mulheres, sendo que nas últimas há maior prevalência de mortalidade relacionada à doença $($ OTTO, 2012).

Como apresentado anteriormente, quanto à faixa etária, a idade média da amostra foi de 74,4 anos, $15(44,1 \%)$ tinham entre 76 e 90 anos, 11 (26\%) tinham entre 61 e 75 anos, 4 $(11,8 \%)$ entre 45 e 60 anos ou mais, $3(8,8 \%)$ mais de 90 anos e 1 (2,9\%) tinha idade menor que 45 anos. Em relação ao tempo de internação no momento da avaliação para coleta de dados, o tempo médio foi de 16,2 dias. A amostra foi essencialmente de pessoas idosas, o que corrobora com a afirmação sobre interferência entre o fator de risco aumento da idade e o câncer.

$\mathrm{O}$ câncer tem prevalência maior em pessoas mais velhas. A maior incidência reflete a importância da duração da exposição à carcinógenos e dos longos períodos de indução em alguns cânceres. Mais de metade de todos os cânceres são diagnosticadas após os 65 anos (OTTO, 2012). 
Dados do INCA indicam que o Brasil vem sofrendo mudanças em seu perfil demográfico, consequência, entre outros fatores, do processo de urbanização populacional, da industrialização e dos avanços da ciência e da tecnologia (INCA, 2015).

A essas novas características da sociedade brasileira, unem-se os novos estilos de vida e a exposição, ainda mais intensa, a fatores de risco próprios do mundo contemporâneo. Esse processo de mudança demográfica, denominado de "envelhecimento" da população, associado à transformação nas relações entre as pessoas e seu ambiente, trouxe uma alteração importante no perfil de morbimortalidade, diminuindo a ocorrência das doenças infectocontagiosas e colocando as doenças crônico-degenerativas como novo centro de atenção dos problemas de doença e morte da população brasileira (INCA, 2015).

Em relação à escolaridade observou-se na amostra estudada prevalência de clientes com escolaridade mínima (85,3\%), estando inclusos neste achado as categorias o ensino fundamental completo e ensino fundamental incompleto. A prevenção do câncer e sua detecção precoce parecem estar diretamente relacionadas ao grau de escolaridade. Em estudo realizado por Gondinho (2004) para análise das fontes de conhecimento das mulheres sobre o câncer de mama foi evidenciado que as pacientes de grau de escolaridade mais baixo possuíam menor informação sobre métodos preventivos, sinais e sintomas da doença e que as informações que possuíam eram provenientes de fontes como televisão e relação interpessoal, fontes para as quais não se conhece o real alcance. A análise estatística desse estudo revelou forte associação entre a escolaridade e o conhecimento adequado sobre o câncer, sua detecção e prevenção, o que corrobora com o dado evidenciado no presente estudo, uma vez que os clientes participantes da amostra tiverem, em sua maioria, diagnóstico oncológico tardio, sendo 76,5\% deles acompanhado de quadro metastático.

$\mathrm{Na}$ análise da renda familiar pode ser observado, na amostra, prevalência de clientes com renda mensal entre 2 e 5 salários mínimos. Embora o valor de renda mensal observado na amostra seja reduzido, todos possuíam plano de saúde na categoria dependente, estando esta dependência condicionada aos filhos ou cônjuge. Em um artigo que trata sobre a atenção necessária à família do paciente oncológico traz que as condições sociais e econômicas da população são determinantes dos processos de saúde e doença e, efetivamente, os segmentos mais pobres têm maiores riscos de adoecimento advindos de dificuldades econômicas e geográficas, insuficiência de serviços e questões culturais. Traz ainda que em relação ao 
câncer, os segmentos mais pobres enfrentam barreiras de acesso a serviços de saúde para detecção e tratamento precoce da doença (CARVALHO, 2007).

Em estudo realizado por Pearce (1997), observou-se que na maioria dos países industrializados, há forte associação entre classe social e câncer, com quase o dobro do risco relativo quando se compara o grupo menos favorecido com o mais favorecido.

Em relação ao estado civil, $22(64,7 \%)$ dos clientes eram viúvos, 9 (26,5\%) eram casados e $3(8,8 \%)$ eram solteiros, dado que pode estar correlacionado com a variável idade. Em linhas gerais a idade avançada aumenta a probabilidade de óbito.

\subsection{Caracterização dos fatores condicionantes à internação hospitalar dos pacientes oncológicos críticos em protocolo de cuidados paliativos}

No que se refere ao tempo de permanência no hospital, durante a internação, observou-se que a maior parte dos clientes esteve internada por período menor ou igual a 20 dias $(82,5 \%)$. Em um estudo envolvendo 50 pacientes terminais, foi observado que desde o momento de identificação de morte inevitável até o óbito os pacientes estiveram internados, em média, por 24 dias (FABER, 1992). O dado observado no presente estudo corrobora com o dado evidenciado na literatura.

Quanto ao desfecho da internação, a maioria $(94,1 \%)$ foi à óbito na própria instituição. Existe um momento durante a internação hospitalar em que o cliente encontra-se, muito provavelmente, no período de morte inevitável. Considerando que 94,1\% da amostra foram admitidos em estado grave, sendo procedente da unidade de emergência e que foram avaliados pelo escore APACHE II com previsão de óbito de $85 \%$ e pontuação média maior que 35 pontos na admissão na UTI, o desfecho esperado era realmente o óbito durante esta internação.

O escore APACHE II (Acute Physiology and Chronic Health Evalution) é uma forma de avaliação e classificação do índice de gravidade da doença, e tem como objetivo principal a descrição quantitativa do grau de disfunção orgânica de pacientes gravemente enfermos, gravidade que é traduzida em valor numérico a partir das alterações clínicas e laboratoriais existentes ou do tipo/número de procedimentos utilizados. Valores de escore APACHE II, 
calculados à admissão do paciente na UTI, têm sido utilizados para determinar sua gravidade, buscando identificar, junto a outros fatores, a gravidade e os preditores de mortalidade no sentido de direcionar a assistência dos profissionais de saúde (KNAUS, 1985).

Em estudo realizado por Freitas (2010) em unidades de terapia intensiva observou-se que dos pacientes com APACHE II com pontuação maior que 30 foram a óbito 85,9\% deles. Este fato observado demonstra relação entre gravidade do cliente crítico e mortalidade.

No que diz respeito ao local de internação, a maioria dos clientes $(94,1 \%)$ estava em unidade de terapia intensiva (UTI). Esse achado expressa a ausência de um setor específico para o atendimento do indivíduo em cuidados paliativos na instituição estudada.

Tal achado chamou a atenção, visto que não se esperava essa conduta em uma clientela de pacientes em cuidados paliativos.

Estudos realizados por Capello (2012), Rodrigues (2009) e Avanci (2009) trazem que a doença é uma experiência de fragilidade que pode provocar no paciente e em seus familiares, a consciência da mortalidade e da finitude da existência. Traz ainda que é quase um consenso que pacientes portadores de neoplasia em estado avançado, refratários a todo e qualquer tipo de tratamento, merecem um final livre de dor e com a presença de seus familiares.

Sendo assim, segundo Moritz (2008) por mais absurdo que possa parecer à equipe multidisciplinar e fontes pagadoras ficar investindo com todo arsenal terapêutico num paciente sem possibilidades de melhora, sabe-se que a família é soberana na decisão e tem o total direito, inclusive legal, de que todo tipo de tratamento seja feito independente do prognóstico e do tempo de internação hospitalar.

Neste contexto, ressalta-se que o tratamento não visa somente à cura, mas também ao alívio da dor, conforto e estabilidade clínica, por mais reservado que seja o prognóstico (KNOBEL, 2004). Nessa perspectiva o dado apresentado corrobora com o dado observado no presente estudo, onde o maior causa de internação em UTI foi motivada pela solicitação dos familiares. 
Pode-se atribuir ainda, a maior frequência das internações em unidades de terapia intensiva de pacientes em cuidados paliativos, o fato de, em muitos hospitais, ainda não existir setores ou enfermarias destinados especificamente ao cliente em cuidados paliativos.

O trabalho de Figueiredo (2008) afirma que, no Brasil, dispomos de poucas unidades dedicadas aos cuidados paliativos dentro de hospitais, sendo que o pioneiro foi iniciado em 1983, pela Dra. Miriam Martelete, do Departamento de Anestesiologia do Hospital das Clínicas da Universidade Federal do Rio Grande do Sul. Em 1986, na Santa Casa de Misericórdia de São Paulo, quando àquela data surgiu o Serviço de Dor e Cuidados Paliativos. Em 1989 surgiram o Centro de Estudos e Pesquisas Oncológicas em Florianópolis e o Centro de Suporte Terapêutico Oncológico no INCA no Rio de Janeiro. Afirma ainda que até o momento não há mais do que 340 grupos no Brasil com unidades de cuidados paliativos dedicados e vinculados às instituições hospitalares.

Sobre os hábitos de vida, observou-se na amostra estudada que, 12 (35,3\%) eram tabagistas e $3(8,8 \%)$ eram etilistas. Em relação aos hábitos e estilo de vida, a Sociedade Americana de Câncer relata que fatores de risco como etilismos, tabagismo, hábitos alimentares e predisposição genética aumentam a incidência das doenças oncológicas. Estimase que o tabagismo seja responsável por $85 \%$ dos óbitos por câncer de pulmão entre os homens e $75 \%$ entre as mulheres (INCA 2015).

Dados do INCA afirmam sobre o tabagismo que, entre todos os cânceres, o de pulmão está mais fortemente associado ao consumo de tabaco, e o risco de ocorrência e morte aumentada quanto maior a intensidade da exposição. A mortalidade por câncer de pulmão entre fumantes é de cerca de 15 vezes maior do que entre pessoas que nunca fumaram na vida, enquanto entre ex-fumantes é cerca de 4 vezes maior. Traz ainda que o câncer de pulmão atualmente supera o câncer de mama como primeira causa em óbito por câncer nas mulheres. A exposição passiva à fumaça do cigarro aparentemente aumenta o risco do câncer pulmonar em não fumantes que vivem com fumantes.

No estudo observou-se a neoplasia de pulmão como a doença de maior prevalência apesar do tabagismo estar presente em apenas 35,3\% da amostra. Esse dado é perfeitamente compreensível quando se observa que 21 clientes $(61,7 \%)$ eram ex-tabagistas ou viviam em exposição passiva. O tabagismo está associado ao câncer de boca, faringe, laringe, esôfago, pâncreas, colo uterino, rim e bexiga (OTTO, 2012). No presente estudo a incidência de 
neoplasias de colo uterino, rim e bexiga foi de $20,6 \%$, o que corrobora com as associações apresentadas pelo INCA entre neoplasias de pulmão, colo uterino, rim e bexiga e o tabagismo e/ou exposição passiva.

Otto (2012) afirma que consumo excessivo de álcool etílico pode originar câncer de cabeça e pescoço, laringe e, possivelmente, fígado e pâncreas. Na amostra estudada apenas $8,8 \%$ dos clientes eram etilistas, o que se justifica levando em consideração as topografias oncológicas citadas como de maior prevalência em clientes que faziam consumo excessivo de álcool. $\mathrm{Na}$ amostra em estudo 2,9\% dos clientes apresentavam neoplasia hepática e 2,9\% neoplasia de tireoide, não havendo clientes com câncer de laringe ou pâncreas.

Quanto a presença de doenças pré-existentes a amostra revelou que a hipertensão arterial sistêmica esteve presente em 34,6\% dos clientes. Souza (2014) realizou revisão bibliográfica das publicações entre 1993 e 2013, e afirma que há associação conhecida entre a quimioterapia e a radioterapia utilizadas no tratamento do paciente com câncer e o desenvolvimento ou agravamento da hipertensão arterial. A pesquisa relata que a prevalência de hipertensão arterial nos pacientes com câncer antes da introdução dos inibidores de angiogênese no tratamento quimioterápico era semelhante àquela da população adulta em geral. Entretanto, o maior acesso ao moderno arsenal quimioterápico e consequente aumento da sobrevida dos pacientes com câncer teve impacto no desenvolvimento ou agravamento da hipertensão. A revisão traz ainda que a hipertensão arterial é a comorbidade mais frequentemente registrada em pacientes com câncer, e sua incidência aumenta com o tratamento quimioterápico.. Esse achado corrobora com os dados encontrados no estudo, uma vez que $79 \%$ da amostra já havia feito tratamento quimioterápico previamente à internação.

Em relação à insuficiência renal, a doença foi observada em $28,8 \%$ da amostra. Em pesquisa realizada por Pontes (2014) observou-se que mais de 60\% de todos os tipos de câncer e $70 \%$ de todos os óbitos relacionados a câncer ocorrem em pacientes com mais de 65 anos. E sabe-se ainda que em torno de 70 anos de idade, a função renal pode estar diminuída em $40 \%$ em relação aos valores iniciais. A frequência da insuficiência renal em pacientes com câncer não está definida, mas estudos mostram prevalência entre 33 até $60 \%$. Os agentes para tratamento de câncer são, em geral, nefrotóxicos, e alguns podem não afetar diretamente os rins, mas apresentam diferentes toxicidades quando a excreção renal não é apropriada. Esses agentes incluem quimioterápicos, terapia de alvo molecular, analgésicos e bifosfonatos $\mathrm{O}$ dado encontrado por Pontes (2014) vai de encontro ao observado no estudo, uma vez que há 
elevada prevalência de idosos na amostra $(85,3 \%)$ e também alto índice de clientes tratados com quimioterapia (79\%).

Outra doença crônica de alta prevalência na clientela oncológica estudada foi a diabetes melittus, presente em 19,2\%. O Estudo realizado por Souza (2014) explica que a existência de doença oncológica e diabetes justifica-se pela concomitância dos fatores de risco para ambas as entidades nosológicas. Nesta pesquisa a análise de diversos estudos epidemiológicos apontam que pessoas diabéticas têm maior risco de desenvolver tumores. Mesmo o pré-diabetes pode elevar esse risco. Após revisar 16 estudos de diversos países de origem sobre diabetes, pesquisadores concluíram que o risco de câncer aumenta $15 \%$ entre pré-diabéticos; e avaliando entre pacientes com índice glicêmico elevado, somado ao sobrepeso ou obesidade, o número salta para 22\% (INCA, 2015). Esse achado publicado pela revista brasileira de diabetologia apoia o achado no presente estudo, uma vez que 10 clientes oncológicos eram também portadores de diabetes.

Os clientes com cardiopatias $(13,5 \%)$ e doenças pulmonares crônicas obstrutivas $(3,8 \%)$ tiveram menor prevalência na amostra estudada.

Quanto à topografia da neoplasia na amostra estudada, houve prevalência das neoplasias pulmonares $(17,6 \%)$, seguidas das neoplasias de sistema nervoso central $(14,7 \%)$, mama $(11,8 \%)$ e próstata $(11,8 \%)$. Outras neoplasias menos frequentes foram de bexiga $(8,8 \%)$, cólon $(8,8 \%)$, renal $(5,9 \%)$ e útero $(5,9 \%)$. As neoplasias gástricas, hepáticas, ósseas, ovarianas e de tireoide apresentaram menor frequência na amostra estudada.

Os dados sobre o câncer, divulgados pelo INCA revelam que em 2016 no Brasil o câncer de pulmão, que é causado principalmente pelo fumo, seja o segundo tipo de câncer mais comum nos homens (16,84\% dos casos) e o quarto mais prevalente nas mulheres (10,54\% dos casos). Nas mulheres a maior prevalência será de câncer de mama, seguido de cólon e reto e em terceiro lugar encontra-se o câncer de colo de útero. Nos homens a estimativa é de próstata como o primeiro câncer mais comum, seguido da doença com topografia pulmonar, colón e reto, estômago, cavidade oral e esôfago (BRASIL, 2015). Esse dado corrobora com o perfil observado no estudo uma vez que as topografias neoplásicas de mama e próstata encontram-se em terceira e quarta colocação no que se refere à frequência. A neoplasia de pulmão é ainda esperada na amostra estudada devido existência de forte associação com tabagismo, observando na amostra mais de $60 \%$ de clientes estavam ou 
estiveram de alguma forma expostos ao tabaco seja como fumante, ex-fumante ou por exposição passiva. Como a neoplasia de pele não melanoma tem bom prognóstico não era esperado a sua prevalência em pacientes em cuidados paliativos.

O segundo câncer mais prevalente na amostra estudada foi o de sistema nervoso central. Na última década, registrou-se um aumento na incidência dos tumores de sistema nervoso central. Dados norte-americanos mostram que durante os anos de 1977 e 1981, a incidência desses tumores era de 2,7 casos a cada 100.000 crianças por ano e no período de 1990 a 1994, esses casos aumentaram de 2,7 para 3,3. O aumento está diretamente relacionado a um maior número de diagnósticos que antes não eram realizados, pois entre esses períodos, houve uma série de avanços nas técnicas de medicina diagnóstica e nas técnicas cirúrgicas - principalmente com as especializações das técnicas de biópsia (análise das células dos materiais recolhidos). Aproximadamente $80 \%$ dos tumores de SNC ocorrem na primeira década de vida, o que corresponde ao primeiro pico de incidência. De uma maneira geral, o risco diminui à medida que a idade avança até um segundo pico de incidência no final da idade adulta, entre sétima e oitava décadas de vida (OMS, 2014). O dado apresentado pela Organização Mundial da Saúde apoia na compreensão do dado encontrado na amostra estudada, pois o maior percentual dos clientes encontravam-se na faixa entre 70 e 80 anos de vida, estando assim no segundo pico de incidência da doença apresentado na literatura.

No que se refere à amostra estudada 26 clientes (76,5\%) possuíam algum tipo de metástase, enquanto $8(23,5 \%)$ não tinham doença metastática diagnosticada.

Brasil (2008) traz que os tumores malignos apresentam duas propriedades peculiares: invasão dos tecidos circunvizinhos e comprometimento à distância (metástase). A metástase é definida como o comprometimento à distância por uma parte do tumor que não guarda relação direta com o foco primário. A disseminação tumoral é um processo complexo e não de todo esclarecido, que pode ser dividido em cinco etapas: 1) invasão e infiltração de tecidos subjacentes por células tumorais, dada a permeação de pequenos vasos linfáticos e sanguíneos; 2) liberação na circulação de células neoplásicas, tanto isoladas como na forma de pequenos êmbolos; 3) sobrevivência dessas células na circulação; 4) sua retenção nos leitos capilares de órgãos distantes; 5) seu extravasamento dos vasos linfáticos ou sanguíneos, seguido do crescimento das células tumorais disseminadas. Ao longo de todo esse processo, fatores mecânicos e imunológicos devem ser superados para que as células neoplásicas 
consigam implantar-se em um novo órgão e terem crescimento autônomo em relação ao tumor primário.

Mukherjee (2011) relata que a célula cancerosa é uma individualista desesperada, "em tosos os sentidos imagináveis, uma inconformada", sendo a palavra metástase usada para descrever a migração do câncer de um lugar para outro, uma curiosa mistura de meta e stasis - "além de imobilidade em latim - um estado sem âncoras, parcialmente instável, que captura a instabilidade peculiar da modernidade.

Brasil (2008) descreve as vias pelas quais o tumor dissemina, são elas: transcavitária, linfática e sanguínea.

- Disseminação transcavitária - As metástases transcavitárias (ou transcelômicas) ocorrem quando células de um tumor maligno penetram alguma cavidade corporal e aí crescem e disseminam-se. Na prática, as cavidades mais afetadas são a peritoneal e a pleural, porém a pericárdica, subaracnóidea e articular podem também ser atingidas (BRASIL, 2008).

- Disseminação linfática - As metástases linfáticas são geralmente o padrão inicial de disseminação das neoplasias de origem epitelial, podendo ser utilizada por outros tipos de tumor. Elas seguem a drenagem linfática normal da área do tumor primário, ocupando os linfonodos mais próximos e que recebem maior número de vasos linfáticos aferentes. Exemplo disto é a disseminação linfática do câncer de pulmão, que invade inicialmente os linfonodos mediastinais e, em sequência, os supraclaviculares e cervicais (BRASIL, 2008).

O mesmo se verifica com o câncer de mama, que invade inicialmente os linfonodos axilares homolaterais, só posteriormente estende-se aos de outras cadeias linfáticas supraclaviculares, infraclaviculares, cervicais, mediastinais e axilar contralateral. Por um tempo não determinado, é possível que os linfonodos consigam impedir a disseminação das células tumorais, pois, chegando aos linfonodos, elas entram em contato com células do sistema imunológico e, então, podem ser destruídas. De outra forma, se resistirem e encontrarem condições vitais favoráveis, poderão multiplicar-se (BRASIL, 2008).

- Disseminação sanguínea - As metástases por via hematogênica têm seu início quando células tumorais invadem os vasos sanguíneos. As veias e vênulas, por possuírem paredes mais frágeis, são mais facilmente penetradas do que artérias e arteríolas. As metástases por 
via arterial podem ocorrer, por exemplo, quando células metastáticas cruzam o leito capilar pulmonar, quando atravessam comunicações arteriovenosas ou quando as próprias metástases pulmonares funcionam como foco de novas células tumorais capazes de metastatizar. (BRASIL, 2008).

Em todo o organismo, os órgãos que mais são comprometidos por esse tipo de disseminação são, obviamente, os mais vascularizados: pulmão e fígado, em parte por receberem, respectivamente, grande volume de sangue procedente das circulações cava e porta, ossos e cérebro (BRASIL, 2008).

O fígado é o principal órgão acometido por metástases hematogênicas provenientes da circulação portal e um frequente alvo de metástases advindas da circulação sistêmica. O acometimento hepático por um tumor metastático é muito mais comum do que por um tumor primário, chegando a ser vinte vezes mais frequente. Em necropsias, cerca de $40 \%$ dos pacientes com tumores extra-hepáticos apresentavam metástase hepática quando obituaram. Esse dado pode ser atribuído ao fato do fígado ser a maior víscera sólida do organismo, recebendo grande fluxo sanguíneo arterial e venoso. Todo sangue da cavidade abdominal drena para a veia porta, passando obrigatoriamente pelo fígado antes de atingir a veia cava. Os principais sítios primários dos tumores metastáticos do fígado são cólon, pâncreas, mama, ovário, reto, estômago, pulmões e rins, respectivamente (OTTO, 2012).

Os dados observados no presente estudo com relação às metástases refletem o descrito na literatura, uma vez que dos 26 clientes que apresentavam metástases tiveram divisão topográfica da seguinte maneira: hepática $(46,1 \%)$, pulmonar $(30,7 \%)$, óssea $(23 \%)$.

No que se refere aos tipos de tratamentos utilizados, no presente estudo predominou o tratamento quimioterápico $(79,4 \%)$ dos clientes, seguido do tratamento oncológico cirúrgico $(73,5 \%)$ e da radioterapia $(32,4 \%)$

As quatro modalidades primárias básicas no tratamento do câncer são: quimioterapia, cirurgia, radioterapia e bioterapia. Para tratamento das neoplasias pulmonares o protocolo mais comum consiste na utilização de uma, duas ou as três modalidades de tratamento. Para a neoplasia pulmonar de células não pequenas a cirurgia, quando possível, é o tratamento de escolha por permitir melhores resultados, porém em cerca de $90 \%$ dos casos não é possível cirurgia na ocasião do diagnóstico ou pela grande extensão da doença. Há também a 
possibilidade que o tumor esteja próximo a estruturas nobres (como o coração), e há ainda situações em que o paciente não suportaria uma perda de parte do pulmão, optando-se inicialmente pela quimioterapia. No caso de neoplasias pulmonares de pequenas células, o tratamento quimioterápico é o tratamento de escolha podendo ser seguido da radioterapia ou não. Normalmente não se indica tratamento cirúrgico para o carcinoma e pequenas células. Os dados apresentados justificam o fato de o tratamento quimioterápico ter apresentado a maior frequência da amostra analisada. Após a quimioterapia o tratamento cirúrgico é o de escolha para tratamento das neoplasias pulmonares (NETO, 2013).

Os tumores do sistema nervoso central, segundo câncer de maior prevalência na amostra (14,7\%), podem ser tratados com cirurgia, radioterapia e/ou quimioterapia. Geralmente, uma combinação dos três é usada. Embora o tratamento possa prolongar a vida do paciente, a maioria dos tumores cerebrais não é curável. Na maioria dos casos, o primeiro passo é a remoção cirúrgica da maior parte possível do tumor, dentro de uma margem de segurança para não comprometer funções normais. Alguns tumores podem ser curados apenas com cirurgia ou com cirurgia combinada à radioterapia (NETO, 2013). Esse dado explica o fato do tratamento cirúrgico ocupar o segundo lugar nos tratamentos utilizados pelos clientes que fizeram parte da amostra.

O tratamento de escolha para o câncer de mama é cirurgia seguida de quimioterapia. Já as neoplasias de próstata possuem como protocolo de tratamento mais comum a cirurgia seguida de radioterapia (NETO, 2013). Esse fato também apoia os achados no presente estudo.

Em relação às escalas aplicadas pôde-se observar em relação ao risco de úlcera por pressão através do escore de Braden que houve predominância de clientes com alto risco para desenvolvimento de lesões cutâneas.

No que se refere ao risco de quedas em que foi utilizada a ferramenta de Morse para predição do risco verificou-se que a maior frequência foi composta por clientes com alto risco para a ocorrência desse fenômeno.

A escala visual analógica de avaliação da dor foi aplicada em dois clientes observando-se a dor como fator presente nos avaliados. Já para os clientes sedados ou com nível de consciência alterado a escala aplicada para verificação da presença ou não de dor foi a BPS, onde a maior parte dos clientes avaliados apresentava comportamento compatível com presença de dor. 
As escalas de avaliação de ansiedade e de percepção de estresse tiveram sua aplicabilidade comprometida, uma vez que se aplicam apenas à pacientes conscientes. Dos clientes conscientes avaliados, em 5,9\% deles a presença de estressores foi identificada e em 2,9\% tinham ansiedade presente.

A discussão mais aprofundada e comparativo com outras pesquisas e dados da literatura será realizada na discussão dos diagnósticos de Risco para integridade da pele prejudicada, Risco de quedas e Dor aguda.

\subsection{Perfil diagnóstico dos clientes oncológicos críticos em protocolo de cuidados paliativos}

Os diagnósticos de enfermagem identificados nos pacientes oncológicos críticos inclusos em protocolo de cuidados paliativos na amostra estudada totalizaram 718 ocorrências em 51 diagnósticos distintos, com média de 21,2 diagnósticos por cliente, admitindo-se assim, a alta demanda por cuidados de enfermagem especializados e integrais.

Observou-se na amostra estudada o predomínio de cinco diagnósticos: Proteção ineficaz, Deglutição prejudicada, Déficit no autocuidado, Mobilidade física prejudicada e Risco de aspiração, que estiveram presentes em 34 clientes (100\%). O diagnóstico Risco de sangramento, seguido dos diagnósticos de Eliminação urinária prejudicada, Risco de síndrome do desuso, Comunicação verbal prejudicada, Risco de olho seco, Processos familiares disfuncionais, Incontinência intestinal, Ventilação espontânea prejudicada/ Padrão respiratório ineficaz, Dor aguda, Risco de integridade da pele prejudicada e Volume de líquidos excessivo, estiveram presentes na amostra com frequência maior que $50 \%$.

No estudo de Salomé (2011), que teve como objetivo identificar os diagnósticos de enfermagem de maior prevalência em doentes críticos internados em UTI, evidenciou-se resultado semelhante onde os diagnósticos de Déficit no autocuidado, Mobilidade física prejudicada, Risco de aspiração, Comunicação verbal prejudicada, Ventilação espontânea prejudicada, Padrão respiratório ineficaz, Dor aguda e Volume de líquidos excessivo também estiveram presentes em mais de 50\% da amostra. Diferentemente do resultado encontrado no presente estudo os diagnósticos de Proteção ineficaz, Deglutição prejudicada, Risco de sangramento, Eliminação urinária prejudicada, do Risco de síndrome do desuso, Risco de olho seco, Processos familiares disfuncionais, Incontinência intestinal e Risco de integridade da pele prejudicada não estiverem presentes na amostra do estudo de Salomé (2011). 
Já no estudo de Sousa (2011), com pacientes onco-hematológicos, os diagnósticos de proteção ineficaz e risco de sangramento também foram identificados em mais de $50 \%$ dos avaliados. Esse dado também corrobora com o resultado encontrado na amostra analisada no presente estudo onde $100 \%$ dos clientes apresentavam proteção ineficaz e $97,1 \%$ apresentavam risco para sangramento.

Observou-se no presente estudo que 31 diagnósticos de enfermagem apresentaram frequências inferiores à 50\% na amostra estudada. Apresentaram frequências entre 47,1\% e 14,7\% os diagnósticos: Disposição para religiosidade melhorada (família), Perfusão renal ineficaz, Integridade tissular prejudicada, Conflito de decisão (família), Desobstrução ineficaz das vias aéreas, Nutrição alterada: menos que as necessidades corporais, Diarreia, Constipação e Troca de gases prejudicada. Apresentaram frequências entre 5,9\% à 2,9\% os diagnósticos: Risco de perfusão tissular cerebral ineficaz, Hipertermia, Mucosa oral prejudicada, Volume de líquidos deficiente, Ansiedade relacionada à morte (família), Distúrbio da imagem corporal, Náusea, Risco de infecção, Atividade de recreação deficiente, Confusão aguda, Débito cardíaco diminuído, Hipotermia, Insônia, , Integridade da pele prejudicada, Memória prejudicada, Obesidade, Desesperança (família), Risco de choque, Risco de confusão aguda, , Risco de desequilíbrio eletrolítico, Risco de nutrição desequilibrada menos que as necessidades e Risco de volume de líquidos desequilibrado

Considerando os três sistemas de King, os resultados indicaram predomínio de problemas (diagnósticos) ligados ao sistema pessoal, seguido do sistema interpessoal e social.

Foram 42 diagnósticos representando o sistema pessoal, 7 dentro do sistema interpessoal e dois vinculados ao sistema social. Esperava-se prevalência de diagnósticos de enfermagem localizados no Sistema Pessoal levando-se em consideração seu perfil de gravidade, pois quanto maior a criticidade do cliente maior será o quantidade de cuidados e intervenções a ele direcionadas.

Deve-se considerar que na própria taxonomia II da NANDA-I há predomínio de diagnósticos que estão mais diretamente vinculados ao indivíduo, seguido da família e da coletividade humana. Há uma proposta de Taxonomia III a ser lançada, possivelmente na próxima reunião da NANDA-I em 2016, em que há claramente a distribuição dos diagnósticos em domínios de cunho individual, familiar e coletivo. Dos 282 diagnósticos propostos, 264 (93\%) estão ligados ao indivíduo, 18 (6\%) ligados à família e apenas três (1\%) 
à coletividade humana (NANDA-I, 2015). De certa forma, essa organização está em consonância com os achados da presente pesquisa.

Analisando sob a perspectiva dos três sistemas mencionados por King, estudo realizado com clientes hematológicos hospitalizados onde foram arrolados 240 diagnósticos, houve predominância de diagnósticos do sistema Pessoal 186 (77,5\%), seguido de diagnósticos inclusos no sistema interpessoal $47(19,6 \%)$ e com menor frequência foram observados diagnósticos ligados ao sistema social 7 (2,9\%) (JESUS, 1992). Este dado corrobora com o estudo em questão uma vez que existe forte semelhança entre o paciente oncológico e o paciente hematológico no que se refere à condição clinica.

Os 20 diagnósticos mais frequentes (maior que 50\%) serão comentados separadamente, considerando sua definição e correlação com a literatura e a prática. Dos 20 diagnósticos de maior prevalência, 14 diagnósticos foram reais e 6 diagnósticos de risco ou vulnerabilidade.

\subsubsection{Déficit no autocuidado para alimentação, banho, higiene íntima e vestir-se}

Esse diagnóstico é definido como a "capacidade prejudicada de desempenhar ou completar as atividades do próprio cuidado, sejam elas de alimentação, banho, higiene íntima ou vestir-se" (NANDA, 2015).

Encontra-se subdividido pela taxonomia II da NANDA-I em: Déficit no autocuidado para banho, para higiene íntima, para vestir-se e para alimentação, separadamente, para cada uma das tarefas das quais o paciente está com sua capacidade diminuída para realizar.

No presente estudo esse diagnóstico foi evidenciado nos 34 clientes avaliados, considerando que $82,4 \%$ encontravam-se sob ventilação mecânica e $83 \%$ dos que estavam em ventilação espontânea, possuíam suporte de oxigênio por máscara, tornando obrigatório o autocuidado com auxílio. Os fatores relacionados levantados para esse diagnóstico foram: o prejuízo neuromuscular relacionado ao uso de sedação por infusão contínua e o prejuízo perceptivo secundário à evolução da doença, à terminalidade e ao rebaixamento do nível de consciência. As características definidoras para o diagnóstico foram a capacidade prejudicada de realizar atividades de autocuidado e a capacidade prejudicada de ingerir/deglutir alimentos. 
Um estudo com pacientes críticos internados em UTI, realizado em 2011, identificou o diagnóstico Déficit no autocuidado também em 100\% dos pacientes avaliados, estando o diagnóstico relacionado ao uso de sondas, cateteres, dificuldade na locomoção e dor (SALOMÉ, 2011).

Em uma revisão integrativa realizada em 2013 sobre diagnósticos de enfermagem mais comuns entre adultos/idosos hospitalizados, detectou-se a presença do diagnóstico déficit no autocuidado em três artigos avaliados. Em um deles, o diagnóstico Déficit no autocuidado estava presente em 56\% dos 196 pacientes estudados, em outro trabalho esteve presente em 66,6\% dos 15 registros analisados e no terceiro estudo o diagnóstico foi observado em 50\% dos 6 pacientes avaliados (JOMAR, 2014).

Os resultados dos estudos acima citados corroboram os achados do presente estudo, indicando haver um predomínio elevado no déficit do auto cuidado em indivíduos com doenças oncológicas com maior destaque no perfil de paciente oncológico crítico, já em cuidados paliativos no ambiente hospitalar (JOMAR, 2014).

\subsubsection{Deglutição prejudicada}

Quanto ao diagnóstico de Deglutição prejudicada, definido como funcionamento anormal do mecanismo de deglutição associado com déficit na estrutura ou na função oral, faríngea ou esofágica (NANDA-I, 2015), foi encontrado em 34 (100\%) dos clientes. Como fatores relacionados destacaram-se as alterações na função cognitiva secundária ao uso de sedativos, a história de alimentação por sonda, a obstrução mecânica (uso de cânulas orotraqueais e traqueostomias) e condição respiratória. Como características definidoras merecem destaque a dificuldade para deglutir e a incapacidade de limpar a cavidade oral, ambos relacionadas à infusão contínua de medicamentos sedativos.

Em estudo realizado por Sousa (2015) com portadores de neoplasia hospitalizados em 2015, 16 (69,5\%) dos pacientes possuíam o diagnóstico em questão. O trabalho associou o diagnóstico à necessidade do uso de sonda nasogástrica ou nasoentérica, fator também observado na clientela estudada. Na maioria dos casos, tal alteração estava relacionada com 
problemas neurológicos, como as sequelas de acidente vascular cerebral, cuja plegia muscular impede os movimentos de mastigação e deglutição.

Já na amostra estudada, o uso de sondas para alimentação esteve relacionado à alternativa indicada para manter aporte calórico necessário, uma vez que os pacientes estavam em uso de sedação contínua. As manifestações mais comuns, em ambos os estudos referem-se ao fechamento incompleto dos lábios (os alimentos caem da boca), tosse e sialorréia. Outros pacientes se encontravam impedidos de deglutir por obstrução mecânica, como cânula de traqueostomia e tumor (SOUSA, 2015). No presente estudo observou-se também a obstrução mecânica como fator presente em $85,3 \%$ dos clientes portadores desse diagnóstico, devido à utilização de cânula de traqueostomia ou orotraqueal.

Esse quadro é compatível com os clientes que estão em unidades de terapia intensiva, pois a intubação orotraqueal é considerada como um dos principais procedimentos de suporte à vida. Sua principal indicação é em situações nas quais haja prejuízo na manutenção da permeabilidade das vias aéreas. Em estudo realizado por Garcia (2015) verificou-se que as principais razões para internação do paciente em UTI são os problemas respiratórios com prevalência de $23,5 \%$ e em seguida os quadros de choque com $22,9 \%$ de frequência.

\subsubsection{Mobilidade física prejudicada}

Define-se como "limitação no movimento físico independente e voluntário do corpo ou de uma ou mais extremidades" (NANDA-I, 2015). O diagnóstico de Mobilidade física prejudicada, também esteve presente em $100 \%$ da amostra estudada, tendo como características definidoras em todos os clientes diagnosticados a redução das habilidades motoras e como fatores relacionados os prejuízos neuromusculares secundário à intubação endotraqueal e consequentemente à sedação em 29 clientes (85,3\%), o uso de agente farmacológico também em 29 clientes $(85,3 \%)$ e o prejuízo sensório-perceptivo em 5 clientes $(14,7 \%)$.

Em estudo semelhante realizado por Salomé (2011), com pacientes críticos internados em Unidade de terapia intensiva, foi observado que 98,7\% dos pacientes apresentaram o diagnóstico de mobilidade física prejudicada. Foram apontados como fatores relacionados a 
intubação e sedação, o que corrobora com o que foi observado na clientela participante da amostra. Foi observado ainda como fatores relacionados o uso de dipositivos que limitavam a mobilidade como sondas, cateteres e drenos, as disfunções neuromusculares e a necessidade de contenção devido agitação psicomotora.

Em outro estudo, realizado por Sousa (2015), com pacientes críticos, observou-se que $65,2 \%$ dos pacientes apresentaram esse diagnóstico, indicando o alto grau de dependência e a importância de cuidadores se atentarem às condições físicas dos pacientes para realizar as tarefas de forma a evitar complicações. Nos idosos a diminuição da capacidade funcional que ocorre em todos os órgãos e sistemas e é agravada pela imobilização no leito. Fisiologicamente, a imobilização traz como consequência a diminuição da mobilidade articular, o que ocasiona contratura e há perda da massa e força muscular, bem como perda massa óssea, além de acentuada deterioração do sistema respiratório e cardiovascular de forma mensurável, em poucos dias. A imobilização no leito contribui, também, para alterações psicológicas, como depressão, mudança de comportamento e alterações da percepção. Esses dados estão em consonância com os achados, evidenciando-se uma alta prevalência desse diagnóstico na clientela estudada, pois o maior percentual dos clientes eram idosos e em condições críticas.

\subsubsection{Proteção ineficaz}

A definição do diagnóstico Proteção ineficaz na NANDA-I consiste na "diminuição na capacidade de proteger-se de ameaças internas ou externas, como doenças ou lesões" (NANDA-I, 2015).

No presente estudo, esse diagnóstico foi formulado em 100\% dos casos, ou seja, os 34 pacientes avaliados apresentaram características definidoras suficientes para o estabelecimento do diagnóstico em questão que foram o prejuízo neurossensorial, a imobilidade, a alteração na coagulação, a dispnéia, a deficiência na imunidade, a presença de úlcera por pressão, a desorientação e a fraqueza. Os fatores relacionados identificados de maior prevalência foram entre o câncer, o fator extremo de idade, o perfil sanguíneo alterado, a nutrição inadequada, regime de tratamento, sendo o mais utilizado o anticoagulante, devido protocolo de prevenção de tromboembolismo venoso. 
Em estudo realizado com pacientes onco-hematológicos em 2013, onde 100\% da amostra também apresentou o diagnóstico de proteção ineficaz houve semelhança nos fatores relacionados, dentre eles citam-se a doença oncológica e terapia com medicamentos. Com relação às características definidoras também houve semelhança nos resultados encontrados sendo observada elevada frequência da alteração na coagulação e deficiência na imunidade (SOUSA, 2015).

Segundo Otto (2012), pacientes portadores de doenças neoplásicas apresentam alta frequência de anormalidades das células sanguíneas. Os mecanismos estão relacionados com a eliminação das células-tronco pluripotentes, dano provocado ao microambiente da medula óssea, inibição de produção de fatores de crescimento hematopoético e/ou produção de citocinas inibidoras da hematopoese. Tais efeitos adversos sobre a hematopoese são frequentemente agravados pelo tratamento da neoplasia (radiação ionizante, drogas antiblásticas). Embora as citopenias observadas no paciente oncológico sejam geralmente consequentes a distúrbios de produção de células sanguíneas, deve-se sempre considerar a possibilidade de uma anemia dilucional e de sequestro, consumo ou destruição excessivos das diferentes linhagens de células hematológicas como mecanismo responsável pela citopenia (OTTO, 2012).

Considerando o estado de vulnerabilidade do paciente crítico bem como as alterações na contagem de hemácias, leucócitos e plaquetas dos pacientes oncológicos, em especial daqueles tratados previamente com terapia quimioterápica, esperava-se que esse diagnóstico apresentasse alta frequência na clientela estudada devido à imunidade deficiente, às possíveis coagulopatias.

\subsubsection{Eliminação urinária prejudicada}

A definição apresentada pela NANDA-I para esse diagnóstico é "disfunção na eliminação de urina" (NANDA-I, 2015). No presente estudo, 94,1\% dos pacientes avaliados apresentaram o diagnóstico durante a internação hospitalar, levando em consideração que $85,3 \%$ (29) eram idosos, dos quais apenas $6 \%$ não apresentaram o diagnóstico em questão.

A característica definidora identificada foi a incontinência urinária. $\mathrm{O}$ uso de fraldas estava presente em todos os clientes com esse diagnóstico. Os fatores relacionados foram o dano sensório motor induzido pela sedação e a presença de infecção no trato urinário. 
No estudo de Silva (2008) sobre os diagnósticos de enfermagem do paciente com neoplasia colorretal $45 \%$ estavam na faixa etária considerada como de idosos e destes $9 \%$ tiveram o diagnóstico de Eliminação urinária prejudicada, relacionando-o aos efeitos do câncer e às repercussões que a doença causou na vida dos pacientes. Já no estudo de Garbaccio (2012) em que foram analisados os diagnósticos de enfermagem em uma instituição de longa permanência 39,7\% dos avaliados apresentavam o diagnóstico de eliminação urinária prejudicada, o que corrobora o dado encontrado no presente estudo, no que se refere à relação do diagnóstico eliminação urinária prejudicada e a idade avançada.

Em estudo realizado por Pasini (1996) com paciente internados em unidade de terapia intensiva o diagnóstico de eliminação urinária prejudicada foi identificado em $79,1 \%$ dos pacientes, dado que também se assemelha ao verificado no presente estudo, inclusive na frequência observada.

\subsubsection{Comunicação verbal prejudicada}

No presente estudo 31 (91,2\%) clientes apresentaram o diagnóstico de Comunicação verbal prejudicada que consiste na "capacidade diminuída, retardada ou ausente para receber, processar, transmitir e/ou usar um sistema de símbolos" (NANDA-I, 2015). Dentre os fatores relacionados vale ressaltar o prejuízo no sistema nervoso central e regime de tratamento, ambos relacionados à sedação utilizada tanto para manutenção de ventilação mecânica como para tratamento da dor oncológica aguda e conforto na terminalidade, sendo o medicamento sedativo também um fator causal do diagnóstico. Outro fator presente em 29 clientes portadores do diagnóstico em questão foi a presença de barreira física (cânula endotraqueal ou cânula de traqueostomia) reconhecido em $93,5 \%$ dos 31 clientes para os quais se definiu esse diagnóstico. As características definidoras identificadas foram o fato do cliente não conseguir falar e a ausência de contato visual.

Em estudo realizado por Salomé (2011) observou-se que 97,8\% dos pacientes críticos internados em UTI analisados apresentavam o diagnóstico de comunicação verbal prejudicada tendo como fatores relacionados a intubação, pós extubação imediata e desconforto respiratório. O primeiro fator citado também foi observado na amostra estudada, já os demais não foram observados. 
A importância da comunicação para a assistência de enfermagem é reconhecida de longa data, sendo esse um dos instrumentos básicos do processo de cuidar, haja vista que dela depende a interação enfermeiro/paciente, essencial para a recuperação deste e a satisfação profissional e pessoal daquele que presta o cuidado. Acrescenta-se que, nos cuidados com pacientes sem condições de utilizar a comunicação verbal, deve se atentar para a interação enfermeiro/paciente e proporcionar um ambiente livre de fatores agressivos, como barulho e comentários impróprios (SALOMÉ, 2011).

\subsubsection{Processos familiares disfuncionais (família)}

A Taxonomia II da NANDA-I (2015) define o diagnóstico de enfermagem Processos familiares disfuncionais como "as funções psicossociais, espirituais e fisiológicas da unidade familiar estão cronicamente desorganizadas, levando ao conflito, à negação de problemas, à resistência a mudanças, à resolução ineficaz de problemas e uma série de crises autoperpetuadas”. Este diagnóstico foi atribuído à família e não ao paciente,

No presente estudo, 88,2\% (30) das famílias dos clientes apresentaram este diagnóstico durante sua internação. Os motivos que levaram a esse diagnóstico estão relacionados às estratégias ineficazes de enfrentamento. Quanto às características definidoras identificadas em ordem de prevalência foram: habilidades insuficientes para solucionar problemas, padrão contraditório de comunicação, incapacidade de lidar com experiências traumáticas de forma construtiva e a expressão inapropriada de raiva.

Em estudo realizado por Trupell (2009) em pacientes internados em UTI esse diagnóstico foi identificado em 65\% das famílias. Já em estudo realizado por Santos (2010) que analisou os diagnósticos de enfermagem prevalentes em pacientes em pós-operatório de cirurgia bariátrica em uma unidade de terapia intensiva identificou o diagnóstico em 100\% dos pacientes e suas famílias. No referido estudo tiveram relação com esse diagnóstico falta de habilidade para resolver problemas e as habilidades de enfrentamento inadequadas e foi evidenciado pela falta de disponibilidade para apoio emocional, negação de problemas e a capacidade reduzida dos membros da família de se relacionarem entre si visando ao crescimento e amadurecimento mútuos. Esses dados corroboram com os dados identificados no presente estudo (SANTOS, 2010). 
A hospitalização em UTI ocorre, geralmente, de forma aguda e inadvertida, restando pouco tempo para o ajustamento familiar. Diante dessa situação estressante, os familiares podem se sentir desorganizados, desamparados e com dificuldades para se mobilizarem. As famílias podem reagir de formas diversas à nova situação.

A família atua como unidade de saúde para seus membros, ou seja, ela tem um referencial para compreender e atuar nas diferentes situações de saúde e doença. A organização e ajustamento estão abalados quando um ente querido está internado em estado crítico numa unidade de terapia intensiva, e essa desorganização e desajuste estão agravados quando é anunciada a proximidade da morte. Sabe-se que a morte é um fato inevitável, contudo, é difícil aceitar que aconteça rapidamente. Lidar com a morte é uma questão difícil. E lidar com as reações das famílias que experienciam o processo de morte precisam ter suas demandas também atendidas (FLORIANI, 2008).

Tratando-se de familiares de clientes em final de vida e considerando a dificuldade da cultura ocidental em viver o processo de morte era esperada a alta frequência desse diagnóstico de enfermagem.

\subsubsection{Dentição prejudicada}

Com relação ao diagnóstico de enfermagem Dentição prejudicada, definido como "ruptura nos padrões de desenvolvimento/erupção dentário ou na integridade estrutural de cada dente" (NANDA-I, 2015), houve incidência em 88,2\% nos casos avaliados, fato esperado para amostra com uma média de idade de 74,4 anos. Na clientela estudada foram elencadas as seguintes características definidoras: halitose, ausência de dentes e dentes desgastados. Também foram identificados os fatores relacionados: dificuldade de acesso a cuidados dentários profissionais e cliente economicamente desfavorecido.

Observa-se a coerência da elevada frequência do diagnóstico ao analisarmos os fatores idade (média de 74,4), grau de criticidade durante a internação e tratamentos oncológicos prévios. Em estudo realizado em 2014 com doentes portadores de câncer de próstata com média de idade de 62,3 anos que objetivou identificar as características definidoras e os fatores relacionados/ de risco que apresentam associação com os diagnósticos de enfermagem presentes em pacientes prostatectomizados, identificou-se o diagnóstico Dentição prejudicada em $18 \%$ dos casos, com maior incidência da característica definidora "falta de alguns dentes" 
e como fator relacionado a higiene oral ineficaz e as barreias no auto cuidado (SALDANHA, 2014).

No estudo de Salomé (2011) que avaliou pacientes críticos hospitalizados o diagnóstico esteve presente em $72,7 \%$ dos pacientes. O referido estudo traz resultado que mais se assemelha ao resultado observado no presente estudo quando comparado ao resultado encontrado por Saldanha (2011), pois os clientes do primeiro estudo apresentam perfil similar ao da amostra no que se refere à média de idade, à gravidade e ao local de internação.

\subsubsection{Pesar (família)}

O diagnóstico de enfermagem Pesar, foi considerado como pertencente à família e não ao indivíduo.

É definido como "processo normal e complexo que inclui respostas e comportamentos emocionais físicos, espirituais, sociais e intelectuais, por meio dos quais indivíduos, famílias e comunidades incorporam uma perda real, antecipada ou percebida às suas vidas diárias" (NANDA-I, 2015).

Foi laborado em $85,3 \%$ da amostra estudada, associado ao quadro de terminalidade e à proximidade do morrer em que os pacientes encontravam-se, bem como ao momento de vida experienciado por seus familiares/cuidadores. As características definidoras de maior prevalência foram sofrimento psicológico, presente em 29 famílias (100\%) com esse diagnóstico, desespero presente em 20 famílias $(68,9 \%)$ e a desorganização identificada em 14 famílias $(48,3 \%)$.

Parkes (2001), ao fazer uma revisão histórica sobre o estudo do luto, descreve que, em 1621, o médico Robert Burton publicou The Anatomy of Melancholie, obra na qual apresenta o pesar como sintoma e causa principal da melancolia ou daquilo que, modernamente, chamamos de depressão clínica.

No trabalho de Rossi (2006) com familiares de pacientes, vítimas de queimaduras, foram identificados 18 diagnósticos de enfermagem e o diagnóstico de pesar esteve presente em $65 \%$ dos entrevistados. Os fatores relacionados ao diagnóstico de pesar no referido estudo 
foram a percepção de um perda potencial e a ameaça no estado de saúde. A evidência clinica observada foi a expressão de sentimentos de tristeza e angústia em relação à morte de seus familiares. Esse dado corrobora com o dado encontrado no presente estudo considerando-se a semelhança em relação ao perfil de gravidade dos clientes críticos oncológicos e doentes acometidos por queimaduras.

Observou-se carência de estudos quantitativos sobre diagnósticos de enfermagem identificados em familiares de clientes acometidos por doenças oncológicas ou situações de hospitalização com prognóstico ruim/indefinido. As publicações encontradas apresentavam abordagem qualitativa tratando sobre os sentimentos apresentados pelos membros da família de doentes terminais dentro do campo de atuação da psicologia e da enfermagem, quase que em sua totalidade. Merecem destaque cinco estudos: Andrade (2012) que trabalha a comunicação como estratégia, Fonseca (2012) que investiga a vivência dos familiares de pacientes com câncer em processo de terminalidade, Avanci (2009) que trabalha a ótica do cuidar em crianças oncológicas na situação do viver/morrer, Inocenti (2008) que estuda as vivências e sentimentos do cuidador e Capello (2011) que trabalhou a questão do enfrentamento frente à terminalidade.

\subsubsection{Tristeza crônica (família)}

Observou-se o diagnóstico Tristeza crônica em 85,3\% dos familiares dos clientes. Esse diagnóstico foi considerado na família e não no indivíduo.

A definição apresentada na Taxonomia II é: "Padrão cíclico, recorrente e potencialmente progressivo de tristeza disseminada, vivenciada (por pai/mãe, cuidador ou indivíduo com enfermidade crônica ou deficiência) em resposta à perda contínua ao longo da trajetória de uma enfermidade ou deficiência” (NANDA-I, 2015).

As características definidoras foram relatos de sentimentos negativos que estiveram presentes em 21 familiares de clientes $(72,4 \%)$ e a tristeza que foram observados em 12 familiares de clientes $(41,4 \%)$ na amostra estudada.

Os fatores relacionados foram: proximidade da morte de uma pessoa amada presente em $100 \%$ dos familiares de pacientes para os quais foi definido esse diagnóstico. Observou-se ainda como fator crise no controle da enfermidade. 
Os achados de Carvalho (2012) estão em consonância com os dados observados na atual pesquisa. Seu trabalho envolvendo familiares de pacientes em tratamento paliativo ou gravemente enfermos indicam a presença desse diagnóstico, porém com frequências variáveis, onde evidenciou-se que o diagnóstico de Tristeza crônica esteve presente em 69\% dos familiares de pacientes sem prognóstico curativo, o que corrobora o achado no presente estudo.

$\mathrm{Na}$ pesquisa de Almeida (2009), que analisou os sentimentos dos familiares em relação ao paciente internado em unidade de terapia intensiva, pôde-se identificar que 78,9\% dos participantes apresentaram angústia e tristeza relacionados à distância do parente, ao fato de não poder ajudar diretamente, à situação de incerteza e à possibilidade constante de morte, assim como ao fato de presenciar o sofrimento do parente e à falta de reação quanto ao tratamento. Dado que se assemelha ao encontrado no presente estudo.

Para Chiattone (2000) a possibilidade de perda é geradora de intensa angústia e desorganização psicológica. O estudo de Silva (2003) afirma que a morte de um dos membros da família é um momento marcante de crise pelos quais esta passará. A forma como a morte é encarada varia drasticamente de cultura para cultura, e de uma época para outra. Por mais suave que seja essa transição, a morte sempre tem algo de doloroso que necessita ser vivenciado. No entanto, apesar de existirem formas específicas para se lidar com a morte em cada cultura, cada família dará uma roupagem própria a esta forma, interpretando-a à sua maneira. Os conceitos trabalhados nos estudos de Chiattone (2000) e Silva (2003) nos trazem subsídios teóricos para compreensão da alta prevalência do diagnóstico de tristeza nos familiares de clientes gravemente doentes e em cuidados paliativos.

Objetivou-se inicialmente a aplicação das Escala de Avaliação de Ansiedade de Hamilton (Ham-A) e Escala de Percepção de Estresse (PSS 14), nos clientes participantes da pesquisa. Mas a aplicabilidade não foi possível uma vez que 32 clientes encontravam sem possibilidade de avaliação devido sedação, rebaixamento do nível de consciência ou confusão mental.

\subsubsection{Incontinência intestinal}

Receberam o diagnóstico de Incontinência intestinal, 97,1\% dos clientes do da amostra estudada. Esse diagnóstico é definido como sendo o estado no qual o indivíduo experimenta 
uma mudança nos hábitos intestinais, caracterizada pela eliminação involuntária de fezes (NANDA-I, 2015). Os fatores relacionados mais frequentes foram o déficit no autocuidado relacionado à higiene íntima, a imobilidade e agentes farmacológicos, presentes em 27 clientes. As características definidoras foram o odor fecal, a presença de manchas de fezes na roupa (fralda ou bolsa de colostomia), e a passagem constante de fezes amolecidas. Observouse que $12 \%$ dos clientes possuíam colostomias.

Dados encontrados na pesquisa de Pagnocelli (2015) corroboram os dados observados no presente estudo, descrevendo que a incontinência fecal afeta de forma significativa a qualidade de vida e tem um importante impacto econômico. A prevalência de incontinência fecal em pacientes em cuidados intensivos é de 18 a 33\%, podendo agravar o quadro clínico de pacientes hospitalizados, especialmente em unidades de terapia intensiva.

Já em pesquisa realizada por Junkin (2007) com 608 pacientes acamados, a frequência desse diagnóstico foi elevada, 87,6\% apresentavam a incontinência fecal, sendo que destes 92,7\% estavam em uso de fraldas devido ausência de controle dos esfíncteres anais pelo uso de medicamentos sedativos por via endovenosa em infusão contínua, dado que muito se assemelha ao resultado encontrado na clientela pertencente à presente amostra.

$\mathrm{Na}$ análise dos pacientes colostomizados, esses dados são corroborados em recente estudo realizado por Lino (2014) com pacientes portadores de estomias gastrintestinais onde evidenciou-se o diagnóstico de Incontinência intestinal em $60 \%$ dos pacientes, onde $58 \%$ dos pacientes avaliados estavam uso de estomias excretórias.

A elevada frequência desse diagnóstico era esperada, uma vez que a maior parte dos clientes encontrava-se em uso de sedação contínua que resulta na incapacidade de controlar a eliminação das fezes. Além da sedação, o fator idade também pode influenciar no controle do esfíncter anal, pois o envelhecimento provoca diminuição das células da musculatura do períneo, denervação com consequente fechamento insuficiente do canal anal (OTTO, 2012).

\subsubsection{Ventilação espontânea prejudicada / Padrão respiratório ineficaz}

Dos 34 pacientes avaliados neste estudo, 76,5\% apresentaram o diagnóstico de enfermagem de ventilação espontânea prejudicada que é definido como a "reserva de energias 
diminuídas, resultando em incapacidade de manter respiração adequada para sustentação da vida" (NANDA-I, 2015).

Já o diagnóstico de enfermagem Padrão respiratório ineficaz, consiste na "inspiração e/ou expiração que não proporciona ventilação adequada" (NANDA-I, 2015). Optou-se por manter esses dois diagnósticos em conjunto por serem complementares. A ventilação mecânica muitas vezes mantém os parâmetros respiratórios do indivíduo dentro da normalidade, uma vez que estabilizam as variáveis críticas como saturação de oxigênio, dióxido de carbono, ritmos e frequências respiratórias. Assim, ao elaborar esse diagnóstico, nos pacientes sob ventilação mecânica, muitas evidências clínicas apontadas pela NANDA-I (2015) não podiam ser identificadas, mas é verdade que a respiração desses indivíduos está afetada. Assim, optou-se por usar em associação com o diagnóstico Padrão respiratório ineficaz, para mostrar a alteração presente.

Assim, considerando os dois diagnósticos, foram elencadas as seguintes características definidoras: padrão respiratório anormal, observada em 26 clientes (100\%), uso de musculatura acessória para respirar $(69,2 \%)$, dispnéia $(38,5 \%)$ e frequência cardíaca aumentada.

Situações que desencadearam essa resposta humana são relativas às doenças respiratórias de base, como a presença de doença pulmonar (84,6\%), uma vez que 22 clientes (65\%) possuíam diagnóstico de pneumonia que alteraram a fisiologia respiratória desses indivíduos. Essa condição gera a dificuldade respiratória e por isso foi acrescentada como um fator relacionado não presente na NANDA-I. Outros fatores relacionados para esses diagnósticos envolveram danos musculoesqueléticos, neurológicos e fadiga respiratória, além do prejuízo neuromuscular induzido pela sedação e a alteração no metabolismo.

Ressalta-se que 26 clientes (100\%) apresentaram esse diagnóstico, todos eles apresentaram vias aéreas artificiais (estavam sob ventilação mecânica).

Estudo realizado por TRUPELL (2009) em uma unidade de pneumologia evidenciou que, dos pacientes que apresentavam neoplasia, detectou-se o diagnóstico Padrão respiratório ineficaz em 29\% dos pacientes e o diagnóstico de Ventilação espontânea prejudicada em 18\% dos avaliados. Já estudo realizado por SALOMÉ (2011) com pacientes críticos demonstraram que $98,7 \%$ dos pacientes avaliados possuíam o diagnóstico Ventilação espontânea 
prejudicada, tendo como características definidoras a dispneia, pCO2 diminuída, agitação, frequência cardíaca aumentada e saturação diminuída.

Estudo realizado por TRUPELL (2009) evidenciou-se o diagnóstico de Ventilação espontânea prejudicada em 95\% dos casos analisados e Padrão respiratório ineficaz em 75\% dos pacientes da terapia intensiva avaliada. Tais achados corroboram a evidência deste estudo, considerando o percentual elevado de $94,1 \%$ dos pacientes internados em UTI, todos com algum tipo de suporte ventilatório (ventilação mecânica ou suporte de oxigênio por máscara).

\subsubsection{Dor aguda}

Esse diagnóstico é definido como: "Experiência sensorial e emocional desagradável associada à lesão tissular real ou potencial ou descrita em termos de tal lesão; início súbito ou lento, de intensidade leve a intensa, constante ou recorrente com término antecipado ou previsível e duração de menos de três meses" (NANDA-I, 2015). Observou-se que 23 clientes $(67,6 \%)$ da amostra apresentaram esse tipo de dor, e foram apresentadas as seguintes características definidoras: evidência de dor usando escalas de avaliação, expressão facial e o autorrelato de intensidade usando escala padronizada. O fator relacionado desse diagnóstico foi a presença de agentes lesivos físicos ou biológicos.

Destaca-se que ao se utilizar as escalas de dor pode-se avaliar clientes com nível de consciência alterado ou até mesmo sedados. No presente estudo as escalas de avaliação da dor foram aplicadas para $100 \%$ da amostra. Utilizou-se a escala verbal analógica para aqueles conscientes, dois clientes, e a Behavioral Pain Scale para os demais (21 clientes). Para os conscientes, $100 \%$ fizeram relato verbal de dor entre 6 e 7 , ou seja dor de intensidade moderada, enquanto 21 deles, que apresentavam rebaixamento do nível de consciência ou estavam sedados $(91,3 \%)$, apresentaram comportamento compatível com presença de dor com escores entre 7 e 12, ou seja dor intensa. Dos 34 avaliados no estudo, 76,5\% possuíam mestástase. Dos clientes avaliados com dor presente no momento da avaliação 61,5\% possuíam diagnóstico de doença metastática. A dor foi avaliada em indivíduos sedados através da escala comportamental e identificada mesmo estando estes em uso de sedação leve a moderada. 
A dor está presente em $50 \%$ dos doentes, quando nos referimos à fase final da vida, a dor atinge uma prevalência de 75 a 85\% (ARANTES, 2008), sendo esse dado semelhante ao dado observado na clientela estudada.

Entre 46 e 92\% dos casos, a dor do doente oncológico está diretamente ligada ao próprio câncer (metástases), em 12 a 29\% relaciona-se com o câncer, em 5 a $20 \%$ está relacionada ao tratamento (ARANTES, 2008). Esse dado também corrobora com o dado observado na clientela diagnosticada com dor aguda, pois 61,5\% possuíam mestástase.

No trabalho de Sousa (2015) o diagnóstico de Dor aguda foi observado em 62,5\% dos pacientes onco-hematológicos e no estudo de Cleeland (1994) realizado com doentes oncológicos portadores de dor, observado em 1.308 doentes com câncer metastático, dor de intensidade igual ou superior a 5 em $62 \%$ dos casos. Em relação à intensidade da dor identificada, o dado apresentado se assemelha ao dado observado uma vez que 90,4\% apresentaram dor de intensidade severa.

A intensidade da dor do câncer varia de acordo com a localização do tumor e das metástases e do estágio de evolução da neoplasia, além das variações relacionadas aos aspectos socioculturais e psicológicos próprios de cada indivíduo (ARANTES, 2008).

\subsubsection{Volume de líquidos excessivo}

Dos 34 pacientes avaliados neste estudo, 58,8\% apresentaram o diagnóstico de enfermagem Volume de líquidos excessivo, definido como a retenção aumentada de líquidos isotônicos (NANDA-I, 2015). As características definidoras foram o edema presente em 90\% dos clientes diagnosticados, hematócrito diminuído (80\%), hemoglobina diminuída (80\%), dispnéia $(38,5 \%)$ e desequilíbrio eletrolítico $(40 \%)$.

O fator relacionado identificado em todos os clientes para os quais esse diagnóstico foi atribuído foi a presença de mecanismo regulador comprometido.

Lopes (1997) avaliou pacientes oncológicos evidenciou-se o diagnóstico de volume de líquidos excessivo em 49,3\% dos clientes relacionado ao retorno venoso prejudicado e evidenciado por edema em membros inferiores e/ou à compressão venosa secundária à 
distensão abdominal e/ou hepatoesplenomegalia, que são características presentes em muitos pacientes oncológicos, em especial em final de vida.

Já estudo realizado por Sousa (2005) esse diagnóstico estava relacionado à infusão excessiva de líquidos (nutrição parenteral contínua, ciclosporina, soroterapia). Nota-se uma relação com os pacientes avaliados nestes estudos, que em sua maioria encontrava-se internado em UTI, local em que há uma série de infusões contínuas entre antibióticos, nutrições parenterais, hemocomponentes e reposições hidroeletrolíticas. Tais achados vão ao encontro dos achados do presente estudo.

\subsubsection{Risco de aspiração}

Observou-se no presente estudo, que $100 \%$ dos clientes avaliados foram diagnosticados com Risco de aspiração, definido como vulnerabilidade à entrada de secreções gastrintestinais, secreções orofaríngeas, sólidos ou líquidos nas vias traqueobrônquicas que podem comprometer a saúde (NANDA-I, 2015). Os fatores de risco de maior prevalência foram a capacidade de deglutição prejudicada, identificada em 34 clientes (100\%), seguido alimentação enteral (29\%) e da presença de resíduo gástrico $(23,5 \%)$.

Os dados do presente estudo referentes ao risco de aspiração também estão em consonância com outros achados de pesquisa.

Em pesquisa realizada por TRUPPEL (2009) com pacientes adultos internados em Unidade de Terapia Intensiva detectou-se que 90\% dos pacientes avaliados apresentavam Risco para aspiração, corroborando o encontrado neste estudo em que 94,1\% estavam internados em UTI, dos quais 87,5\% estavam em ventilação mecânica e utilizavam sonda nasoenteral, ambos fatores de risco para aspiração.

\subsubsection{Risco de quedas}

O diagnóstico Risco de quedas é definido como: "Vulnerabilidade ao aumento da susceptibilidade a quedas que pode causar dano físico e comprometer a saúde" (NANDA-I, 2015). Este diagnóstico foi identificado em todos os clientes estudados (100\%). Os fatores de risco de maior incidência no estudo foram a idade acima de 65 anos, a mobilidade física prejudicada e a própria neoplasia. Estudos recomendam que o enfermeiro utilize um sistema de escores para avaliação do risco de quedas e implemente ações preventivas em conjunto 
com outros profissionais da equipe multidisciplinar (URBANETTO, 2013). No estudo em questão utilizou-se o score de risco de Morse, onde 100\% da amostra apresentou escore compatível com alto risco para quedas (pontuação maior que 50). A pontuação média foi de 81,6 pontos. Dentre os itens avaliados na escala três clientes $(8,8 \%)$ apresentavam história de queda nos últimos 3 meses, o que conferiu a cada cliente 25 pontos, 82,3\% possuíam algum diagnóstico secundário (comorbidades) recebendo assim 15 pontos na escala, dois $(5,8 \%)$ necessitavam de ajuda para caminhar recebendo por este motivo 30 pontos e os demais não foram avaliados devido sedação, 94,1\% possuíam algum tipo de acesso venoso o que conferiu a cada cliente 20 pontos, $100 \%$ dos clientes estavam acamados ou imóveis ( 0 pontos) e 94,1\% estavam em sedação, rebaixamento do nível de consciência ou confusão o que impediu que esta variável fosse avaliada nesses clientes.

Os dados do presente estudo referentes ao risco de queda estão em consonância com outros achados de pesquisa como o relatado por Urbanetto (2013) e Costa (2015).

No estudo de Costa (2015) que realiza revisão integrativa sobre a neuropatia periférica induzida pela quimioterapia através de estudo exploratório prospectivo, o autor avaliou os possíveis fatores de risco para quedas em um grupo de paciente com neuropatia periférica induzida pela quimioterapia. Os resultados indicaram que idade avançada, fadiga, fraqueza generalizada, fraqueza, atrofia muscular e anemia aumentam o risco de quedas em paciente oncológicos em processo de quimioterapia. Afirmam, ainda, que pessoas idosas com mais de 75 anos tem 5 vezes mais chances de queda comparada a pessoas idosas com 65 anos ou menos.

No trabalho de Aquino (2011), que realizou o mapeamento dos diagnósticos de enfermagem em uma unidade de pneumologia em 2011, dos 35 pacientes avaliados, 23\% apresentavam algum tipo de neoplasia pulmonar. Neste estudo, verificou-se o diagnóstico Risco de quedas em $59 \%$ dos casos, tendo como principais fatores de risco a força diminuída nas extremidades inferiores (60\%) e idade acima de 65 anos (55\%).

\subsubsection{Risco de sangramento}

Com relação ao diagnóstico Risco de sangramento, definido na taxonomia NANDA-I como "vulnerabilidade à redução no volume de sangue que pode comprometer a saúde", houve a incidência em $97,1 \%$ dos casos avaliados no presente estudo. Na amostra em questão 
97,1\% dos clientes apresentaram como fatores de risco para esse diagnóstico o regime de tratamento e a função hepática prejudicada.

Corroborando com Sousa (2015), o risco de sangramento também apresentou frequência maior que 50\% nos casos observados, estando relacionado à coagulopatias inerentes à doença e/ou tratamento, pois além do número de plaquetas reduzido, os pacientes onco-hematológicos também apresentavam sintomatologia decorrentes desta redução. A condição do paciente hematológico muito se assemelha à condição do paciente oncológico no que diz respeito às alterações hematológicas secundárias à doença relacionadas à realização de quimioterapia prévia e ao uso de anticoagulantes.

\subsubsection{Risco de síndrome do desuso}

O diagnóstico de enfermagem de Risco de síndrome do desuso é definido como a "vulnerabilidade à deterioração de sistemas do corpo como resultado da inatividade musculoesquelética prescrita ou inevitável que pode comprometer à saúde" (NANDA-I, 2015). Foi diagnosticado em 94,1\% dos clientes oncológicos em cuidados paliativos avaliados, os quais se encontravam em sua totalidade internados em UTI, acamados, em sedação, $92 \%$ em uso de ventilação mecânica e $8 \%$ em uso de máscara para suporte suplementar de oxigênio. Além disso, 88,4\% apresentavam algum tipo de metástase. Os fatores de risco relacionados a esse diagnóstico foram a imobilização $(90,6 \%)$ e o nível de consciência alterado presente nos cinco clientes $(15,6 \%)$ que não estavam sedados.

Em trabalho realizado por Moreira (2008) com pacientes críticos com diagnóstico de acidente vascular encefálico foi evidenciado o diagnóstico de risco de síndrome do desuso como um dos sete mais frequentes, estando presente em $80,2 \%$ dos pacientes avaliados.

O que confirma que as doenças crônicas como acidente vascular encefálico e o câncer favorecem o risco de síndrome do desuso devido ao elevado tempo de internação, às condições clinicas e sequelas que estas doenças provocam nos indivíduos que são por elas acometidos.

\subsubsection{Risco de olho seco}

O diagnóstico de enfermagem de Risco de olho seco é definido como "vulnerabilidade ao desconforto ocular ou danos à córnea e à conjuntiva devido à quantidade reduzida ou 
qualidade das lágrimas para hidratar o olho" (NANDA-I, 2015). No presente estudo, 91,2\% dos pacientes avaliados apresentaram o diagnóstico em questão, sendo o fator de risco de maior prevalência o regime de tratamento, a ventilação mecânica que estiveram presentes em 29 clientes $(93,5 \%)$ diagnosticados com esse risco. Outro fator identificado foi o envelhecimento, uma vez que o maior percentual de clientes da amostra era idosos.

Estudo realizado por ARAÚJO (2014) afirma-se que as drogas relaxantes musculares e sedativas são complexas e ameaçadoras para o olho seco, sendo apontadas, em sua revisão bibliográfica, em 55,55\% e 70,37\% dos estudos, respectivamente. Explica, ainda, que quando os sedativos e relaxantes musculares são administrados, o fechamento das pálpebras é determinado apenas por forças passivas, dessa forma, a incapacidade de mantê-las completamente fechadas conduz à exposição da conjuntiva e/ou da córnea resultando em secagem ocular.

Todos os pacientes que apresentaram Risco de olho seco no presente estudo estavam em ambiente de UTI, em uso de sedativo ou relaxante muscular e $87 \%$ estavam em ventilação mecânica.

\subsubsection{Risco de integridade da pele prejudicada}

O diagnóstico de Risco de integridade da pele prejudicada é definido como "vulnerabilidade à alteração na epiderme e/ou derme, que pode comprometer a saúde" (NANDA-I, 2015). No presente estudo, 61,8\% dos pacientes avaliados apresentaram o diagnóstico Risco de Integridade da pele prejudicada. Esse fato é justificável tendo em vista que $94,1 \%$ estavam internados em UTI e que, destes, 87,5\% estavam em ventilação mecânica e sedação, o que reduz a capacidade de mobilidade no leito, elevando o risco para integridade da pele prejudicada.

Os fatores de risco identificados foram os fatores mecânicos presentes em 21 clientes, pressão sobre saliência ósseas, o risco evidenciado pela escala de Braden e o extremo de idade que estiveram presentes em 21 indivíduos, já o estado nutricional desequilibrado estava presente em apenas 8 destes. Dos avaliados 23,5\% possuíam úlcera por pressão, quatro apresentavam mucosite e apenas um apresentou dermatite associada à incontinência. Das 
úlceras por pressão observadas $75 \%$ tinham localização sacra e $25 \%$ se apresentavam no calcâneo, e 62,5\% das lesões eram de grau III.

Segundo Otto (2012) as lesões cutâneas de maior prevalência em pacientes oncológicos críticos são em ordem de frequência as úlceras por pressão, as dermatites relacionadas à incontinência e as mucosite. Esse dado corrobora com o dado observado nos clientes que participaram da amostra do presente estudo.

Em pesquisas realizadas por Hendrichova (2010) a prevalência de úlcera por pressão em pessoas em cuidados paliativos variou de 10,5 a 26\%. Já o estudo realizado por Queiroz (2014) que avaliou a prevalência e as características dos pacientes em cuidados paliativos portadores de úlcera por pressão foi observado que 58,3\% dos pacientes possuíam alguma úlcera, sendo o estágio três, o estágio mais frequente $(47,3 \%)$. Os dados obtidos no presente estudo se assemelham ao que foi observado por Hendrichova (2010) no que se refere à incidência da lesão, tendo frequência bem maior que a observada no estudo de Queiroz (2014). No que se refere ao estágio da lesão, o dado observado na clientela do presente estudo reafirma a prevalência do grau III apresentada por Queiroz (2014).

Utilizou-se nesse estudo a aplicação da escala de Braden para avaliação do risco de úlcera por pressão com pontuação média de 7,6 pontos. Foi observado que 94,1\% apresentavam alto risco para desenvolver úlcera por pressão e 5,9\% tinham risco moderado. $\mathrm{Na}$ categoria percepção sensorial 85,3\% dos clientes eram completamente limitados e 14,7\% eram muitos limitados. Na categoria umidade 20 clientes $(58,8 \%)$ estavam constantemente úmidos e 41,2\% deles encontravam-se em situação de muita umidade, ambos relacionados ao uso de fraldas. Já na categoria atividade 85,3\% eram acamados e dentro da categoria mobilidade 29 clientes estavam completamente imobilizados devido uso de sedação contínua. Em relação à nutrição $76,5 \%$ dos clientes avaliados apresentavam estado nutricional provavelmente adequado, estando apenas 23,5\% com nutrição muito pobre. Quando avaliado fricção/cisalhamento o problema esteve presente em 76,5\% dos clientes e 23,5\% deles apresentavam potencial para esse problema.

Estudo realizado por Mercês (2011) que avaliou pacientes portadores de tumores de cabeça e pescoço, dos 58 diagnósticos de enfermagem identificados, o diagnóstico de Risco de Integridade da pele prejudicada foi o de maior prevalência. 
Estudo realizado por Sousa (2015) evidenciou que 16,7\% dos pacientes estudados apresentavam o diagnóstico de risco de integridade da pele prejudicada. Os fatores de risco foram emagrecimento e pele com turgor diminuído, que também foram identificados nos clientes oncológicos críticos do presente estudo. 


\section{CONCLUSÕES}

O presente estudo teve como objetivo identificar os diagnósticos de enfermagem mais frequentes em um grupo de pacientes oncológicos críticos em protocolo de cuidados paliativos, utilizando a Classificação da Taxonomia da NANDA-I, com fundamentação na Teoria do Alcance de Metas de Imogene King.

A articulação sistêmica entre cliente, enfermeiro, organização social e processo de enfermagem já é um grande desafio, considerando a assistência de enfermagem em geral. Quando se trata da assistência ao paciente oncológico, crítico e em cuidados paliativos, o processo de enfermagem, para que tal articulação ocorra, torna-se ainda mais complexo e desafiador, sendo necessária a atuação fundamentada em conhecimento científico e evidenciada por um processo de enfermagem claro sobre a assistência a ser prestada.

Com relação ao contexto socioeconômico-demográfico, pôde-se concluir neste estudo que houve paridade entre os sexos, com prevalência de idade média de 74,4 anos, com escolaridade de ensino fundamental completo, renda familiar entre 2 e 5 salários mínimos e predomínio de viúvos.

Relacionado à internação hospitalar, o tempo médio de permanência foi de 16,2 dias, com maior incidência de permanência entre 2 a 10 dias, com desfecho de óbito de 94,1\% dos 34 pacientes avaliados. Em relação à topografia da doença oncológica observou-se maior prevalência das neoplasias pulmonares 6 pacientes $(17,6 \%)$, seguido das neoplasias de sistema nervoso central 5 pacientes $(14,7 \%)$, mama e próstata 4 pacientes cada $(11,8 \%)$, bexiga e cólon 3 pacientes cada $(8,8 \%)$, renal e útero 2 pacientes cada $(5,9 \%)$, neoplasias gástricas, hepáticas, ósseas, ovarianas e de tireoide apresentaram frequência de 2,9\% cada, correspondendo a 1 paciente.

A avaliação através das escalas aplicadas apresentou-se com os seguintes resultados: $79,4 \%$ com alto risco para desenvolvimento de úlcera por pressão, conforme Escala de Braden; $82,4 \%$ com risco para quedas, conforme escala de Morse; paridade entre dor moderada e dor severa para EVA e 64,7\% com características comportamentais para dor, conforme BPS. As escalas de avaliação de ansiedade e percepção de estresse foram utilizadas apenas em 02 pacientes, devido ao nível de consciência adequado para a análise apenas nesta pequena amostra. 
Foram relacionados neste estudo, 718 diagnósticos de enfermagem para os 34 clientes, com levantamento de 51 rótulos diferentes de diagnósticos elaborados de acordo com a taxonomia II da NANDA-I. Na perspectiva dos três sistemas mencionados por Imogene King, observou-se que os diagnósticos encontrados contemplaram todos os sistemas propostos, com prevalência daqueles vinculados ao sistema pessoal $(82,4 \%)$, seguido do sistema interpessoal $(13,7 \%)$ e apenas $3,9 \%$ no sistema social.

Com relação à distribuição dos diagnósticos por domínios nos 34 clientes avaliados, encontrou-se: 35 diagnósticos no domínio Promoção da Saúde; 68 diagnósticos no domínio Nutrição; 76 diagnósticos no domínio Eliminação e Troca; 145 diagnósticos no domínio Atividade/Repouso; 64 diagnósticos no domínio Percepção/Cognição; três diagnósticos no domínio Autopercepção; 60 diagnósticos no domínio Enfrentamento / Tolerância ao estresse; 28 diagnósticos no domínio Princípios da vida; 214 diagnósticos no domínio Segurança e Proteção, e 25 diagnósticos no domínio Conforto.

A taxonomia da NANDA-I possibilitou o levantamento de 718 diagnósticos de enfermagem ao todo na amostra estudada, com média de 21,11 diagnósticos por paciente. Destes obteve-se um total de 51 diagnósticos diferentes, sendo 38 deles diagnósticos reais e 13 de vulnerabilidade.

Os diagnósticos com frequência maior que 50\% foram: Déficit no autocuidado, Deglutição prejudicada, Mobilidade física prejudicada, Proteção ineficaz, Risco de queda e Risco de aspiração, Risco de sangramento, Eliminação urinária prejudicada, Risco de síndrome do desuso, Comunicação verbal prejudicada, Risco de olho seco, Processos familiares disfuncionais, Dentição prejudicada, Pesar, Tristeza crônica, Incontinência intestinal, Ventilação espontânea prejudicada/ Padrão respiratório ineficaz, Dor aguda, Risco de integridade da pele prejudicada e Volume de líquidos excessivo.

Os objetivos do estudo foram alcançados, e o método utilizado adequado, permitindo conhecer melhor o paciente em questão. O instrumento permitiu abordagem do cliente e de sua família no que se refere ao acesso aos dados de maior relevância para a identificação de problemas reais e potenciais.

O uso das classificações de diagnósticos proporcionou levantamento completo dos problemas através de linguagem padronizada. Quanto às limitações do estudo, destacam-se a ausência de estudos similares com pacientes oncológicos em cuidados paliativos, que 
possibilitassem uma discussão maior; necessidade de mais estudos que abordem os diagnósticos direcionados à família para validação da proposta atual; a inexistência de setor destinado à pacientes oncológicos onde de fato os princípios do cuidados paliativos pudessem ser aplicados em sua totalidade e as deficiências no processo de comunicação de más noticias entre equipe de saúde, cliente e famílias. A questão da ausência de estudos similares com pacientes oncológicos em cuidados paliativos pode também ser vista como uma lacuna de conhecimento que justifica a elaboração da presente pesquisa.

$\mathrm{Na}$ etapa de análise dos casos percebeu-se a importância do raciocínio diagnóstico e do conhecimento da taxonomia, especialmente para a definição de qual diagnóstico se aplicava melhor àquela realidade observada, mas a reflexão apoiada na definição de cada conceito diagnóstico e o processo de validação com perito da área possibilitou melhor raciocínio para a aplicação do diagnóstico mais apropriado.

Acredita-se que, com os resultados obtidos neste estudo, os instrumentos aqui utilizados servirão de apoio aos enfermeiros atuantes em Unidades oncológicas e Unidade de Terapia Intensiva no que se refere à aplicação do processo de enfermagem nos casos de clientes oncológicos em cuidados paliativos e às suas famílias.

O processo de realização deste estudo permitiu reflexões sobre a importância de se conhecer a essência do raciocínio clínico e as diferentes habilidades, que envolvem a aplicação do processo de enfermagem.

Foi obtido, através dessa pesquisa, um resultado não planejado, mas de repercussão extremamente positiva no hospital do estudo. Houve a criação de um grupo de discussão multidisciplinar, com reuniões semanais, envolvendo todos os membros da equipe de saúde que assistem os pacientes e familiares em questão. A política de paliativismo e terminalidade foi reestruturada e houve refinamento nos critérios para encaminhamento do cliente para as Unidades de Terapia Intensiva do serviço de saúde campo desta pesquisa. Houve ainda revisão no processo de acolhimento dos familiares do paciente oncológico e aprimoramento na participação do profissional psicólogo no que se refere ao atendimento e acompanhamento destes.

Espera-se que este estudo possa contribuir com o conhecimento da enfermagem e, em especial, com o processo revisão na implementação da Sistematização da Assistência de 
Enfermagem e cuidado ao paciente Oncológico em cuidado paliativo na Instituição onde foi realizado o estudo. 


\section{REFERÊNCIAS}

ABREU, L. A. Sobre narrativas orais, narradores e cuidados paliativos. In: Santos FS editor. Cuidados Paliativos: diretrizes, humanização e alivio dos sintomas. São Paulo: Atheneu; 2011.

AHLERS, S.J. The use of the Behavioral Pain Scale. 2010.

ALMEIDA, A. S. Sentimentos dos familiares em relação ao paciente internado na unidade de terapia intensiva. Revista Brasileira de Enfermagem, v. 62, n. 6. Brasília 2009.

ANDRADE, C. G. Cuidados paliativos: a comunicação como estratégia de cuidado para o paciente em fase terminal. Revista Ciências \& Saúde coletiva. V. 18, n. 9. 2013.

AQUINO, R.D. Mapeamento dos diagnósticos de enfermagem em uma unidade de pneumologia. Revista Acta Paul Enferm. V.24 n. 2. 2011.

ARANTES, A.C.L.Q. Avaliação e tratamento da dor. Cuidado Paliativo. São Paulo: Conselho Regional de Medicina do Estado de São Paulo, 2008.

ARAÚJO, D.D. Predição de risco e incidência de olho seco em pacientes críticos. 2014. Dissertação (Mestrado em Enfermagem) - Escola de Enfermagem, Universidade Federal de Minas Gerais, Belo Horizonte, 2014.

AVANCI, B. S. Cuidados Paliativos à criança oncológica na situação viver/morrer: a ótica do cuidar em enfermagem - Escola Anna Nery Revista de Enfermagem, V. 13, n. 4. 2009.

AYRES, J.R, Hermenêutica e humanização das práticas de saúde. Revista Ciências Saúde Coletiva. v. 10, n. 3. 2005.

BARbOSA, A. N. Manual de Cuidados Paliativos. Lisboa, Faculdade de Medicina de Lisboa, 2006.

BARROS, A.L.B. Classificações de diagnóstico e intervenção de enfermagem: NANDANIC. Revista Acta Paul Enfermagem, v.22, Especial - 70 Anos. 2009. 
BRASIL. Estimativa 2014: Incidência de Câncer no Brasil / Instituto Nacional de Câncer José Alencar Gomes da Silva, Coordenação de Prevenção e Vigilância. 2014.

BRASIL. Estimativa 2016: Incidência de Câncer no Brasil / Instituto Nacional de Câncer José Alencar Gomes da Silva, Coordenação de Prevenção e Vigilância / Divisão de Vigilância. 2015. Disponível em: < http://www.inca.gov.br/dncc>. Acesso em: 20 dez. 2015.

BRASIL. Instituto Nacional do Câncer José Alencar Gomes da Silva. In: Números. Rio de Janeiro, 2015. Disponível em: < http://www.inca.gov.br/wcm/dmdc/2015/numeros.asp>. Acesso em: 8 mar. 2015.

BRASIL. Ministério da Saúde. Instituto Nacional de Câncer. Intervenções de Enfermagem para controle do câncer. Rio de Janeiro: INCA, 2008.

BRASIL. Ministério da Saúde. Instituto Nacional de Câncer. Cuidados paliativos oncológicos: controle de sintomas. Rio de Janeiro: INCA, 2001.

BRASIL. Ministério da Saúde. Secretaria de Assistência à Saúde. Manual Brasileiro de Acreditação Hospitalar / Secretaria de Assistência à Saúde. - 3. ed. rev. e atual. - Brasília: Ministério da Saúde, 2002.

BREITBART, W. Physician-assisted suicide: the influence of psychosocial issues. Rev. Cancer Control, New York. 1999.

BULECHEK, G.M. Classificação das Intervenções de Enfermagem (NIC). $5^{\circ}$ ed. Rio de Janeiro: Elsevier, 2010.

BURNS, N; GROVE, S.K. Investigacion em enfermaria. 6a . Edição. Espanha: Elsevier Espanha, 2004.

CAMPBELL, M. L. Cuidados paliativos em enfermagem: Nurse to nurse. São Paulo. 2009.

CAPELLO, E. M. C. S. Enfrentamento do paciente oncológico e do familiar/cuidador frente à terminalidade de vida. Revista J Health Sci Inst. V. 30, n. 3. 2012.

CARPENITO, L. J. Planos de cuidados de enfermagem e documentação: diagnósticos de enfermagem e problemas colaborativos. 2. ed. Porto Alegre: Artmed, 1999. 
CARVALHO, M.W.A. Diagnósticos de enfermagem para pacientes com dor oncológica baseados na CIPE. Revista de enfermagem UFPE on line. Recife, v. 9, n. 1. 2015.

CHIATONNE, H. B. C. A significação da psicologia no contexto hospitalar. In V. A. Angerami-Camon (Org.). Psicologia da saúde: um novo significado para a prática clínica (pp.73- 137). São Paulo: Brasil. 2000.

CLEELAND, C.S. Pain and its treatment in outpatients with metastatic cancer, N Engl J Med, v. 330, n. 9, 1994.

COLLIÉRE, F. M. Cuidar: a primeira arte da vida. $2^{\text {a }}$. Edição - Portugal: Lusociência 2003.

Conselho Internacional de Enfermeiros. Classificação Internacional para Prática de Enfermagem CIPE ${ }^{\circledR}$ Versão 1.0. São Paulo (Brasil): Algol; 2007.

COSSA, R. M.V. O ensino do Processo de Enfermagem em uma Universidade Pública e Hospital Universitário do Sul do Brasil na perspectiva de seus docentes e enfermeiros. Rio Grande do Sul, Brasil. 2011.

COSTA, F. Como Implementar Cuidados Paliativos de Qualidade na Unidade de Terapia Intensiva Revista Brasileira de Terapia Intensiva, v 20, n. 1, 2008.

COSTA, T. C. Neuropatia periférica induzida pela quimioterapia: revisão integrativa da literatura. Revista escola de enfermagem da USP, vol.49, n.2. Nova York. 2015.

CRAIG, J.R. Tumors of the Liver and the Intrahepatic Bile Ducts. Washington DC: Armed Forces Institutes of Pathology, 1989.

DOENGES, M.E.; MOORHOUSE, M. F. Diagnósticos De Enfermagem - Intervenções, Prioridades, Fundamentos - Editora: Guanabara Koogan - 12 ${ }^{\mathrm{a}}$ Ed. Rio de Janeiro. 2011.

DONATO, J. Tumores ósseos. In: Metástase de carcinoma. Rio de Janeiro: Rocca; 2001.

FABER, L.K. Process of forgoing life-sustaining treatment in a university hospital: an empirical study - Crit Care Med 1992;20:570-7. 
FIGUEIREDO, M. T. A. Reflexões sobre os cuidados paliativos no Brasil. Revista Brasileira de Terapia Intensiva, V. 47, n. 3. 2008.

FLORIANI, C.A. Palliative care: interfaces, conflicts and necessities. Revista Ciência e Saúde Coletiva. 2008.

FONSECA, C. O. S. Vivências de familiares de pacientes com câncer em processo de terminalidade de vida: um estudo clínico-qualitativo. Dissertação (Mestrado). Escola de Enfermagem de Ribeirão Preto. Universidade de São Paulo, 2012.

FONSECA, J. J. S; Metodologia da pesquisa científica. Fortaleza: UEC, 2002.

FREITAS, E. R. F. S. Perfil e gravidade dos pacientes das unidades de terapia intensiva: aplicação prospectiva do escore APACHE II. Rev. Latino-Am. Enfermagem v. 18, n. 3. 2010, Disponível em 〈http://www.scielo.br/pdf/rlae/v18n3/pt_04.pdf>Acesso em: 16 novembro 2015.

GARCIA. T. P. R. Principais motivos de internação do paciente com Insuficiência Renal Aguda na Unidade de Terapia Intensiva. Arq. ciênc. saúde; v, 12, n. 3. 2015.

GEOVANINI, F; BRAZ, M. Conflitos éticos na comunicação de más notícias em oncologia. Revista de Bioética. (Impr.). v. 21, n. 3. 2013.

GIL, A. C. Como elaborar projetos de pesquisa. 4. ed. São Paulo: Atlas, 2007.

GONDINHO, E. R.; KOCH, A. H. Fontes utilizadas pelas mulheres para a aquisição de conhecimentos sobre o Câncer de Mama. Radiologia Brasileira, São Paulo, v. 38, n. 03. 2004.

INOCENTI, A. Vivências e sentimentos do cuidador familiar do paciente oncológico em cuidados paliativos. Revista Eletrônica de Enfermagem, V. 11, n. 4. 2009. Disponível em http://www.fen.ufg.br/revista/v11/n4/v11n4a11.htm Acesso em 20 de outubro 2015.

JESUS, C.A.C. Assistência de Enfermagem a clientes hematológicos: uma visão sistêmica. Dissertação (Mestrado). Escola de Enfermagem de Ribeirão Preto. Universidade de São Paulo, 1992. 
JNCI - Relatório Anual à Nação sobre o Estatuto da Câncer, 1975-2011 - Incidência de Câncer subtipos da mama por Raça / Etnia, pobreza e Estado. 2013.

JOHNSON, M. Ligações NANDA - NOC - NIC: condições clínicas: suporte ao raciocínio e assistência de qualidade. Rio de Janeiro: Elsevier, 2012.

JOMAR, R.T. Diagnósticos de enfermagem mais comuns entre adultos/idosos hospitalizados com câncer: revisão integrativa. Rio de Janeiro. Disponível em < http://ecancer.org/journal/8/pdf/462-pt-the-most-common-nursing-diagnosis-among-adultsseniors-hospitalised-with-cancer-integrative-review.php> Acesso em 20 out 2015.

JUNKIN, J. Prevalence of incontinence and associated skin injury in the acute care inpatient. J Wound Ostomy Continence Nurs. V. 34, n. 3. 2007.

KING, I.M. A theory for nursing: systems, concepts, process. New York: J. Wiley, 1981.

KNAUS, W. A, et al. APACHE II: a severity of disease classification system. Crit Care Med. V. 818, n. 29. 1985.

KOVACS, M. J. A Morte no contexto dos cuidados paliativos - 2014 .

KOVÁCS, M. J. Paciente terminal e a questão da morte. In M. J. Kovács (Org.). Morte e desenvolvimento humano (pp.188-203). São Paulo: Brasil.1992.

LINO, A.I.A. Diagnósticos e intervenções de enfermagem no atendimento de indivíduos com estomas gastrointestinais: aplicando o processo de enfermagem. 2014. Disponível em http://repositorio.unb.br/bitstream/10482/16986/1/2014_AlexandraIsabeldeAmorimLino.pdf Acesso em 18 out 2015.

LOPES, R. A. M. Diagnósticos de enfermagem mais frequentes em uma unidade de internação de oncologia. Rev.latino-am.enfermagem, Ribeirão Preto, v. 5, n. 4, 1997.

LUFT, C.D.B. Versão brasileira da Escala de Estresse Percebido: tradução e validação para idosos. 2007.

MACIEL, M. G. S. A terminalidade da vida e os cuidados paliativos no Brasil: considerações e perspectivas. Ver. Prática Hospitalar v.28 n.3, 2006. 
MACIEL, M. G. S. Ética e cuidados paliativos na abordagem de doenças terminais. A Terceira Idade, 2007.

MACIEL, M.G.S. Critérios de qualidade para os cuidados paliativos no Brasil / documento elaborado pela Academia Nacional de Cuidados Paliativos - Rio de Janeiro. 2006.

MANFRO, G. Relação entre idade, sexo, tratamento realizado e estágio da doença com a sobrevida em pacientes terminais com carcinoma epidermóide de laringe - Revista Brasileira de Cancerologia v. 52, n. 1. 2006.

Manual Cuidado Paliativo - CREMESP - Coordenação Institucional de Reinaldo Ayer de Oliveira. São Paulo: Conselho Regional de Medicina do Estado de São Paulo, 2008.

MERCÊS, C.A.M.F. Diagnósticos de enfermagem em pacientes portadores de tumores de cabeça e pescoço: identificação e validação. Projeto Gráfico: Serviço de Edição e Informação Técnico-Científica / CEDC / INCA. 2011.

MINAYO, M.C.S. Uma releitura da obra de Elisabeth Kubler-Ross - Revista Ciência \& Saúde Coletiva, v. 18, n. 9. 2013.

MOORHEAD, S. Classificação dos Resultados de Enfermagem (NOC). $4^{\circ}$ ed. Rio de Janeiro: Elsevier, 2010.

MOREIRA, RP. Acidente vascular encefálico - análise dos diagnósticos de enfermagem da classe atividade/exercício. Fortaleza, 2008. Disponível em $<$ http://www.repositorio.ufc.br/ri/bitstream/riufc/2017/1/2008_dis_rpmoreira.pdf $>$ Acesso em 20 out 2015.

MUKHERJEE, S. O imperador de todos os males: uma biografia do câncer. Tradução: Berilo Vargas. 1ª Edição - São Paulo. Companhia das letras, 2012.

NANDA International. Diagnósticos de enfermagem da NANDA: definições e classificação 2007-2008. Porto Alegre: Artmed, 2008.

NANDA International. Diagnósticos de enfermagem da NANDA: definições e classificação 2012-2014. Porto Alegre: Artmed, 2014.

NANDA International. Diagnósticos de enfermagem da NANDA: definições e classificação 2015-2017. Porto Alegre: Artmed, 2015. 
NEVES, R. S. Diagnósticos de enfermagem em pacientes lesados medulares segundo o modelo conceitual de Horta e a Taxonomia II da NANDA. Dissertação (Mestrado). Faculdade de Ciências da Saúde. Universidade de Brasília.2003.

OMS. Manual Cuidados Paliativos. Brasília, DF: Ministério da Saúde, OMS, 2015. Disponível em: http://www.paliativo.org.br/ancp.php?p=oqueecuidados $>$ Acesso em: 24 de dezembro 2015.

OTTO, S.E, Oncologia. Tradução: Ivan Lourenço Gomes, Maria Angélica Borges dos Santos. Rio de Janeiro: Reichmann e Affonso Editores. 2012.

PARANHOS, W. Avaliação de risco para úlceras de pressão por meio da Escala de Braden, na língua portuguesa. 1999.

PARKES, C. M. A Historical Overview of the Scientific Study of Bereavement. Handbook of Bereavement Research. Consequences, Coping and Care. Washington, D.C., American Psychological Association. 2001.

PASINI, D. e t al. Diagnósticos de enfermagem de paciente $s$ internados em unidades de terapia intensiva. Revista Escola de Enfermagem USP. v. 30 ,n.3, São Paulo, 1996.

PEDROSA, L.C.S. Cuidados de Enfermagem ao paciente com câncer de retossigmóide e uso de ileostomia: estudo de caso. Revista Rede de Cuidados em Saúde. V.12 n. 3. 2006.

PIVA, J. P, Carvalho P.R.A. Considerações éticas nos cuidados médicos do paciente terminal. Disponível em <http:// www.medicinaintensiva.com.br/eutanasia1.htm. $>$ Porto Alegre. Acesso em fev 2014.

PONTES, L. V. Epidemiologia das doenças cardiovasculares e neoplásicas: quando vai ocorrer o cruzamento das curvas? Rev Soc Cardiol Estado de São Paulo. V. 19, n. 4. 2014.

QUILL, T.E. e Brock, D.W., et al. Last-resort options for palliative sedation. Ann Intern Med 2009.

SALDANHA, E. A, Diagnósticos de enfermagem em pacientes submetidos à prostatectomia: identificação da significância dos seus componentes. Universidade 
Federal do Rio Grande do Norte, Programa de Pós-Graduação em Enfermagem. Natal-RN, Brasil. 2014.

SALluH, J. I. F. Políticas de Admissão de Pacientes Oncológicos na UTI: Hora de Rever os Conceitos Revista Brasileira Terapia Intensiva. V. 20, N. 4. 2008.

SALOMÉ, G.M, Diagnósticos de Enfermagem dos pacientes internados em uma Unidade de Terapia Intensiva. Revista Saúde Coletiva, v. 47, n. 8. 2011.

SANTOS, B. N, Diagnósticos de Enfermagem Prevalentes de Pacientes em Pós Operatório de Cirurgia Bariátrica em uma Unidade de Terapia Intensiva. Botucatu, 2010.

SANTOS, R.R, Diagnósticos de enfermagem emocionais identificados na visita préoperatória em pacientes de cirurgia oncológica, Revista Cogitare Enfermagem, v. 12, n. 1. 2007.

SAPORETTI, L. A. Espiritualidade em Cuidados Paliativos. Cuidado paliativo, CREMESP, v. 4, n. 1. 2008.

SILVA, A. L. P, O acompanhamento psicológico a familiares de pacientes oncológicos terminais no cotidiano hospitalar. Revista Interação em Psicologia, v. 7, n. 1. Brasil, 2003.

SILVA, M. J, Comunicação de más Noticias. Revista o Mundo da Saúde. V. 1, 2012.

SILVA, M. J. P; Comunicação com o paciente fora de possibilidades terapêuticas. In: Humanização e cuidados paliativos. São Paulo: Centro Universitário São Camilo/Loyola; 2002.

SILVA, M. J. P; Falando da Comunicação. In: Manual de cuidados paliativos CREMESP. São Paulo: 2008.

SILVA, P. O, Diagnósticos de enfermagem do paciente com neoplasia colorretal em tratamento quimioterápico- uma pesquisa qualitativa. Brazilian Journal of Nursing, v. 7, n. 2. São Paulo, 2008. hematológicos. Anna Nery Revista de Enfermagem. V. 19, n. 1. 2015. 
SOUZA, V. B, Hipertensão Arterial no Paciente com Câncer. Arq Bras Cardiol. [online].ahead print, PP.0-0. 2014.

TANNURE, M.C.; GONÇALVES, A.M.P.; Sistematização da Assistência de Enfermagem, Rio de Janeiro, Guanabara Koogan, 2010.

TOFTHAGEN, C, Peripheral neuropathy in patients with colorectal cancer receiving oxaliplatin. Clin J Oncol Nurs. V.15. n. 2. 2011.

TRUPEL, A. M. Sistematização da Assistência de Enfermagem em Unidade de Terapia Intensiva terapia Intensiva. 2009. Disponível em

http://www.scielo.br/pdf/reben/v62n2/a08v62n2.pdf Acesso em 21/10/2015.

URBANETTO, J.S, Morse Fall Scale: tradução e adaptação transcultural para a língua portuguesa. 2013.

VIEIRA, S.C e SCHNEIDER, F. J. Teoria do Alcance de Metas de King: uma Revisão de Literatura - Rev. Ciência, Cuidado e Saúde - Maringá, v. 2, n. 2, p. 169-176, jul./dez. 2003. 


\section{ANEXOS}

Anexo A

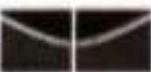

I inisersidate de Brasilia

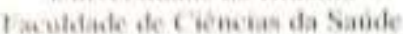

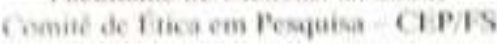

FROKOSOD AUISE DE PROM TO DE PESOHSA

Terule do Proicte: DIACONOSTICOS DH INIIRMAGEM EM PACIENTIS

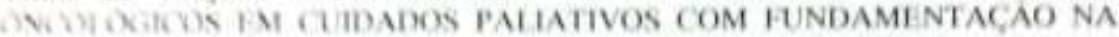
12.

Preqeisaders Roppensavel: SIMONI PRADO DI I IMA DE MIRANDA

Bnta de Burrada: $2011 / 2014$

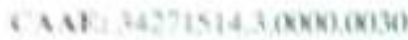

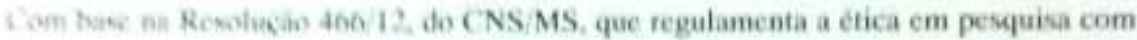
sters hamanos, o comite de flica em Pespuisa com Seres llumanos da Faculdade de

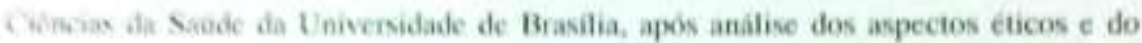

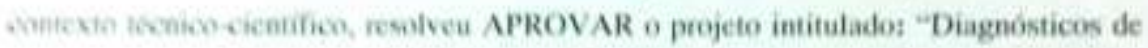
Fatecmagem em Proientex Oncologicos em Cuidados Paliativos com fundamentaçao na Toora do Aleanove de Meias de lmogene King, "Parecer n" 911.607, em 09 de dezembro Ac 3014

Vonition ce o(a) perquisador(a) responsivel da obrigatoriedade da apresentaçáo de um felatono semcsiral e relatorio final sobre o desenvolvimento do projeto, no prazo de 1 (em) ano a comiar da data de aprovaço.

Brasilia, 26 de fevereiro de 2015.

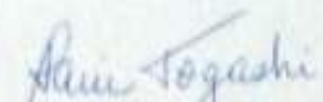

Profa. Dra. Marie Togashi

Coprdenador do CFP.FS/UB

Whef vou Meriv Thuali

Cemad Copolarainva

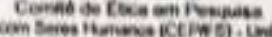

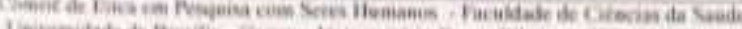

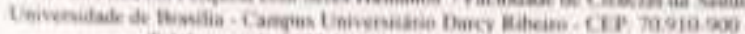

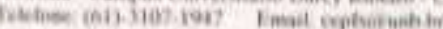




\title{
10. APÊNDICES
}

\section{Apêndice A}

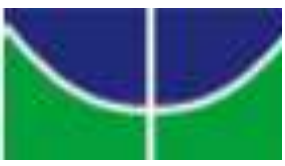

\section{Universidade de Brasília}

\section{Faculdade de Ciências da Saúde}

\section{Programa de Pós-Graduação em Enfermagem}

\section{Mestrando: Simone Prado de Lima de Miranda}

\author{
Orientador: Dra. Cristine Alves Costa de Jesus
}

\section{Termo de Consentimento Livre e Esclarecido - TCLE}

Convidamos o(a) Senhor(a) a participar do projeto de pesquisa Diagnósticos de Enfermagem em Pacientes Oncológicos críticos inclusos em Protocolo de Cuidados Paliativos com fundamentação na Teoria do Alcance de Metas de Imogene King, sob a responsabilidade do pesquisador Simone Prado de Lima de Miranda. O projeto fará caracterização dos pacientes oncológicos em cuidados paliativos quanto ao perfil identificando os problemas reais ou potenciais decorrentes da hospitalização e/ou processo de doença. Uma vez identificados esses problemas será traçado plano de cuidados de enfermagem com fundamentação científica para tratamento e/ou prevenção.

O objetivo desta pesquisa é melhorar a qualidade da assistência de enfermagem através da identificação dos problemas decorrentes da doença e/ou da hospitalização em pacientes oncológicos. Assim, gostaria de consultá-lo (a) sobre seu interesse e disponibilidade de cooperar com a pesquisa.

$\mathrm{O}$ (a) senhor(a) receberá todos os esclarecimentos necessários antes e no decorrer da pesquisa e lhe asseguramos que seu nome não aparecerá sendo mantido o mais rigoroso sigilo pela omissão total de quaisquer informações que permitam identificá-lo(a)

A sua participação se dará por meio de entrevista e realização de exame físico que acontecerá no hospital no leito onde o senhor (a) já encontra-se internado na data combinada com um tempo estimado de 30 minutos para sua realização.

Não existem riscos decorrentes de sua participação na pesquisa, porém se o senhor (a) se sentir desconfortável com alguma pergunta da entrevista ou etapa do exame físico, esse incomodo poderá ser sinalizado e o processo será imediatamente interrompido. Se você aceitar participar, estará contribuindo para melhoria do cuidado de enfermagem prestado a pacientes oncológicos.

$\mathrm{O}(\mathrm{a})$ Senhor(a) pode se recusar a responder qualquer questão que lhe traga constrangimento, podendo desistir de participar da pesquisa em qualquer momento sem nenhum prejuízo para o(a) senhor(a). Sua participação é voluntária, isto é, não há pagamento por sua colaboração.

Caso haja algum dano direto ou indireto resultante dos procedimentos de pesquisa, você poderá ser indenizado, obedecendo-se as disposições legais vigentes no Brasil.

Os resultados da pesquisa serão divulgados na Universidade de Brasília podendo ser publicados posteriormente. Os dados e materiais utilizados na pesquisa ficarão sob a guarda do pesquisador por um período de no mínimo cinco anos, após isso serão destruídos ou mantidos na instituição.

Se o(a) Senhor(a) tiver qualquer dúvida em relação à pesquisa, por favor telefone para: Simone Prado de Lima de Miranda, no Hospital Santa Luzia no telefone 61. 3445.6165 / 61. 9988.4673, no horário 12:00 as 14:00h. 
Este projeto foi Aprovado pelo Comitê de Ética em Pesquisa da Faculdade de Ciências da Saúde (CEP/FS) da Universidade de Brasília. O CEP é composto por profissionais de diferentes áreas cuja função é defender os interesses dos participantes da pesquisa em sua integridade e dignidade e contribuir no desenvolvimento da pesquisa dentro de padrões éticos. As dúvidas com relação à assinatura do TCLE ou os direitos do participante da pesquisa podem ser obtidos através do telefone: (61) 3107-1947 ou do e-mail cepfs@unb.br ou cepfsunb@gmail.com, horário de atendimento de 10hs às $12 \mathrm{hs}$ e de $14 \mathrm{hs}$ às $17 \mathrm{hs}$, de segunda a sexta-feira.

Este documento foi elaborado em duas vias, uma ficará com o pesquisador responsável e a outra com o Senhor(a).

Nome / assinatura

Pesquisador Responsável

Nome e assinatura

Brasília de de 
Apêndice B

INSTRUMENTO DE COLETA DE DADOS
Elaborado por Simone Prado de Lima de Miranda adaptado da Teoria de King

DADOS BÁSICO DO CLIENTE

NOME:

SETOR DE INTERNAÇÃO:

1. RELATIVOS AO SISTEMA PESSOAL

\subsection{Identificacão}

Idade: Naturalidade:

Precedente: ( ) domicilio ( ) emergência ( ) enfermaria ( ) Asilo ( ) outro hospital Profissão: Ocupação atual: Estado civil:

Escolaridade: ( ) Ensino fundamental completo ( ) Ensino fundamental incompleto

( ) Ensino médio completo ( ) Ensino médio incompleto () Superior ( ) Especialização Renda familiar: ( ) menor que 1 salário ( ) maior que 1 e menor que 2 ( ) 3 a 5 salários ( ) maior que 5 Data de admissão: Inicio da doença:

Motivo da internação:

Doenças pré-existentes:

Tratamentos prévios: ( ) Cirurgia ( ) Quimioterapia ( ) Radioterapia

\subsection{Hábitos de vida}

\subsubsection{Alimentação / Hidratação}

Tipo de dieta:

Aceitação: Via:

Apetite:

Problemas identificados: ( ) naúseas ( ) vômitos ( ) dificuldade de deglutição ( ) ausência de dentes Peso atual: $\mathrm{kg}$ Estatura m Peso ideal: $\mathrm{Kg}$ IMC:

Restrição na ingesta hidrica: ( ) Sim ( ) Não

Abdomen: ( ) plano( ) globos ( ) distendido( ) Timpânico( ) RHA presentes( ) Doloroso( ) Sem alterações

\subsubsection{Eliminação}

Evacuação: ( ) presente ( ) ausente - Se ausente há quantos dias?

Consistência das fezes: Frequência:

Problemas identificados: ( ) Diárreia ( ) Constipação / ( ) Uso de fraldas ( ) colostomia Diurese: ( ) presente ( ) ausente - Frequência:

$$
\text { Aspecto: }
$$
( ) fralda ( ) comadre / papagaio ( ) SVD

Problemas identificados: ( ) incontinência ( ) retenção ( ) sangramento

\subsubsection{Sexualidade}

Mantém relacionamento sexual: ( ) Sim ( ) Não ( ) Não avaliado

Houve alteração na vida sexual relacionada à doença () Sim ( ) Não ( ) Não avaliado 
Mestruação: ( ) presente ( ) ausente - Se presente identifica ciclo e problemas:

\subsubsection{Atividade e repouso}

Faz exercicios: ( ) Sim ( ) Não

Gostaria de praticar: ( ) Sim ( ) Não ( ) Não avaliado

Necessita de auxilio para as atividades de vida diária: ( ) Sim ( ) Não

Necessita de auxilio para locomoção: ( ) Sim ( ) Não

Padrão de sono: ( ) preservado ( ) insônia ( ) sedado

Músculo Esquelético: ( ) mialgia ( ) Plegia ( ) Paresia ()Parestesia () deambula () não deambula

\subsubsection{Higiene}

Atividades de vida diária: ( ) independente ( ) auxilio ( ) dependente

Se auxilio ou dependência especificar: ( ) alimentação ( ) banho ( ) higiene intima

( ) higiene oral ( ) vestir-se

\subsubsection{Respiração}

Padrão: ( ) eupneico ( ) bradipneico ( ) traquipneico ( ) dispneico

Oxigênio suplementar: () Não () Sim - Se sim especificar: ( ) Cateter ( ) Mascara ( ) VM - FiO2 / F:

Se VM: ( ) endotraqueal ( ) traqueostomia

Problemas identificados: ( ) tosse ( ) expectoração ( ) doença pulmonar ( ) falta de ar ( ) tabagismo

\subsubsection{Circulação}

Doença cardiológica: ( ) Não ( ) Sim - Se sim especificar:

Problemas identificados: ( ) flebite () dormência ( ) trombose ( ) outros:

Ausculta Cardiaca: () Bulhas Normofonéticas () Sopros ()

Padrão Cardiaco: ( ) Normocárdico ( ) Bradicárdico ( ) Taquicárdico

1.2.8. Dor/ Escala utilizada: ()EVA ( ) BSP

Dor presente: () Não () Sim - Se sim especificar score: Local:

Escala visual analógica

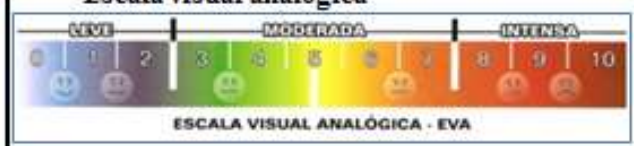

Escala Behavioral Pain Scale - BPS

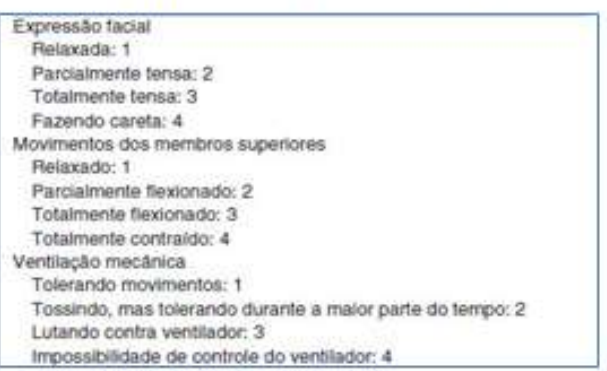

Impossibilidade de controle do ventiador: 4 


\subsubsection{Segurança}

() Alergia - Se sim especificar.

( ) Hipertermia

( ) Lesões - Se sim especificar:

Tugor da Pele: () Preservado ( ) Diminuido

Etilista: ( ) Sim ( ) Não

Risco de sangramento: ( ) Não ( ) Sim - Se sim descrever o (s) fator (es):

Recebeu transfusão durante a internação: ( ) Não ( ) Sim - Se sim indicação?

Uso de prótese: () Não () Sim - Se sim especificar:

Acesso Venoso: ( ) $\sin ($ ) não ( ) central

() Perférico Data:

Riscos: () queda - Socre: e Risco: ( ) Úlcera por pressão

Riscos: ( ) Úlcera por pressão - Socre: e Risco:

Escala de Risco de quedas de MORSE

\begin{tabular}{|c|c|}
\hline Itom & Deflesicăo Operacieal \\
\hline \multicolumn{2}{|l|}{ 1. Históricè de qquedas } \\
\hline Nso & 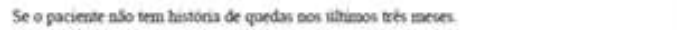 \\
\hline Sm & 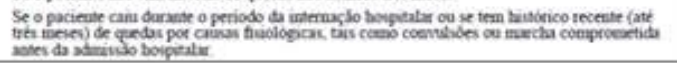 \\
\hline \multicolumn{2}{|l|}{ 2. Diagnounke wenadirio } \\
\hline $\mathrm{N} 3 \mathrm{O}^{\circ}$ & 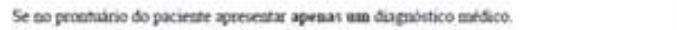 \\
\hline $\operatorname{sim}$ & 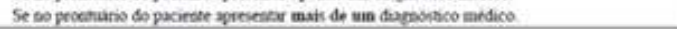 \\
\hline \multicolumn{2}{|l|}{ A. Arutibo na desinbelaratio } \\
\hline 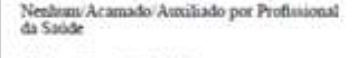 & 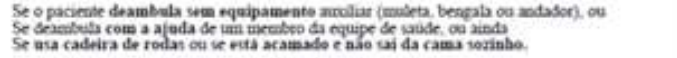 \\
\hline Miden Bemela Astador & 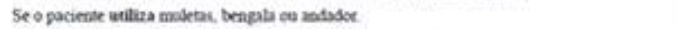 \\
\hline Moblinio Riente & 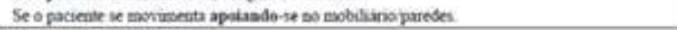 \\
\hline \multicolumn{2}{|c|}{ 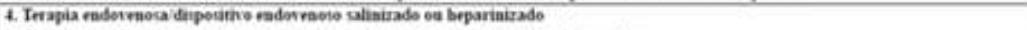 } \\
\hline $\mathrm{NB}$ & 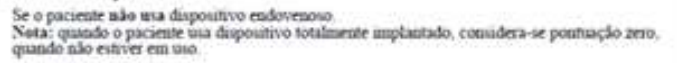 \\
\hline Sim & 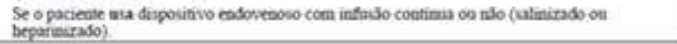 \\
\hline \multicolumn{2}{|l|}{ 5. Marcha } \\
\hline 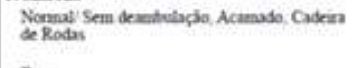 & 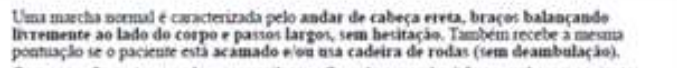 \\
\hline Fraca & 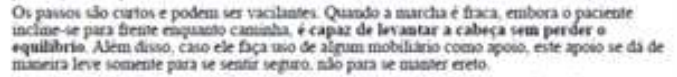 \\
\hline Confrouvetian Cembalemente & 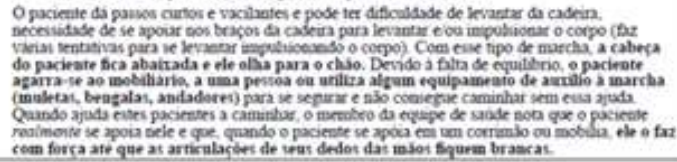 \\
\hline \multicolumn{2}{|l|}{ 6. Euado weratal } \\
\hline 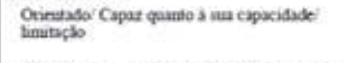 & 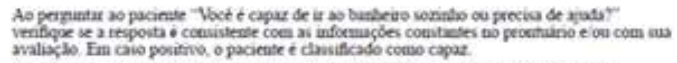 \\
\hline Superetina copocitase Esprece limitaples & 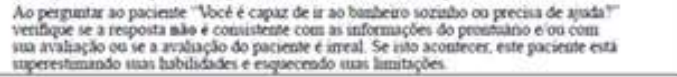 \\
\hline
\end{tabular}

AVALIAÇĀo DO GRAU DE RISCO

\begin{tabular}{|c|c|c|c|c|}
\hline \multicolumn{5}{|c|}{ ESCALA DE BRADEN * } \\
\hline Perceppbo sensorial & $\begin{array}{l}\text { 1. Totsimente } \\
\text { Imitado }\end{array}$ & 2 Muna limicado & $\begin{array}{l}\text { 3. Levemente } \\
\text { Imeado }\end{array}$ & $\begin{array}{l}4 \text { Nenhuma } \\
\text { imatapdo }\end{array}$ \\
\hline Umidade & $\begin{array}{l}\text { 1. Completsmente } \\
\text { mohada }\end{array}$ & 2. Munso molhada & $\begin{array}{l}\text { 3. Ocasiconsinente } \\
\text { mohada }\end{array}$ & $\begin{array}{l}\text { 4. Raramente } \\
\text { mohada }\end{array}$ \\
\hline Alindade & 1. Acamado & $\begin{array}{l}2 \text { Conlinedo h } \\
\text { codera }\end{array}$ & $\begin{array}{l}\text { 3. Ando } \\
\text { ocasionalmente }\end{array}$ & $\begin{array}{l}\text { 4. Ands } \\
\text { frequentemente }\end{array}$ \\
\hline Moobdade & 1. Tasimpnten movol & $\begin{array}{l}\text { 2. Bontanto } \\
\text { Iminado }\end{array}$ & $\begin{array}{l}\text { 3. Levomente } \\
\text { imeado }\end{array}$ & $\begin{array}{l}4 \text { Nbo apresenta } \\
\text { limilagofes }\end{array}$ \\
\hline Nutricalo & 1. Mito pobre & $\begin{array}{l}\text { 2. Provsurimentente } \\
\text { nadeguabo }\end{array}$ & 3. Adequsdo & 4. Exccilente \\
\hline $\begin{array}{l}\text { Finçabso } \\
\text { Cisalhamento }\end{array}$ & 1. Problipina & $\begin{array}{l}\text { 2. Probleme oen } \\
\text { potencal }\end{array}$ & $\begin{array}{l}\text { 3. Nenthum } \\
\text { problema }\end{array}$ & \\
\hline
\end{tabular}




\subsubsection{Neurossensorial}

Dificuldades identificadas: ( ) auditiva ( ) visual ( )ofativa ( ) gustativa ( ) tátil ( ) fraqueza ( ) convulsão

\subsection{Percepcões do cliente}

1.3.1. Percepção sobre a doença está preservada: ( ) Sim ( ) Não

1.3.2. Percepção sobre o tratamento: ( ) adequada ( ) alterada

1.3.3. Percepção do Corpo - ( ) Preservada ( ) Alterada ( ) Crise Percebida

1.3.4. Percepção de suas necessidades: ( ) preservada () alterada

1.3.5. Concepção de si mesmo (self): ( ) Preservada ( ) Alterada

1.3.6. Reação ao Ambiente Hospitalar: ( ) Adequada ( ) Alterada

1.3.7. Espaço Pessoal: ( ) Bem definido ( ) Necessidade de definição

\subsection{Self e imagem corporal}

1.4.1. A doença trouxe mudanças em sua maneira de vida: ( ) Não ( ) Sim ( ) Não informado Se sim qual seu sentimento em relação à isso?

1.4.2. Ocorreram mudanças no seu corpo após a doença: ( ) Não ( ) Sim Se sim sepecificar:

\subsection{Estado atual do cliente}

Sinais Vitais: FR: irpm; FC: bpm; $\mathrm{SpO2}$ : $\%$

PA: $\quad) \times(\quad)(\quad)$; T. Axilar: ${ }^{\circ} \mathrm{C}$

Couro Cabeludo: ( ) alopécia ( ) cicatriz ( ) lesão ( ) sem alterações ( ) outros:

Olhos: ( ) hiperemia ( ) Nistagmo ( ) Uso de óculo/lente ( ) sem alterações ( ) outros:

Nariz: ( ) Epistaxe ( ) Obstrução ( ) Sem alterações ( ) Outros:

Orofaringe: ( ) uso de prótese ( ) Lesão ( ) Disfagia ( ) Dislalia ( ) Gânglios ( ) sem alterações Nível de Consciência: Glasgow:

( ) consciente ( ) confuso ( ) agitado ( ) inconsciente

Pescoço: ( ) rigidez de nuca ( ) Gânglios ( ) Turgência de Jugular ( ) Sem alterações

Mucosa: ( ) corada ( ) hidratada ( ) desidratada ( ) descorada

\section{RELATIVOS AO SISTEMA INTERPESSOAL}

2.1. Relacionamento Familiar: ( ) Papéis bem definidos. Qual papel do cliente?

2.2. Papel desempenhado na Familia / organização: ( ) preservado - equilibrio ( ) presença de conflitos

2.3. A familia sabe sobre a doença: ( ) Não ( ) Sim

2.4. Tolerância ao Estresse:

Estressores Percebidos: () Sim () Não - Se sim: Identifica Estressores: () Sim () Não 
Escala de Percepção de Estresse (PSS 14)

\begin{tabular}{|c|c|c|c|c|c|c|}
\hline \multicolumn{7}{|c|}{ Neste último mês, com que fequêência... } \\
\hline 1 & $\begin{array}{l}\text { Vocế tem ficado triste por causa de algo que aconteceu } \\
\text { inesperadamente? }\end{array}$ & 0 & 1 & 2 & 3 & 4 \\
\hline 2 & $\begin{array}{l}\text { Você tem se sentido incapaz de controlar as coisas importantes em } \\
\text { sua vida? }\end{array}$ & 0 & 1 & 2 & 3 & 4 \\
\hline 3 & Você tem se sentido nervoso e "estressado"? & 0 & 1 & 2 & 3 & 4 \\
\hline 4 & Você tem tratado com sucesso dos problem as dificeis da vida? & 0 & 1 & 2 & 3 & 4 \\
\hline 5 & $\begin{array}{l}\text { Você tem sentido que está lidando bem as mudan ças importantes } \\
\text { que estão ocorrendo em sua vida? }\end{array}$ & 0 & 1 & 2 & 3 & 4 \\
\hline 6 & $\begin{array}{l}\text { Você tem se sentido confiante na sua habilidade de resolver } \\
\text { problemas pessoais? }\end{array}$ & 0 & 1 & 2 & 3 & 4 \\
\hline 7 & $\begin{array}{l}\text { Você tem sentido que as coisas estão acontecendo de acordo com } \\
\text { a sua vontade? }\end{array}$ & 0 & 1 & 2 & 3 & 4 \\
\hline 8 & $\begin{array}{l}\text { Você tem achado que não conseguiria lidar com todas as cois as } \\
\text { que você tem que fazer? }\end{array}$ & 0 & 1 & 2 & 3 & 4 \\
\hline 9 & Vocế tem conseguido controlar as imitaçôes em sua vida? & 0 & 1 & 2 & 3 & 4 \\
\hline 10 & Vocế tem sentido que as coisas estăo sob o seu controle? & 0 & 1 & 2 & 3 & 4 \\
\hline 11 & $\begin{array}{l}\text { Você tem ficado irnitado porque as coisas que acontecem estăo } \\
\text { fora do seu controle? }\end{array}$ & 0 & 1 & 2 & 3 & 4 \\
\hline 12 & $\begin{array}{l}\text { Você tem se encontrado pensando sobre as coisas que deve } \\
\text { fazer? }\end{array}$ & 0 & 1 & 2 & 3 & 4 \\
\hline 13 & Você tem conseguido controlar a maneira como gasta seu tempo? & 0 & 1 & 2 & 3 & 4 \\
\hline 14 & $\begin{array}{l}\text { Você tem sentido que as dificuldades se acumulam a ponto de } \\
\text { você acreditar que não pode superá-las? }\end{array}$ & 0 & 1 & 2 & 3 & 4 \\
\hline
\end{tabular}

Possui mecanismos internos eficazes para combater Estressores: ( ) Sim ( ) Necessita ajuda

\subsection{Definição de Metas:}

Paciente participa na definição de metas do cuidado: ( ) Sim ( ) Não

Paciente consegue manter atividades de vida diária: ( ) Sim ( ) Necessita ajuda

Maneira de se alcançar metas: ( ) participativo ( ) significativo ( ) sem significado ( ) Indiferente Quem influencia na tomada de decisão do paciente?

2.6. Barreiras à comunicação: ( ) Não ( ) Sim - Se sim especificar:

\subsection{Avaliação de Ansiedade:}

Ansiedade: ( ) Presente ( ) Ausente ( ) Não avaliado 


\section{Escala de Ansiedade de Ham- A}

\begin{tabular}{|c|c|}
\hline A 1) Eu me sinto tenso ou contraido: & A 9) Eu tenho uma sensaçä̀ nim de medo, como um frio na \\
\hline & \\
\hline 2( ) Boa parte do tempo & $O($ ) Nunca \\
\hline 1(1) De vez em quando & 1 ( ) De vez em quando \\
\hline 0 ( ) Nunca & 2() Muitas vezes \\
\hline \multirow{5}{*}{$\begin{array}{l}\text { D 2) Eu ainda sinto gosto pelas mesmas coisas de antes: } \\
\text { ( ) Sim, do mesmo jeito que antes } \\
1 \text { ( ) Năo tanto quanto antes } \\
2 \text { ( ) So um pouco } \\
3 \text { ( ) Já năo sinto meis prazer em nada }\end{array}$} & $3($ ) Cuase sempre \\
\hline & D 10) Eu perdi o interesse em cuidar da minha aparência: \\
\hline & 3 () Completamente \\
\hline & 2 ( ) Nào estou mais me cuidando como deveria \\
\hline & 1f ) Talvez năo tanto quanto antes \\
\hline \multirow{2}{*}{$\begin{array}{l}\text { A 3) Eu sinto uma espécie de medo, como se alguma coisa nim } \\
\text { fosse acontecer: }\end{array}$} & of ) Me cuido do meșmo jelto que antes \\
\hline & A 11) Eu me sinto inquieto, como se eu nầ pudesse ficar parado \\
\hline 3 () Sim, e de um jeito multo forte & enth lugar nerhum: \\
\hline 2 ( ) Sim, mas nä̀ tăo forte & 3() Sim, demais \\
\hline 1) () Um pouco, mas isso nào me preocupa & $2($ ) Bastante \\
\hline O ( ) Näo sinto nada disso & 1 ( ) Um pouco \\
\hline D 4) Dou risada e me divitto quando vejo coisas engraçadas: & O( ) Nibo me sinto assim \\
\hline o( ) Do mesmo jeito que antes & D 12) Fico esperando animado as coisas boas que estäo por vir: \\
\hline 1 ( ) Atualmente um pouco menos & o( ) Do mesmo jeito que antes \\
\hline 2() Atualmente bem menos & 1( ) Um pouco menos do que antes \\
\hline 3 ( ) Não consigo mais. & 2 () Bem menos do que antes \\
\hline A 5) Estcu com a cabeça cheia de preocupaçles: & $3($ ) Ouase nunca \\
\hline 3 () A maior pante do tempo & A 13) De repente, tenhe a sensaçao de entrar em párico: \\
\hline 2 () Boa parte do tempo & 3() A quase todo momento \\
\hline 1( ) De vez em quando & $2($ ) Vánas vezes \\
\hline o() Raramente & 1 (i) De vez em quando \\
\hline D 6) Eu me sinto alegre: & O ( ) Näo sinto isso \\
\hline 3 () Nunca & D 14) Consigo sentir prazer quando assisto a um bom programa \\
\hline 2 () Poucas vezes & de televisào, de rádio ou quando leio alguma coisa: \\
\hline 1(i) Muitas vezes & O() Quase sempre \\
\hline O() A maior parte do tempo & 1() Varias vezes \\
\hline \multirow{5}{*}{$\begin{array}{l}\text { A 7) Consigo ficar sentado a vontade e me sentir relacado: } \\
\text { o( ) Sim, quase sempre } \\
1 \text { ( ) Muitas vezes } \\
2 \text { ( ) Poucas vezes } \\
3 \text { ( ) Nunca }\end{array}$} & 2 () Poucas vezes \\
\hline & 3 ( ) Quase nunca \\
\hline & \\
\hline & \\
\hline & \\
\hline \multirow{5}{*}{$\begin{array}{l}\text { D 8) Eu estcu lento para pensar e fazer as coisas: } \\
3 \text { ( ) Quase sempre } \\
2 \text { ( ) Muitas vezes } \\
\text { 1( ) De vez em quando } \\
\text { of ) Nunca }\end{array}$} & \\
\hline & \\
\hline & \\
\hline & \\
\hline & \\
\hline
\end{tabular}

\section{RELATIVOS AO SISTEMA SOCLAL}

\subsection{Meio mabiente}

Tipo de casa:

Saneamento básico: ( ) presente ( ) ausente ( ) Não informado

\subsection{Abordagem familiar}

Estado civil: ( ) Solteiro ( ) Casado ( ) Viúvo ( ) Divorciado ( ) Outros:

Tem filhos: ( ) Sim ( ) Não

Mora com quem?

Doenças na familia:

Como a familia encara a doença do cliente?

Acompanhado durante a internação: ( ) Sim ( ) Não

Recebe visitas: ( ) Não ( ) Sim - Se sim especificar: 
Processo de comunicação com familiares: ( ) adequada ( ) inadequada ( ) contraditória

Religiosidade: ( ) ausente ( ) presente - Se presente espeficar:

Familia acompanhada pelo serviço de psicologia: ( ) Sim ( ) Não - Motivo:

Estado Emocional dos familiares: ( ) ajustamento emocional à sua condição de saúde ( ) apatia ( ) dificuldade para se expressar ( ) agressividade ( ) tristeza ( ) deseperança

\section{PROCESSO DE ENFERMAGEM}

\begin{tabular}{|c|c|c|c|}
\hline Domínio & Diagnóstico de enfermagem & $\begin{array}{l}\text { Características } \\
\text { definidoras }\end{array}$ & $\begin{array}{c}\text { Fatores realcionado } \\
\text { Fatores de risco } \\
\end{array}$ \\
\hline & & & \\
\hline & & & \\
\hline & & & \\
\hline & & & \\
\hline & & & \\
\hline & & & \\
\hline & & & \\
\hline & & & \\
\hline & & & \\
\hline & & & \\
\hline & & & \\
\hline & & & \\
\hline & & & \\
\hline & & & \\
\hline & & & \\
\hline & & & \\
\hline & & & \\
\hline & & & \\
\hline
\end{tabular}

